University of Louisville

ThinkIR: The University of Louisville's Institutional Repository

Electronic Theses and Dissertations

$5-2012$

\title{
The impact of adsorbed cellulase inactivation on enzymatic hydrolysis kinetics.
}

Zhuoliang Ye

University of Louisville

Follow this and additional works at: https://ir.library.louisville.edu/etd

\section{Recommended Citation}

Ye, Zhuoliang, "The impact of adsorbed cellulase inactivation on enzymatic hydrolysis kinetics." (2012). Electronic Theses and Dissertations. Paper 1623.

https://doi.org/10.18297/etd/1623

This Doctoral Dissertation is brought to you for free and open access by ThinkIR: The University of Louisville's Institutional Repository. It has been accepted for inclusion in Electronic Theses and Dissertations by an authorized administrator of ThinkIR: The University of Louisville's Institutional Repository. This title appears here courtesy of the author, who has retained all other copyrights. For more information, please contact thinkir@louisville.edu. 
THE IMPACT OF ADSORBED CELLULASE INACTIVATION ON ENZYMATIC HYDROLYSIS KINETICS

\author{
By \\ Zhuoliang Ye \\ B.E., Fuzhou University, 2006

\begin{abstract}
A Dissertation
Submitted to the Faculty of the J. B. Speed School of Engineering

University of Louisville

in Partial Fulfillment of the Requirements

for the Degree of
\end{abstract}

Doctor of Philosophy

Department of Chemical Engineering

Louisville, KY

May 2012 
THE IMPACT OF ADSORBED CELLULASE INACTIVATION ON ENZYMATIC HYDROLYSIS KINETICS

by

Zhuoliang Ye

B.E., Fuzhou University, 2006

A Dissertation Approved On

April 25, 2012

(Date)

By the Following Committee:

Dr. R. Eric Berson, Dissertation Director

Dr. Andrew N. Lane

Dr. Gerold A. Willing

Dr. Mahendra K. Sunkara

Dr. Moises A. Carreon 


\section{ACKNOWLEDGMENTS}

I would like to express my deepest gratitude to my advisor, Prof. R. Eric Berson, for his guidance, support and encouragement through my research and writing. Dr. Berson provided an exciting working environment with many opportunities to explore new ideas and work on a promising area.

I would like to thank Prof. Andrew N. Lane for his guidance, helpful discussions on data interpretation and technical advice on enzyme separation; thank Prof. Gerold A. Willing for his guidance and support with AFM imaging technique in this research; thank Prof. Mahendra K. Sunkara for supplying valuable resources at Conn Center for Renewable Energy Research during this research; and thank Prof. Moises A Carreon for his guidance and help with instruments in his lab.

I would like to acknowledge the following sources of support during my graduate

studies: United States Department of Energy (DE-FC36-046014221), Kentucky Department for Energy Development and Independence (PON212710000041941), Fellowship Award from the Conn Center for Renewable Energy Research at the University of Louisville, Doctoral Dissertation Completion Fellowship Award from University of Louisville, and the National Center for Research Resources (P20RR018733).

Finally, I would like to thank my family for their encouragement and support, without which this dissertation and research would not have been possible. 


\section{ABSTRACT \\ THE IMPACT OF ADSORBED CELLULASE INACTIVATION ON ENZYMATIC HYDROLYSIS KINETICS \\ Zhuoliang Ye}

\section{APRIL 27, 2012}

Several technical and economic obstacles currently hamper the industrial development of ethanol from biomass. One of the key bottlenecks is the slow kinetics of the enzymatic hydrolysis of cellulose, and the subsequent rate reduction as the reaction proceeds. As a result, this research focused on understanding underlying causes for the slow kinetics, rate reduction, and low yield during cellulose hydrolysis. Mechanisms traditionally thought to cause these results were investigated, such as change of substrate properties and deactivation of enzyme due to environmental mechanisms, but neither was found to contribute significantly to the slow kinetics and low yield. Inactivation due to enzyme-substrate interactions was then proposed as a key factor. Results here show that inactivation of adsorbed enzyme played the most significant role for the hydrolysis rate reduction and low yield based on the following findings: (1) a kinetic model featuring inactivation of adsorbed enzyme accurately accounted for experimental cellulose hydrolysis data for two different types of substrates; the enzyme's apparent maximum reaction rate was found to decrease with a first order exponential decay function of time due to inactivation of the adsorbed enzyme, which has historically always been 
considered to remain constant. (2) comparison of relative extents of enzyme activity loss due to environmental mechanisms (such as thermal and/or mechanical factors) with inactivation due to enzyme-substrate interactions revealed that enzyme- substrate interactions contributed more towards the overall activity loss than did environmental mechanisms; (3) AFM imaging visualized crowding of Cellobiohydrolase 1 (CBH1) on cellulose substrate surface and thereafter became inactivated; (4) desorption of inactive $\mathrm{CBH} 1$ was slower compared to desorption of active $\mathrm{CBH} 1$, implying that once inactivated, CBH1 cannot dissociate immediately to find another site on a substrate surface to start another digestive cycle.

The overall conclusion is that inactivation of adsorbed enzyme is a primary contributor to the hydrolysis rate reduction. Near complete conversion (99\%) of cellulose was predicted by the model to occur within 10 20 hours if inactivation of adsorbed cellulase can be prevented, compared to 7-10 days or more to achieve a lower yield when inactivation occurs. Finally, factors to consider when developing a cellulose hydrolysis process were proposed based on the inactivation mechanism. One important strategy proposed is to desorb inactive cellulases from the substrate, such as with the addition of $\mathrm{GdnHCl}$. Additionally, a technique for scaling-up separation of $\mathrm{CBH} 1$ was developed. The technique allows for efficient purification of active $\mathrm{CBH} 1$ from commercial cellulase cocktails at a cost of less than $10 \%$ compared to the conventional small-scale FPLC method. 


\section{TABLE OF CONTENTS}

Page

APPROVAL PAGE

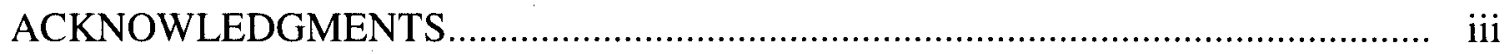

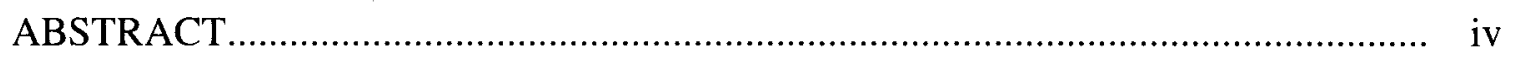

LIST OF TABLES

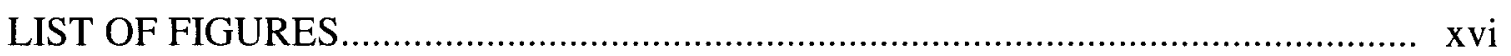

CHAPTER

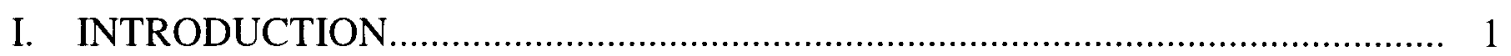

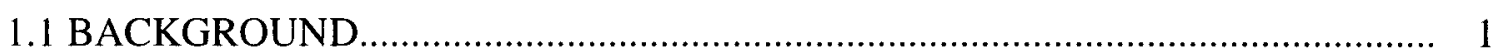

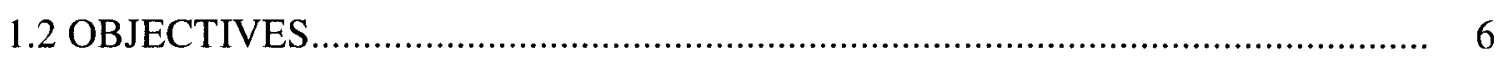

II. LITERATURE REVIEW ................................................................................ 7

2.1 STRUCTURE OF CELLULOSE .................................................................... 7

2.2 SOURCES OF VARIOUS CELLULOSE SUBSTRATES..................................... 8

2.3 TYPE OF CRYSTALLINE CELLULOSE ............................................ 8

2.4 EFFECT OF ENZYME DEACTIVATION DUE TO ENVIRONMENTAL

MECHANISMS ON CELLULOSE HYDROLYSIS ................................... 9

2.5 EFFECT OF SUBSTRATE PROPERTIES ON CELLULOSE HYDROLYSIS.... 9 
2.6 EFFECT OF ACTIVITY LOSS OF ADSORBED ENZYME.ON CELLULOSE HYDROLYSIS ............................................................................. 10

2.7 PRODUCT INHIBITION AND MASS TRANSFER LIMITATION ........... 11

2.8 KINETIC MODELING CONSIDERING INACTIVATION OF ADSORBED ENZYME TO ACCOUNT FOR CELLULOSE HYDROLYSIS............... 12

2.9 CELLULASE STRUCTURE AND FUNCTION ........................................ 14

2.10 SEPARATING CBH1 FROM A COMMERCIAL CELLULASE MIXTURE.. 15

2.11 SCALED-UP SEPARATION OF CBH1 FROM A COMMERCIAL

CELLULASE MIXTURE................................................... 16

2.12 INVESTIGATION OF ENZYME-SUBSTRATE INTERACTIONS USING

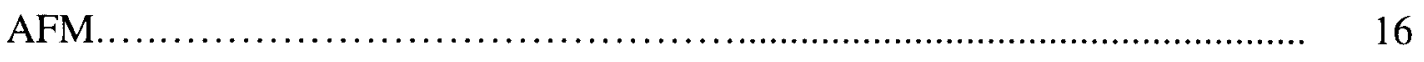

2.13 PROCESSIVITY OF CELLOBIOHYDROLASE...................................... 17

2.14 ENZYME ADSORPTION ...................................................... 17

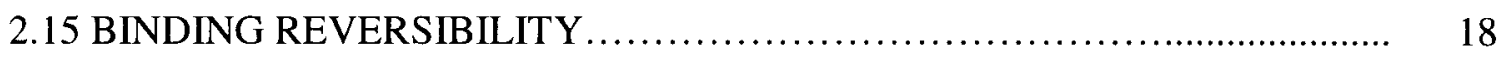

2.16 DEACTIVATION OF INDIVIDUAL CELLULASE COMPONENTS......... 18

2.17 SYNERGISM......................................................... 19

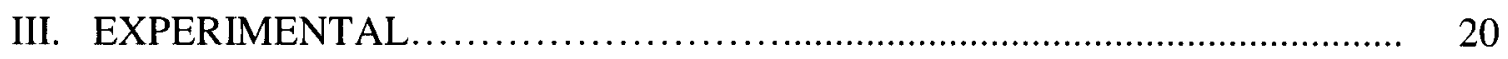

3.1 EXPERIMENTAL PLAN ................................................................... 20

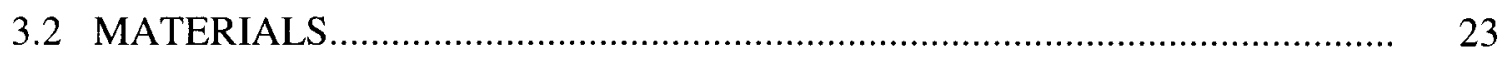


3.3 PROCEDURE: EFFECT OF ENZYME DEACTIVATION DUE TO ENVIRONMENTAL MECHANISMS AND VARIATION OF SUBSTRATE PROPERTIES ON CELLULOSE HYDROLYSIS …………………………...... 25

3.3.1 CELLULASE DEACTIVATION FROM MECHANICAL /THERMAL MECHANISMS.................................................... 25

3.3.2 CHARACTERIZATION OF SUBSTRATE CRYSTALLINITY USING X-RAY DIFFRACTION (XRD),.......................................... 25

3.3.3 SSA AND PORE SIZE MEASUREMENT......................................... 26

3.3.4 CELLULOSE HYDROLYSIS ......................................................... 26

3.4 PROCEDURE: ACTIVITY LOSS OF ADSORBED ENZYME........................ 26

3.4.1 EXAMINE RELATIVE EXTENTS OF ENZYME ACTIVITY LOSS FROM ENZYME-SUBSTRATE INTERACTIONS AND DUE TO THERMAL/MECHANICAL MECHANISMS.......... 26

3.4.2 GLUCOSE MEASUREMENT_........................................................ 28

3.5 PROCEDURE: SCALED-UP SEPARATION OF CBH1 FROM A COMMERCIAL CELLULASE MIXTURE TO STUDY HYDROLYSIS AND INACTIVATION MECHANISMS............................................................. 28

3.5.1 PREPARATION OF SPEZYME CP SAMPLE ................................ 28

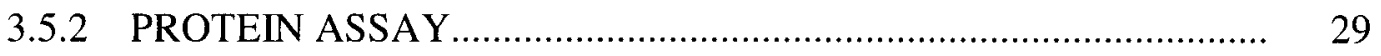

3.5.3 CONTINUOUS GRADIENT ELUTION........................................ 30 
3.5.4 STEP ELUTION (WITH VACUUM MANIFOLD) AND SCALE-UP 30

3.5.5 SDS-PAGE ANALYSIS .............................................................. 32

3.5.6 PNPC-ACTIVITY ASSAY ........................................................... 32

3.5.7 STABILITY OF CBH1 _...................................................... 33

3.5.8 ADSORPTION OF CBH1 ON BMCC............................................ 33

3.5.9 HYDROLYSIS OF BMCC..........................................................

3.6 PROCEDURE: DEACTIVATION OF INDIVIDUAL CELLULASE

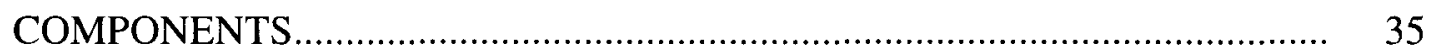

3.6.1 EFFECT OF INCUBATING TIME ON CELLULASE

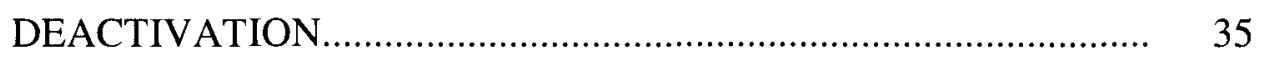

3.6.2 EFFECT OF MIXING INTENSITY ON CELLULASE

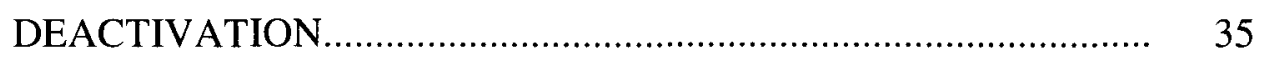

3.6.3 EFFECT OF ENZYME CONCENTRATION ON CELLULASE

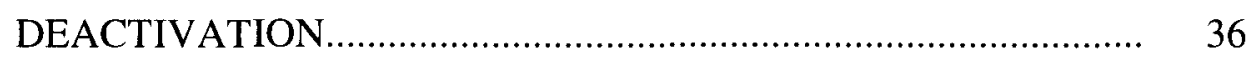

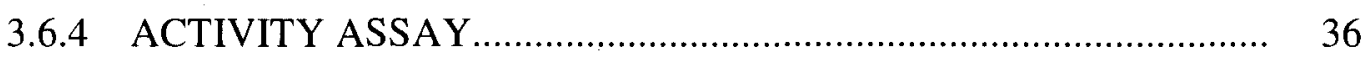

3.7 PROCEDURE: DESORPTION OF CBH1 AT REDUCED ACTIVITY........... 37

3.7.1 DEACTIVATION BY MECHANICAL DEACTIVATION.......... 37

3.7.2 DEACTIVATION BY COMPETITIVE INHIBITOR ............... 37

3.7.3 DEACTIVATION BY LOW REACTION TEMPERATURE........ 37

3.7.4 DEACTIVATION BY $\mathrm{K}_{2} \mathrm{PDCL}_{6}$ (DENATURANT) ................ 37 
3.8 PROCEDURE: FACTORS TO CONSIDER WHEN DEVELOPING A CELLULOSE HYDROLYSIS PROCESS.

3.8.1 KINETIC MODELING TO DETERMINE ACTIVATION ENERGY 38

IV. EFFECT OF ENZYME DEACTIVATION DUE TO ENVIRONMENTAL MECHANISMS AND VARIATION OF SUBSTRATE PROPERTIES ON CELLULOSE HYDROLYSIS

4.1 EXTENT OF TOTAL CELLULASE DEACTIVATION FROM THE REACTION ENVIRONMENT.

4.2 EFFECT OF VARYING SUBSTRATE PROPERTIES ON CELLULOSE HYDROLYSIS.

4.3 SUMMARY

V. ACTIVITY LOSS OF ADSORBED ENZYME.

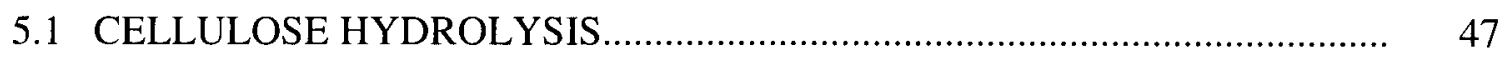

5.2 THEORETICAL MODELING ...................................................................... 48

5.3 CALCULATION OF THE VALUES OF RATE CONSTANTS....................... 52

5.4 COMPARISON OF THEORETICAL MODEL PREDICTION TO EXPERIMENTAL HYDROLYSIS RESULTS.

5.5 RELATIVE EXTENTS OF ENZYME ACTIVITY LOSS FOR ENZYMESUBSTRATE INTERACTIONS AND THERMAL/MECHANICAL MECHANISMS 
5.6 DETERMINATION OF APPARENT INACTIVATION RATE CONSTANT FROM ENZYME-SUBSTRATE INTERACTIONS ..................... 64

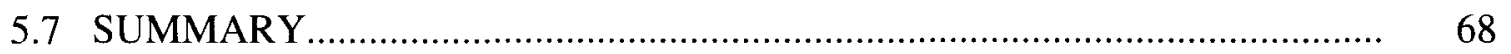

VI. SCALED-UP SEPARATION OF CBH1 FROM A COMMERCIAL

CELLULASE MIXTURE TO STUDY HYDROLYSIS AND INACTIVATION

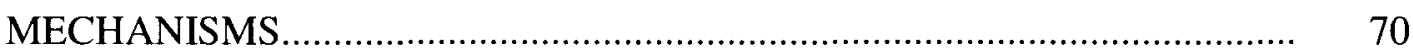

6.1 ASSAY OF TOTAL PROTEIN CONCENTRATION IN THE SPEZYME CP CELLULASE............................................................................ 70

6.2 IDENTIFICATION OF CBH1 IN SPEZYME CP CELLULASE..................... 70

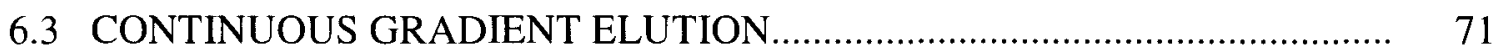

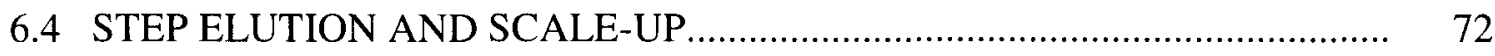

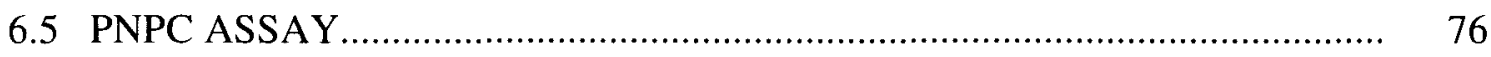

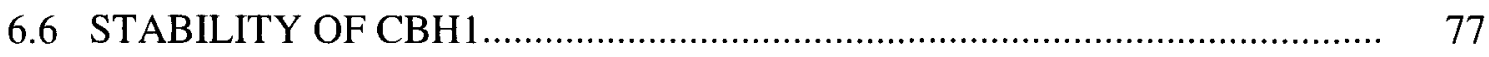

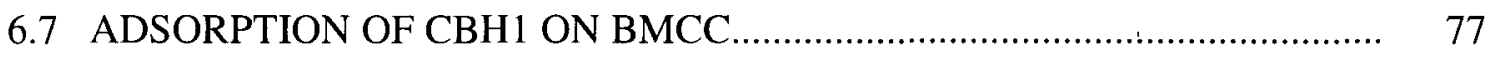

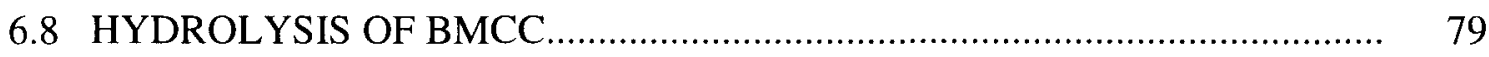

6.9 INACTIVATION OF ADSORBED ENZYME ...................................... 80

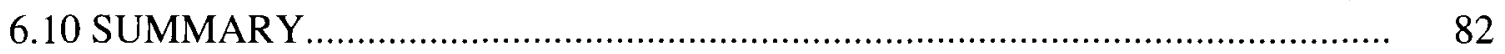

VII. DEACTIVATION OF INDIVIDUAL CELLULASE COMPONENTS............. 84

7.1 EFFECT OF INCUBATING ON CELLULASE DEACTIVATION........... 84

7.2 EFFECT OF MIXING INTENSITY ON CELLULASE DEACTIVATION..... 86

7.3 EFFECT OF ENZYME DEACTIVATION ON CELLULASE 
DEACTIVATION.

7.4 SUMMARY.

VIII. DESORPTION AT REDUCED ACTIVITY 92

8.1 EFFECT OF MECHANICAL DEACTIVATION 92

8.2 EFFECT OF COMPETITIVE INHIBITOR ON CBH1 DESORPTION......... 92

8.3 EFFECT OF TEMPERATURE ON DESORPTION.......................................... 94

8.4 EFFECT $\mathrm{K}_{2} \mathrm{PDCL}_{6}$ (DENATURANT) ON CBH1 DESORPTION................... 95

8.5 SUMMARY

IX. FACTORS TO CONSIDER WHEN DEVELOPING A CELLULOSE HYDROLYSIS PROCESS

9.1 KINETIC MODELING TO DETERMINE ACTIVATION ENERGY 97

9.2 DETERMINE ACTIVATION ENERGY FOR HYDROLYSIS AND INACTIVATION. 98

9.3 EFFECT OF REACTION TEMPERATURE ON CELLULOSE HYDROLYSIS 101

9.4 EFFECT OF INCUBATION TIME ON CELLULOSE HYDROLYSIS. 103

9.5 EFFECT OF SUBSTRATE SURFACE AREA ON CELLULOSE HYDROLYSIS

9.6 EFFECT OF ENZYME BINDING CHARACTERISTICS ON CELLULOSE HYDROLYSIS 106

9.7 SUMMARY 108 


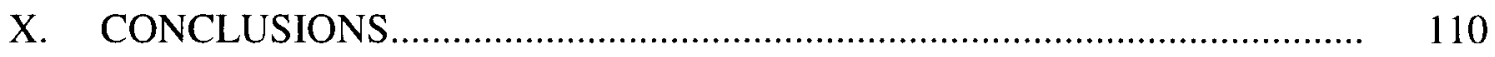

XI. RECOMMENDATIONS FOR FUTURE STUDY ………………………..... 114

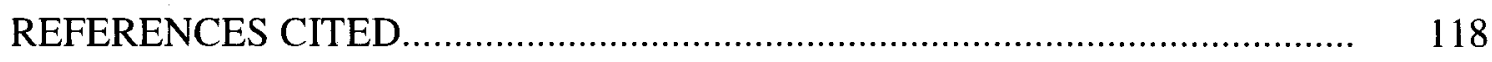

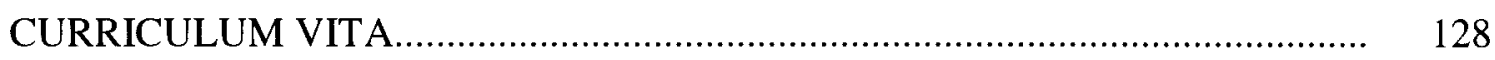




\section{LIST OF TABLES}

TABLE 3.1 - Summary of experimental procedure for determining total deactivation of enzyme following incubation with different amounts of substrate.....

TABLE 3.2 - Profile for step elution

TABLE 4.1 - Initial physical properties of different substrates

TABLE 5.1 - Parameters from the first order exponential decay fitting of activity of cellulases following interaction with substrate.

TABLE $5.2-V_{\max , a p p}$ and $K_{m}$ as functions of reaction time 54

TABLE 5.3 - Comparison of estimated parameters for Solka Floc and Sigmacell...... 60

TABLE 5.4 - Parameters from data fitting to second order exponential growth from hydrolysis results in Figure 3.1. 66

TABLE 6.1 - Comparison of protein yields of CBH1 separated by FPLC, a single column vacuum system, and scaled-up vacuum manifold system. Initial loading of Spezyme CP cellulases was $40 \mathrm{mg}$ to each column

TABLE 7.1 - Effect of rotating speed on the generated shear stress in a flask 88

TABLE 9.1 - Parameters for the cellulose hydrolysis model (Equation 7.1). 99 
TABLE 9.2 - Accessible surface area for different substrates........................... 105 


\section{LIST OF FIGURES}

FIGURE 1.1 - A simplified scheme to produce ethanol from cellulosic substrate......

FIGURE 2.1 - Composition of cellulose

FIGURE 3.1 - Scaled-up separation of CBH1 by a vacuum manifold system. (a) flow route of the separation system; (b) experimental set-up.

FIGURE 4.1 - Activities of cellulases after 3-day incubation in buffer solution...... 40

FIGURE 4.2 - XRD profile of Sigmacell during 72-hour reaction........................... 41

FIGURE 4.3 - Change of (a) SSA, (b) pore volume and (c) average pore sizes during the reaction for Sigmacell.

FIGURE 4.4 - Comparison of hydrolysis of three different cellulose substrates.

FIGURE 5.1 - Glucose released during 72-hour incubation for Solka Floc.

FIGURE 5.2 - A plot of $t / P$ versus $1 / P \times \ln \left[\left(1.1 \times(S)_{0}-P\right) / P\right]$ at substrate concentrations

$$
\text { of } 1-20 \mathrm{~g} / \mathrm{L}
$$

FIGURE 5.3 - Regression of $V_{m a x, a p p}$ and $K_{m}$ as a function of time.

FIGURE 5.4 - First order exponential decay fitting of $V_{\text {max }, \text { app }}$ as a function of reaction time to calculate inactivation rate constant. 
FIGURE 5.5 - Proposed minimal theoretical model to account for cellulose

hydrolysis...............................................

FIGURE 5.6 - Comparison of measured and predicted glucose released. (a) Solka Floc;

(b) Sigmacell

FIGURE 5.7 - Activity of cellulase on Solka Floc following incubation in buffer

solution for 2-72 hours

61

FIGURE 5.8 - Activity of cellulase following interaction with different amounts of

substrate during the initial incubation

FIGURE 5.9 - Relative extents of cellulase activity loss between enzyme-substrate interactions and thermal/mechanical mechanisms.

FIGURE 5.10 - A plot of apparent inactivation rate constantant $k_{f, a p p}$ versus substrate concentration to calculate inactivation rate of adsorbed enzyme $k_{f} \ldots \ldots$ 68

FIGURE 6.1 - SDS-PAGE of the crude Spezyme CP cellulases

FIGURE 6.2 - Separation of CBH1 by a FPLC system. (a) Separation of CBH1 from Spezyme CP cellulases with a continuous salt gradient at $\mathrm{pH} 7$. (b) SDS-PAGE of the fractions collected in the three peaks as shown in (a). (c) The separated $\mathrm{CBH} 1$ was applied at $\mathrm{pH}=6$ to examine its purity and whether a second separation is needed 
FIGURE 6.3 - Examination of the purity of $\mathrm{CBH} 1$ separated by the vacuum manifold system. (a) Comparison of SDS-PAGE of CBH1 separated by FPLC and vacuum manifold. (b) SDS-PAGE of the scaled-up separation by step elution

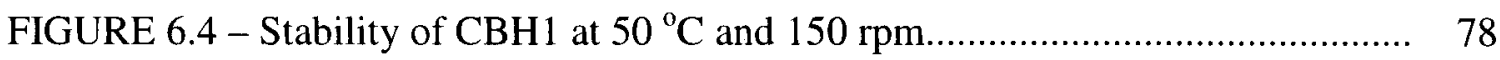

FIGURE 6.5 - Binding isotherms of $\mathrm{CBH} 1$ and $\mathrm{BSA}$ on $\mathrm{BMCC}$ at $0^{\circ} \mathrm{C} \ldots \ldots \ldots \ldots \ldots \ldots . . . . . . . . .79$

FIGURE 6.6 - Height change of cellulose fiber during the reaction. (a) Height of cellulose fiber before reaction. The fiber is pointed out by a pair of cursors. (b) Height of cellulose fiber after 45 minutes of reaction. (c) Height of cellulose fiber after 1.5 hours of reaction. (d) Height of cellulose fiber after 2.5 hours of reaction

FIGURE 6.7 - Phase images of inactivation of $\mathrm{CBH1}$ on a BMCC substrate surface. Arrows point to the edge of the fiber. The phase images at 45, 90 and 150 minutes are related to the topography images at the same time points.

Crowding of enzyme is highlighted in circles. 82

FIGURE 7.1 - (a). Activities of cellulases after incubation at $150 \mathrm{rpm}$. (b). Activities of cellulases after incubation (without mixing).

FIGURE 7.2 - Effect of mixing speed on cellulase deactivation after 24-h incubation. 87

FIGURE 7.3 - Time dependent deactivation of $\mathrm{CBH} 1$ for different mixing conditions

FIGURE 7.4 - Wall shear stress $(\mathrm{Pa})$ in an orbital shaking flask at $250 \mathrm{rpm}$.

FIGURE 7.5 - Effect of enzyme concentration on deactivation. 
FIGURE 8.1 - Effect of mechanical deactivation on CBH1 activity and desorption.

(a) Activity of $\mathrm{CBH} 1$ at 150 and $300 \mathrm{rpm}$. (b) Fraction of free $\mathrm{CBH} 1$ during desorption, which was normalized according to total enzyme added in the reaction

FIGURE 8.2 - Effect of competitive inhibitors on CBH1 desorption

FIGURE 8.3 - Desorption of $\mathrm{CBH} 1$ at 0 and $50{ }^{\circ} \mathrm{C}$

FIGURE 8.4 - Effect of $\mathrm{K}_{2} \mathrm{PdCl}_{6}$ on CBH1desorption.

FIGURE 9.1 - Proposed minimal theoretical model to account for cellulose hydrolysis 97

FIGURE 9.2 - Comparison of experimental and predicted glucose released for

Sigmacell at (a) $50{ }^{\circ} \mathrm{C}$; (b) $35^{\circ} \mathrm{C}$; (c) $20^{\circ} \mathrm{C}$. 100

FIGURE 9.3 - Arrhenius Plots for determining activation energies for (a) hydrolysis step and (b) inactivation step. 101

FIGURE 9.4 - (a) $V_{\max \text {.app }}$ as a function of incubating time at three different temperatures for Sigmacell; (b) effect of temperature on product formation for Sigmacell substrate with a solid concentration of $2.0 \%$ $(w / v) ;(c)$ effect of temperature on product formation for Sigmacell substrate with a solid concentration of $0.1 \%(\mathrm{w} / \mathrm{v})$

FIGURE 9.5 - Comparison of hydrolysis of different substrates at (a) $5 \%$ solid (w/v); (b) $0.1 \%$ solid $(\mathrm{w} / \mathrm{v})$. 106

FIGURE 9.6 - Predicted conversion of Sigmacell at $50^{\circ} \mathrm{C}$ in the absence of inactivation of adsorbed enzyme. 108 


\section{CHAPTER I}

\section{INTRODUCTION}

\subsection{Background}

Biologically derived fuels have received increasing attention as an alternative to fossil fuels used for transportation due to political, environmental, and economic reasons. The ethanol industry in the United State has traditionally used corn as the feedstock, which is considered a $1^{\text {st }}$ generation biofuel. However, corn is an important food source for both humans and livestock. Increasing demands of corn from the ethanol industry will drive up the price of corn as well as other products that depend on corn as an intermediate feedstock. Therefore, efforts have focused on producing ethanol from cellulosic substrates, such as corn stover, sawdust, bagasse, and other agricultural products and residues, which can be hydrolyzed to produce fermentable sugars. Ethanol derived from cellulosic substrates is considered to be a $2^{\text {nd }}$ generation biofuel.

Public policy is driving most of the momentum towards the use of biofuels. The Energy Policy Act of 2005 required the use of 7.5 billion gallons of renewable fuel by 2012. The Energy Independence and Security Act of 2007 increased this renewable fuels standard to 36 billion gallons of annual renewable fuel use by 2022 . Of this, 16 billion 
gallons are required to come from cellulosic sources. A joint U.S. Department of Energy (DOE)/U.S. Department of Agriculture (USDA) study found that 1.3 billion tons of cellulosic feedstock could be produced for biofuels in the U.S. annually with only modest changes in farming practices. This quantity of feedstock can be used to make enough ethanol to satisfy about one third of current U.S. petroleum demand.

For cellulosic derived ethanol production, enzymatic hydrolysis is usually employed to release fermentable sugars from cellulose. Other key steps in the process include pretreatment prior to hydrolysis and fermentation following hydrolysis. Pretreatment is performed to open up the substrate structure for cellulases to attack. After cellulose is hydrolyzed, the hydrolysis product, glucose, is fermented to produce ethanol. A simplified scheme is shown in Figure 1.1. Pretreatment time is on the order of minutes and fermentation time is on the order of hours. However, enzymatic hydrolysis of cellulose is on the order of several days. The slow kinetics of enzymatic hydrolysis is a key technical and economic obstacle hindering the industrial development of ethanol from cellulose.

The hydrolysis rate during enzymatic hydrolysis of cellulose is known to decrease as the reaction proceeds and yield typically does not approach 100\% (Dasari and Berson, 2007; Dasari et al., 2009; Dunaway et al., 2010; Nidetzky and Steiner, 1993; Valjamae et al., 1998). The main cause for the rate reduction and low yield is not yet understood, and determining the primary mechanism will have important implications in the optimal design of an enzymatic hydrolysis process. Several possible reasons for the low rate and yield have been suggested in the literature: change of reactivity (Nidetzky and Steiner, 1993; Zhang et al., 1999) and physical properties of substrate, such as crystallinity 
(Betrabet and Paralikar, 1977; Ooshima et al., 1983); change of specific surface area (SSA) during the reaction (Hong et al., 2007); deactivation of enzyme as a result of mechanical mixing (Ganesh et al., 2000; Ghadge et al., 2005b; Kim et al., 1982; Reese and Mandels, 1980); and inactivation of adsorbed enzymes (Jalak and Valjamae, 2010; Ma et al., 2008; Valjamae et al., 1998; Xu and Ding, 2007).

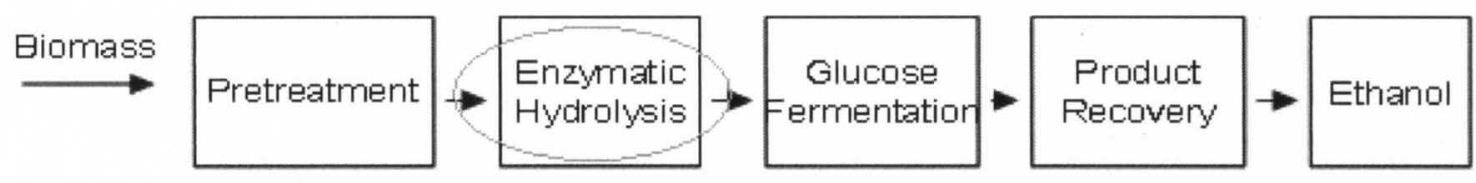

Figure 1.1. A simplified scheme to produce ethanol from cellulosic substrate

Nidetzky and Steiner (1993) and Zhang et al. (1999) believed that the hydrolysis rate slowed when the easily hydrolyzed part of the cellulose was consumed, and the remaining part was less accessible to enzyme. However, this assumption is weakened by the fact that accessibility of substrate to enzyme could not be related to any physicochemical properties of the substrate, such as crystallinity, surface area, or degree of polymerization (Nidetzky and Steiner, 1993). Moreover, this theory was contradicted by Ooshima et al. (1991), Desai and Converse (1997), and Yang et al (2006), who all found that the reactivity of substrate changed little during hydrolysis. Also, the two-types of cellulose mechanism cannot explain the monophasic first-order reaction for some substrates such as cotton and regenerated cellulose (Lenz et al., 1990; Schurz and Honel, 1989).

Effects of change in substrate crystallinity and SSA during the reaction are controversial in the literature. Some studies reported that crystallinity increases over the 
course of cellulose hydrolysis as a result of preferential reaction of amorphous cellulose (Betrabet and Paralikar, 1977; Ooshima et al., 1983). However, Lenze et al. (1990), Ohmine et al. (1983), Puls and Wood, (1991) found crystallinity did not increase during enzymatic hydrolysis.

Mosier et al. (1999) found increasing SSA during Solka Floc hydrolysis, although Hong et al. (2007) found that SSA decreased as the reaction proceeded when working with the cellulose substrate Avicel. It is, therefore, desirable to further examine whether or not the change of substrate properties such as crystallinity and SSA affect the cellulose hydrolysis rate.

Activity loss of cellulases during the reaction, which is another possible reason for the rate reduction and low yield, has traditionally been associated with mechanical and/or thermal mechanisms (Kim et al., 1982; Zhang et al., 2010). However, several studies showed that mechanical/thermal effects on enzyme deactivation were insufficient to account for the reduction in the reaction velocity of cellulose hydrolysis (Eriksson et al., 2002; Ooshima et al., 1991). Furthermore, Levine et al (2010) concluded that an enzyme half-life much shorter than that reported for thermal deactivation would be needed to account for the slow kinetics of cellulose hydrolysis. It is, therefore, necessary to further examine to what extent the deactivation is caused by mechanical/thermal mechanisms.

Product inhibition has been suggested as another reason for the rate reduction (Gusakov and Sinitsyn, 1992; Howell and Stuck, 1975). However, Nidetzky and Steiner (1993) reported that inhibition by glucose is weak. Additionally, the hydrolysis rate still declined significantly when products were continuously removed in a membrane reactor 
(Converse et al., 1988; Howell and Mangat, 1978). Väljamäe et al. (1998) and Zhang et al. (1999) also provided evidence against product inhibition affecting hydrolysis kinetics.

Since there is a lot of evidence against existing theories for the rate reduction, it is desirable to explore an alternative mechanism that may offer a better explanation. Attention is focused here on activity loss due to enzyme-substrate interactions, particularly activity loss of adsorbed enzyme. Such activity loss has been reported to be caused by: (1) the cellobiohydrolases becoming stuck on the substrate surface due to a crystalline defect or when surrounding cellulose chains prevent further processive action (Valjamae et al., 1998); (2) enzyme jamming on the substrate surface resulting in hydrolysis rate reduction (Xu and Ding, 2007); (3) negligibly reversible cellulase binding (Ma et al., 2008); or (4) non-productive binding of adsorbed cellulase (Jalak and Valjamae, 2010). Evidence of inactivation of adsorbed cellobiohydrolase 1 (CBH1) was presented in recent studies using atomic force microscopy (AFM) by Igarashi et al. (2009; 2011). They observed that some CBH1 was inactivated on a substrate surface while other active $\mathrm{CBH} 1$ could freely proceed along the substrate surface. Although these individual factors have been studied, a kinetic model linking overall activity loss of adsorbed enzyme to cellulose hydrolysis rates and yields has yet to be developed and validated experimentally.

If adsorbed enzyme became inactive, it would necessarily return to the bulk solution more slowly (if at all) and be unable to find a new binding site to start another hydrolysis cycle immediately. This underlying phenomenon would support the adsorbed enzyme inactivation theory, but this has not been examined so far either. Since cellulases are composed of several different enzyme species, and different enzymes have different 
binding characteristics, it is necessary to separate a sufficient amount of a representative component to perform mechanistic studies. CBH1 is the most abundant species and is an important processive cellobiohydrolase that hydrolyzes crystalline cellulose. It is desirable to first develop a process for separating large amounts of this enzyme from a typical cellulase cocktail, and then characterize its deactivation and desorption characteristics under reduced activity.

A mechanism for the rate reduction, which considers inactivation of adsorbed cellualses, has been developed and experimentally validated here. Using these results, factors to consider when developing a cellulose hydrolysis process were then proposed. The specific objectives of this dissertation are summarized below.

\subsection{Objectives}

1. Examine whether change of substrate properties or deactivation of enzyme due to environmental mechanisms is more responsible for the rate reduction during enzymatic hydrolysis of cellulose.

2. Develop a mathematical model to describe cellulose hydrolysis that considers activity loss of adsorbed enzyme and validate the model experimentally.

3. Develop a scaled-up process for separating $\mathrm{CBH} 1$ from a commercial cellulase cocktail.

4. Study deactivation (due to environmental mechanisms) of individual cellulase components, such as endo- and exo- glucanases.

5. Examine desorption of $\mathrm{CBH} 1$ under reduced activity conditions.

6. Propose factors to consider when developing a cellulose hydrolysis process. 


\section{CHAPTER II}

\section{LITERATURE REVIEW}

\subsection{Structure of Cellulose}

Cellulose is glucan linked by $\beta$-glycosidic bonds (Figure 2.1 ). The $\beta$-glycosidic linkage (the bonds joining the simple sugars together) is above the plane of the rings. The cellobiose unit cell of crystalline cellulose has a length of $1.03 \mathrm{~nm}$. Cellobiose units are assembled in bundles of three. About 36 cellulose chains are associated to compose an elementary fibril with a diameter of $3.5 \mathrm{~nm}$. These elementary fibrils are assembled into microfibrils with a diameter varying from 10 to $30 \mathrm{~nm}$. The microfibrils form macrofibrils that range from 60 to $360 \mathrm{~nm}$ in diameter (Lee et al., 2000).

Cellulose has 200-300 glucose units per chain while starch exhibits branches every 17 to 26 glucose units (Bertoldo and Antranikian, 2002). Therefore, cellulose has a smaller frequency of chain ends and, therefore, a lower fraction of accessible external bonds for enzyme than starch.

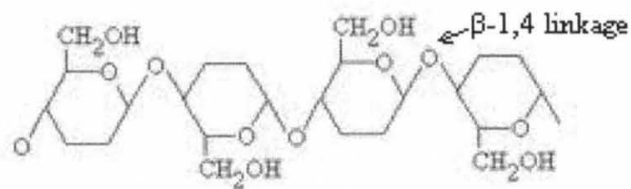

Figure 2.1. Structure of cellulose. 


\subsection{Sources of Various Cellulose Substrates}

Common cellulose model substrates include Solka Floc, Avicel, filter paper, cotton fiber, bacterium microcrystalline cellulose (BMCC) and phosphoric acid swollen cellulose (PASC). Solka Floc, Avicel and filter paper, which are derived from bleached wood pulp, are a blend of amorphous and crystalline forms. Particularly, Solka Floc is cellulose with $0.2 \%-0.4 \%$ lignin and $2.3 \%$ pentosans (Lee and Fan, 1982), while the other two substrates are pure cellulose. Dewaxed cotton fibers are one of the purest sources of cellulose and BMCC was prepared from cultures of Acetobacter xylinum. These two substrates are considered high crystalline cellulose. PASC is prepared by acid swollen of Avicel, which usually is regarded as amorphous cellulose.

\subsection{Types of Crystalline Cellulose}

There are three types of crystalline cellulose. Most native cellulose is a mixture of the I $\alpha$ and I $\beta$ structures, with the I $\alpha$ form being prevalent in cellulose that is produced by algae and bacteria, whereas I $\beta$ is dominant in higher plants (Wada et al., 2004). $\alpha$ cellulose is resistant to $17.5 \%$ and $9.45 \%$ sodium hydroxide solution, while $\beta$ cellulose is soluble and re-precipitated on acidification of the solution. Cellulose II was produced by treating native cellulose I from flax with $23 \% \mathrm{NaOH}$, followed by rinsing and drying. Cellulose II can also be prepared by precipitation from solution, as in the manufacture of rayon, and by bacteria that are either mutants or at low temperature. Cellulose III, results from treatment with amines that are subsequently evaporated or rinsed off (Wada et al., 2004). Cellulose III has a much larger portion of hydrophobic surface than cellulose I (Igarashi et al. 2011). 


\subsection{Effect of Enzyme Deactivation due to Environmental Mechanisms on Cellulose}

\section{Hydrolysis}

The reaction rate in enzymatic hydrolysis of cellulose is known to decrease significantly as the reaction proceeds (Dasari and Berson, 2007; Dasari et al., 2009; Dunaway et al., 2010; Nidetzky and Steiner, 1993; Valjamae et al., 1998). The leading cause of this effect has traditionally been associated with enzyme deactivation due to thermal/ mechanical mechanisms or variation of substrate properties.

Zhang et al. (2010) proposed cellulase deactivation due to the reaction environment, which includes thermal and mechanical mechanisms, to be one possible reason for the slow kinetics of cellulose hydrolysis. However, the thermal stability of cellulases is usually good (Ooshima et al., 1991). Deactivation of cellulases due to mechanical shear was found to be considerable at high shear rate but only in the presence of a gas-liquid interface (Kim et al 1981). These findings suggest that deactivation due to thermal/mechanical alone is not likely a universal reason for the hydrolysis rate reduction, although more significant thermal/mechanical deactivation of some cellulase was found by Reese and Mandels (1980), or due to mechanical mixing in a stirred tank. Therefore, it must still be determined whether deactivation due to thermal/mechanical mechanisms can account for rate reduction in cellulose hydrolysis.

\subsection{Effect of Substrate Properties on Cellulose Hydrolysis}

Variation of substrate properties during the reaction is another factor that may affect cellulose hydrolysis. Important substrate properties affecting cellulose hydrolysis include: crystallinity, specific surface area (SSA), average size of pore. 
The role of crystallinity in impacting hydrolysis is controversial so far. Cellulose hydrolysis rates mediated by fungal cellulases are typically 3-30 times faster for amorphous cellulose as compared to high crystalline cellulose (Lynd et al., 2002), and the increase of crystallinity during the reaction after amorphous cellulose was depleted (Betrabet and Paralikar, 1977; Ooshima et al., 1983) might be one reason for the significant rate reduction in hydrolysis. However, Lenze et al. (1990), Ohmine et al. (1983), Puls and Wood (1991) found crystallinity did not increase during enzymatic hydrolysis. Furthermore, Jalak and Valjamae (2010) found that a common apparent hydrolysis rate constant existed for several different substrates such as lignocellulose, Avicel, and amorphous cellulose when they were hydrolyzed with a cellobiohydrolase. Therefore, it must still be determined whether crystallinity change and variations of initial crystallinity affect cellulose hydrolysis.

Besides crystallinity, surface area is another important physical feature that may affect cellulose hydrolysis, as it reflects the capability of substrate to adsorb enzyme. Higher surface adsorption of enzyme is expected to yield faster hydrolysis rate. Pore volume and average pore size, which indicate the degree of openness of structure attacked by enzyme, are also key structures that may affect hydrolysis (Choi et al., 2007). It is therefore desired to know whether these features change during the reaction and affect cellulose hydrolysis.

\subsection{Effect of Activity Loss of Adsorbed Enzyme on Cellulose Hydrolysis}

Due to inconclusive or contradictory results reported in the literature regarding these previous two mechanisms, it is desirable to explore a new mechanism that is more likely to explain the rate reduction. In the recent decade or so, activity loss of adsorbed 
enzyme has been proposed as a possible reason for this. Adsorbed enzyme can become deactivated due to the following possible reasons: (1) the cellobiohydrolases become stuck on the substrate surface due to a crystalline defect, or when surrounding cellulose chains prevent further processive action (Valjamae et al., 1998); (2) enzymes jam on the substrate 'surface resulting in hydrolysis rate reduction (Xu and Ding, 2007); (3) negligibly reversible cellulase binding (Ma et al., 2008) ; or (4) non-productive binding of adsorbed cellulase (Jalak and Valjamae, 2010) . Recently, real-time AFM imaging revealed that a significant portion of adsorbed Cellobiohydrolase $1(\mathrm{CBH} 1)$ got stuck on the substrate surface and became inactivated thereafter (Igarashi et al., 2009). Any of these events that cause inactivation of adsorbed cellulases can result in significant hydrolysis rate reduction. Igarashi et al. (2011) further found that enzyme jamming contributed significantly to the hydrolysis rate reduction.

\subsection{Product Inhibition and Mass Transfer Limitation}

Nidetzky and Steiner (1993) reported that inhibition by glucose is weak, although Howell and Mangat (1975) and Gusakov and Sinitsyn (1992) reported that product inhibition may be a potential reason for the rate reduction. Furthermore, it was found the hydrolysis rate still declined significantly when continuously removing products in a membrane reactor, (Howell and Mangat, 1978; Converse et al., 1987). Therefore, product inhibition cannot be the reason for the decrease of hydrolysis rate, as also pointed out by Valjamae et al. (1998) and Zhang et al. (1999). It was shown that the initial hydrolysis rate decreased about $84 \%$ when the cellobiose product reached a concentration of $60 \mu \mathrm{M}$; however, with the presence of $60 \mu \mathrm{M}$ initial cellobiose, the hydrolysis rate only decreased 
less than $10 \%$ compared to a control experiment in the absence of initial cellobiose (Valjamae et al. 1998).

For mass transfer in cellulose hydrolysis, Philippidis et al. (1992) reported that products such as cellobiose and glucose are small molecules with high diffusivity and their diffusion should not be rate limiting step. Furthermore, it was reported that enzyme diffusion is relatively rapid compared to hydrolysis at substrate loading of $5 \%(\mathrm{w} / \mathrm{v})$ or less (Lee and Fan, 1982), although at high solid loading, mass transfer may be the limiting step in cellulose hydrolysis (Dasari et al., 2009).

\subsection{Kinetic Modeling Considering Inactivation of Adsorbed Enzyme to Account for}

\section{Cellulose Hydrolysis}

One methodology to model cellulose hydrolysis is based on empirical equations, such as the Response Surface Methodology (Ferreira et al., 2009; Qi et al., 2009), and this does not provide any insight into the mechanistic details of the process and cannot be applied outside the conditions under which they were developed. As a result, mechanistic models which reveal rate limiting steps will be more helpful for optimization and understanding the process (Bansal et al., 2009; Zhang et al., 2010).

Nidetzky and Steiner (1993) proposed a kinetic model considering heterogeneity of substrate as the main reason responsible for slow cellulose hydrolysis, which described a slow down of the hydrolysis rate when the easily hydrolyzed part of the cellulose was consumed and the less accessible part remained. However, this assumption is weakened by the fact that they cannot find any different accessibility of substrate to enzyme related to physicochemical properties of substrate, such as crystallinity, surface area, or degree of polymerization. Moreover, the assumption of two kinds of cellulose present in substrate 
was contradicted by Ooshima et al. (1991), Desai and Converse (1997), and Yang et al (2006). It was found that the reactivity of substrate did not change during hydrolysis. Meanwhile, the assumption of two kinds of cellulose in substrate cannot explain the monophasic first-order reaction for some substrates such as cotton and regenerated cellulose (Schurz and Honel, 1989; Lenz et al., 1990). Therefore, it is desirable to develop a model considering change of enzyme activity during the reaction that can account for cellulose hydrolysis.

Kinetic modeling validated by experimental evidence can help resolve possible mechanisms. Although previously both Howell and Mangat (1978) and Converse et al. (1988) had developed mathematical models to account for the slow kinetics of cellulose hydrolysis by considering deactivation of the adsorbed cellulase, there are some common limitations in both of their models. First, Howell and Mangat (1978) proposed a model based on the Michaelis-Menten kinetics, which is not appropriate for heterogeneous cellulose hydrolysis (Lynd et al., 2002). The model developed by Converse et al. (1988) assumed adsorption of cellulases to substrate is proportional to the second order of substrate concentration, although it has not been validated by experiments. Second, initial guesses required for their model are critical since multi-optima occur. These are the two disadvantages that new kinetic models should overcome.

Shen and Agblevor (2008) further pointed out that some drawbacks in previous modeling, such as Fan and Lee (1983) and Gan et al. (2003), were: (1) the models consisted of several ordinary differential equations which were too complicated to solve analytically; (2) too many parameters could not be uniquely determined in the ODE's; 
and (3) the values of some parameters were arbitrarily chosen rather than from a fitting process based on experiments.

\subsection{Cellulase Structure and Function}

Cellulose hydrolysis usually involves cellulases from $T$. reesei and some other bacteria or fungi. $T$. reesei cellulases have three major components: endoglucanases (EG1 5), exoglucanases or cellobiohydrolases (CBH1 2) and $\beta$-glucosidase, which have different structures, hydrolysis mechanisms and substrate specificities. The structure of $\mathrm{CBH} 1, \mathrm{CBH} 2$, and EG1 features a catalytic domain and a cellulose-binding domain connected by a glycolysated peptide linker (Zhang and Lynd, 2004). The structure of intact CBHI determined by small-angle X-ray scattering is a tadpole shaped enzyme $18 \mathrm{~nm}$ long and $4 \mathrm{~nm}$ wide. Structural determination by X-ray diffraction defined the dimensions of the catalytic core to be $6 \times 5 \times 4 \mathrm{~nm}$, containing the substrate binding site that was found to be a tunnel $4 \mathrm{~nm}$ long, with binding sites for 7 glucose units (Lee et al., 2000). The catalytic domain structures of $\mathrm{CBH} 1$ and $\mathrm{CBH} 2$ are entirely different but both feature tunnel-shaped structures (Divne et al., 1994). Cellobiose is the primary product of hydrolysis mediated by $\mathrm{CBH} 1$ and $\mathrm{CBH} 2$. The $T$. reesei $\mathrm{CBH} 1$ and $\mathrm{CBH} 2$ can cleave several bonds following a single adsorption event before the dissociation of the enzyme substrate complex (Imai et al., 1998). EG1 and CBH1 have significant homology (45\% identity) and belong to the same family (Cel7). However, the active site of EG1 is a groove rather than a tunnel, allowing glucan chains to be cleaved randomly to two shorter chains (Divne et al., 1994).

Therefore, endoglucanases decrease the degree of polymerization (DP) of substrate by cleaving the substrate at internal sites, whereas exoglucanases release 
cellobiose from ends of the substrate thus gradually decreasing the length of the cellulose. $\beta$-glucosidase hydrolyzes cellobiose to two molecules of glucose. In order to study specific hydrolysis mechanisms of some representative component in more detail, it is necessary to separate it from other cellulase components.

\subsection{Separating CBH1 from a Commercial Cellulase Mixture}

The relative abundance of the three major cellulases in $T$. reesei is as follows: $\mathrm{CBH} 1 \sim 60 \%, \mathrm{CBH} 2 \sim 20 \%, \mathrm{EG} 2 \sim 12 \%$ (Zhang and Lynd, 2004). CBH1 is the most abundant and important cellulase in hydrolysis of crystalline cellulose. The kinetics of purified $\mathrm{CBH} 1$ reacting with cellulosic substrate have been extensively studied (Valjamae et al., 1998; Xu and Ding, 2007), as have hydrolysis from reducing or non-reducing ends (Imai et al., 1998; Stahlberg et al., 1993), binding reversibility (Bothwell et al., 1997; Kyriacou et al., 1989; Ma et al., 2008; Nidetzky et al., 1994), synergism effects with other cellulase components (Irwin et al., 1993; Mansfield et al., 1999; Walker et al., 1992), processivity (Kipper et al., 2005; Medve et al., 1998a) and shear deactivation of exoglucanase (Gunjikar et al., 2001).

Pure CBH1 can be separated from cultured T. reesei (Nidetzky et al., 1994; Walker et al., 1992), but a good separation of CBH1 from other cellulase components is a complex multistep process, involving a combination of ammonium sulfate precipitation, affinity chromatography, and ion-exchange chromatography processes. Medve et al. (1998b) reported a one step separation of CBH1 from Novozyme cellulases by ionexchange chromatography which relies on different pIs of cellulases using fast protein liquid chromatography (FPLC) and has greatly simplified the separation procedure for CBH1. 


\subsection{Scaled-up Separation of CBH1 from a Commercial Cellulase Mixture}

Since specific activities of cellobiohydrolases are lower than other enzyme components (Den Haan et al., 2007), it is desirable to obtain large amounts of CBH1 to study hydrolysis mechanisms.

One way to obtain a large amount of purified $\mathrm{CBH} 1$ is to express the gene in other bacteria or fungi (Den Haan et al., 2007; Godbole et al., 1999; Takashima et al., 1996). However, it is uncertain whether the recombinant enzymes behave differently from the native ones due to a possibly different glycosylation (Godbole et al., 1999; Reinikainen et al., 1992; Takashima et al., 1998). Medve et al. (1998b) reported a scaled-up separation (50 $\mathrm{ml}$ sample compared to a $3 \mathrm{ml}$ sample in their small-scale separation) performed with a Pharmacia XK 26/20 column (26 mm I.D., length of $20 \mathrm{~cm}$ ) that was developed based on their small-scale separation.

\subsection{Investigation of Enzyme-Substrate Interactions Using AFM}

Recently, AFM has been used during the investigation of enzyme-substrate interactions. Liu et al. (2009) used AFM and found that CBH1 bound to the hydrophobic surface of crystalline cellulose. Igarashi et al. (2009) recorded video of the processive movement of $\mathrm{CBH} 1$ on a cellulose surface. More recently, Igarashi et al. (2011) reported that traffic jams reduce hydrolytic efficiency of cellulase on a cellulose surface. All these results, especially the result by Igarashi et al. (2011), are breakthrough findings that provide direct evidence of cellulase functions, such as binding and processive movement. They also showed that inactivation of adsorbed enzyme directly affects cellulose hydrolysis rate reduction. 


\subsection{Processivity of Cellobiohydrolase}

Processivity of cellulases has been thoroughly discussed on a structural basis (Divne et al., 1994). Kipper et al. (2004) reported that hydrolysis of fluorescence-labeled celluloses revealed processivity values of $88 \pm 10,42 \pm 10$ and $34 \pm 2.0$ cellobiose units for $\mathrm{CBH} 1$ on bacterial cellulose, bacterial microcrystalline cellulose and endoglucanasepretreated bacterial cellulose substrate, respectively. Using the ratio of produced cellobiose to that of the sum of glucose and cellotriose as a measure of processivity, Medve et al. (1998a) found the processivity for $\mathrm{CBH} 1$ to be approximate 5-10 cellobiose units on Avicel. Using the same algorithm, a rough estimate of processivity of 23 cellobiose units was reported for $\mathrm{CBH} 1$ acting on BMCC (Von Ossowski I et al., 2003). Recently, processive movement of $\mathrm{CBH} 1$ on substrate was directly observed using AFM (Igarashi et al., 2009), with a rate of $7.1 \mathrm{~nm} / \mathrm{s}$ (Igarashi et al., 2011).

\subsection{Enzyme Adsorption}

Cellulase adsorption is most frequently modeled with the Langmuir adsorption equation (Kumar and Wyman, 2008; Kyriacou et al., 1988; Nidetzky et al., 1994; Tu et al., 2007), although the assumptions for the Langmuir adsorption, such as each binding is equivalent and there is no interaction between adsorbed molecule on adjacent sites, may not be valid in some cases. Two site adsorption models (Linder et al., 1996; Medve et al., 1997) and Freundlich isotherms (Medve et al., 1997) are, therefore, sometimes employed for those considerations. 


\subsection{Binding Reversibility}

There is currently a lot of controversy concerning the binding of cellulsase to cellulose. Direct measurement of the dissociation rate constant has not been reported (Jalak and Valjamae, 2010). A study by Kipper et al. (2005) implied that at the beginning of hydrolysis the dissociation rate of $\mathrm{CBH} 1$ is about $0.003 \mathrm{~s}^{-1}$ by studying steady-state release of the end-label from the reducing-endlabeled cellulose and assuming that binding is fast and recruitment of $\mathrm{CBH}$ is limited by the dissociation rate.

However, cellulase adsorption is reported to be neglibly reversible in many studies (Jung et al., 2003; Nidetzky et al., 1993; Kyriacou et al., 1989). Contradict to this, evidence has also been presented that CBHI is reversibly bound with cellulose by experiments showing the exchange of cellulase on the substrate surface (Bothwell et al., 1997). In addition, Linder and Teeri (1996) also found that the CBD (cellulose-binding domain) of CBHI exhibits reversible adsorption. However, interestingly, Carrard and Linder (1999) reported that the CBD of CBHII is initially bound to substrate reversibly, but eventually the reversible binding becomes irreversible or negligibly reversible.

\subsection{Deactivation of Individual Cellulase Components}

Deactivation of cellulase mixtures have been well studied, however deactivation extents of individual cellulase components and how they affect total deactivation have not yet been studied. $T$. reesei cellulases have three major components: endoglucanases (EG1 5), exoglucanases or cellobiohydrolases ( $\mathrm{CBH} 1, \mathrm{CBH} 2)$, and $\beta$-glucosidase, which have different substrate specificities. In previous studies, deactivation of cellobiohydrolases was mostly studied indirectly using total cellulase mixtures on the substrate Avicel, rather than by using purified $\mathrm{CBH} 1$ directly. Hydrolysis of cellulose 
always involves activity of several different enzymes working in synergy. For example, endoglucanases and cellobiohydrolases show a degree of synergism (DS) of 1.4-4.9 during the hydrolysis of Avicel (Zhang and Lynd, 2004). Therefore, the loss of Avicelase activity may not represent the deactivation extent of just cellobiohydrolase, and it is unknown whether the deactivation of endoglucanase would affect the measured Avicelase activity due to a synergistic effect.

\subsection{Synergism}

When the activity exhibited by mixtures of components is greater than the sum of the activity of these components evaluated separately, synergism of different components occur. If the degree of synergism (DS) is defined equal to the ratio of the activity exhibited by mixtures of components divided by the sum of the activities of separate components, the highest DS values are on Bacterium Cellulose (5-10) and cotton (3.97.6) for the synergism between endoglucanases and exoglucanases. Less pronounced but still significant synergism is exhibited on Avicel (DS 1.4-4.9), while the smallest synergistic effects (DS 0.7-1.8) have been reported on phosphoric acid-swollen and other acid-treated amorphous celluloses (Zhang and Lynd, 2004).

Synergism between endoglucanases and exoglucanases is the most widely studied type of synergy and is among the most quantitatively important for hydrolysis of crystalline cellulose. Other types of synergism proposed in the cellulose hydrolysis include: 1) exoglucanase and exoglucanase 2) endoglucanase and endoglucanase 3) exoglucanase or endoglucanase and $\beta$-glucosidase, which reduces inhibition by cellobiose (Zhang and Lynd, 2004). 


\section{CHAPTER III}

\section{EXPERIMENTAL}

\subsection{Experimental Plan}

In the work presented here, some traditional factors considered to affect cellulose hydrolysis, such as enzyme deactivation due to the reaction environment and variation of substrate properties, were examined. Deactivation extents of total cellulase mixture were studied on several substrates, such as Sigmacell, filter paper and cotton fiber which differ in crystallinity and morphology, to examine whether enzyme deactivation due to themal/mechanical mechanisms is a universal reason that can explain significant rate reduction in cellulose hydrolysis. Also examined were effects of variation of substrate properties such as crystallinity, specific surface area and average size of pore on the cellulose hydrolysis. Substrates in powdered form, such as Sigmacell, Cellulose, microcrystalline, and Solka Floc, which can be conveniently loaded into an X-ray diffractometer and adsorption apparatus to measure physical properties, were used.

In order to study inactivation of adsorbed enzyme, a kinetic model describing inactivation of adsorbed enzyme as the main effect for the rate reduction of cellulose hydrolysis was developed. The modeling was first applied to account for glucose release rates and yields from Solka Floc, a regenerated cellulose containing minor xylan contamination, and then the same procedure was applied to Sigmacell Type 20, a microcrystalline cellulose, to examine whether the derived parameters were valid for 
substrates with different properties. The relative crystalline indices measured by acid hydrolysis for Sigmacell Type $20(\sim 90 \%)$ are much greater than Solka Floc ( $45-65 \%)$ (Weimer and Weston, 1985). Other properties such as degree of polymerization and area accessible to enzyme differ among these substrates as well. Then, the relative extent of enzyme activity loss from (1) enzyme-substrate interactions and (2) deactivation due to thermal/mechanical mechanisms were quantified.

To study hydrolysis mechanism of individual cellulase, $\mathrm{CBH} 1$ was separated by modification made to the protocol reported by Medve et al. (1998b). A vacuum manifold system was used to provide a steady flow through parallel columns to achieve scaled-up quantities of CBH1 from Spezyme CP cellulases. This manifold system used step elution in place of the continuous gradient. The modification here employed a straightforward way to scale up the process by maintaining the same column length while increasing the effective cross-sectional area by operating multiple columns in parallel. To test the feasibility of this scale-up method, the purity and specific p-nitrophenyl- $\beta$-D-cellobioside (pNPC) activity of CBHI were examined and compared to $\mathrm{CBHI}$ separated conventionally with a FPLC system. Stability was also tested, and adsorption and hydrolysis of bacterial microcrystalline cellulose (BMCC) were performed with the CBHI separated from the scaled-up process.

Deactivation extents of cellobiohydrolase, endoglucanase, and a total cellulase mixture were studied independently as functions of incubating time (a form of thermal deactivation) and mixing intensity. Cellobiohydrolase 1 (CBH1) was separated from a commercial cellulase mixture (Spezyme CP) and then used to study specific CBH1 activity loss towards p-nitrophenyl- $\beta$-D-cellobioside (pNPC). Endoglucanase activity was 
studied by using total cellulase on Carboxymethyl cellulose sodium salt (CMCNa) (CBH1 and $\beta$-glucosidase have very little activity towards $\mathrm{CMCNa}$ ) (Takashima et al., 1998). Activity of the total cellulase mixture was studied on phosphoric acid swollen cellulose (PASC). Meanwhile, computational fluid dynamics (CFD) was used to quantify the shear in a rotating Erlenmeyer flask at different mixing intensity and investigate whether there is any correlation between the shear stress in orbiting flask and cellulase deactivation.

If adsorbed enzyme becomes inactive, it would necessarily return to the bulk solution more slowly (if at all) and be unable to find a new binding site to start another hydrolysis cycle immediately. However, this underlying phenomenon has not been examined so far. Directly quantifying desorption of inactive enzyme is difficult since the structure of inactive enzyme may be similar to that of active enzyme following desorption, making it hard to distinguish inactive enzyme from active enzyme in the bulk solution. Alternatively, an indirect method can be used whereby activity is intentionally suppressed and then desorption is compared to an unsuppressed control.

In this study, such desorption studies were performed using $\mathrm{CBH} 1$ as the model enzyme species. CBH1 activity was reduced by one of four treatments: (1) mechanical deactivation, (2) addition of a competitive inhibitor, (3) operating at low temperature, or (4) addition of a denaturant.

Finally, guidance for process development is presented based on the mechanistic model considering first order inactivation of adsorbed cellulases. Effects of reaction temperature, reaction time, accessible surface area of substrate, and desorption of inactive enzyme on process improvement are discussed. 


\subsection{Materials}

Solka Floc from FD\&S Corporation Urbana, $\mathrm{OH}$, Sigmacell substrates from Sigma-Aldrich St Louis, MO, Cellulose, microcrystalline from Alfa Aesar Ward Hill, MA, dewaxed cotton from Johnson \& Johnson New Brunswick, NJ, and filter paper from thermo fisher scientific Waltham, MA were purchased. Dewaxed cotton fiber, Sigmacell and filter paper were used to assay cellulase activity on substrates since these three substrates can represent most substrate forms used in cellulose hydrolysis. Cotton fiber and Sigmacell are high crystalline cellulose while filter paper is more amorphous (Zhang and Lynd, 2004). Furthermore, dewaxed cotton fiber, Sigmacell and filter paper are in quite different shapes as ball, powder and disks, respectively, which may represent shapes of most substrates in hydrolysis.

Since Sigmacell, Cellulose, microcrystalline, and Solka Floc are powder-form cellulose, which can be conveniently put into X-ray diffractometer and adsorption apparatus to measure physical properties, these three substrates were chosen to study the effect of initial difference in substrate physical properties on cellulose hydrolysis. Sigmacell, and Cellulose, microcrystalline are high crystalline cellulose. Solka Floc, is a regenerated cellulose containing minor xylan contamination. The relative crystalline indices measured by acid hydrolysis for Solka Floc ( $45-65 \%)$ are much smaller than Sigmacell Type $20(\sim 90 \%)$ (Weimer and Weston, 1985).

Moreover, Sigmacell and Solka floc were used in the kinetic modeling considering inactivation of adsorbed enzyme to account for cellulose hydrolysis. Spezyme CP cellulase enzyme provided by Genencor International, Inc Rochester, NY, USA, [lot \# 3016295230] was used to hydrolyze the substrate. 
For separation of $\mathrm{CBH} 1$ from commercial Spezyme $\mathrm{CP}$ cellulases, triethanolamine (TEA), HCl, D-(+)-cellobiose, p-nitrophenol, pNPC, (3-aminopropyl)triethoxysilane (APTES) and ammonium acetate were purchased from Sigma-Aldrich Co., MO. QUICK START Bradford Dye Reagent $1 \times$ was purchased from Bio-Rad Laboratories, Hercules, CA. BMCC was a kind gift from Dr. David Wilson, Cornell University. Vivaspin centrifuge tubes (10 kDa molecular weight cutoff) were purchased from Vivascience, Hannover, Germany. Spezyme CP cellulase used in this study was donated from Genencor International, Inc. [lot \# 3016295230]. HiTrap Q HP anion exchange columns were purchased from GE Healthcare Bio Sciences AB, Uppsala, Sweden.

To study desorption of $\mathrm{CBHI}$ at reduced activity, $\mathrm{D}-(+)$-cellobiose, guanidine hydrochloride $(\mathrm{GdnHCl})$, and potassium hexachloro palladate (IV) $\left(\mathrm{K}_{2} \mathrm{PdCl}_{6}\right)$ were purchased from Sigma-Aldrich Co., MO. Cellobiose (Henriksson et al., 1996) and GdnHCl (Woodward et al., 1990) are competitive inhibitors for $\mathrm{CBH} 1$, while $\mathrm{K}_{2} \mathrm{PdCl}_{6}$ is a denaturant for CBH1 (Lassig et al., 1995). pNPC from Sigma-Aldrich Co., MO was a substrate used to assay CBH1 activity. QUICK START Bradford Dye Reagent $1 \times$ was purchased from Bio-Rad Laboratories, Hercules, CA. and used to assay protein concentration. 


\subsection{Procedure: Effect of Enzyme Deactivation due to Environmental Mechanisms and Variation of Substrate Properties on Cellulose Hydrolysis}

\subsubsection{Cellulase Deactivation from Mechanical/Thermal Mechanisms}

$0.6 \mathrm{~mL}$ of Spezyme CP cellulases with $50 \mathrm{FPU} / \mathrm{ml}$ were incubated in $100 \mathrm{ml}$ reaction volume Erlenmeyer flask for up to 3 days at $50{ }^{\circ} \mathrm{C}, 150 \mathrm{rpm}$ on an orbital shaker. The $\mathrm{pH}$ of each flask was adjusted to 4.8 with citrate buffer. Samples were initially incubated for for $2,4,8,24,48$ or 72 -hours, and $2 \mathrm{~g}$ substrate was added for a second incubation period for $1 \mathrm{~h}$. The activity of the cellulase was assayed. Released glucose content was assayed using an YSI 2700 Select Biochemistry Analyzer. The above experiments were performed with duplicate samples and the measurements for each sample were repeated twice.

\subsubsection{Characterization of Substrate Crystallinity Using X-Ray Diffraction (XRD)}

Substrate crystallinity were characterized using an X-ray diffractometer (Bruker

D8 Discover; Bruker AXS Co., TX) as reported elsewhere (Rezania et al., 2009). The measurement conditions were as follows: Drive $=$ coupled; Steptime $=0.5 \mathrm{~s}$; Stepsize $=$ $0.05^{\circ}$, Stepmode $=$ Stepscan; Start $2 \Theta=7^{\circ} ;$ End $2 \Theta=40^{\circ} ;$ Radiation Cu K $0.154 \mathrm{~nm}$; Detector type $=$ Scintillation counter; $\mathrm{HV}=774$; voltage, $40 \mathrm{kV}$; current, $40 \mathrm{~mA}$.

Crystallinity index $(\mathrm{CrI})$ of different celluloses was calculated by:

$$
\mathrm{CrI}=\left[\left(\mathrm{I}_{002}-\mathrm{I}_{\mathrm{am}}\right) / \mathrm{I}_{002}\right] * 100
$$

where $\mathrm{I}_{002}$ is the height of the 002 plane peak and $\mathrm{I}_{\mathrm{AM}}$ is the height of the minimum, representing amorphous cellulose, between the 002 and the 101 plane peaks(Choi et al., 2007). 


\subsubsection{SSA and Pore Size Measurement}

The SSA and pore size of substrates were measured by nitrogen gas adsorption and desorption isotherms as reported elsewhere (Choi et al., 2007) using an adsorption apparatus (Micromeritics Instrument Corporation, Tristar 3000). The operating conditions are as follows: sample mass was $0.14-0.21 \mathrm{~g}$; temperature was $77.300 \mathrm{~K}$; equilibration interval was $5 \mathrm{~s}$. The ranges of SSA, average pore size and total pore volume for various cellulose substrates were determined from the nitrogen adsorption and desorption isotherms, respectively, with the BJH model.

\subsubsection{Cellulose Hydrolysis}

Cellulose substrate and $0.75 \mathrm{ml}$ of Spezyme CP cellulases (corresponding to 50 FPU (filter paper unit)/mL cellulases activity or $15 \mathrm{FPU} / \mathrm{g}$ cellulose) were incubated for up to 3 days. Tests were run at 150 RPM in $250 \mathrm{~mL}$ flasks in an Innova 4230 incubator shaker. The pH of each flask was adjusted to 4.8 with citrate buffer. To prevent bacterial growth, $3 \mu \mathrm{L} / \mathrm{mL}$ of cycloheximide and $4 \mu \mathrm{L} / \mathrm{mL}$ of tetracycline were added to the slurry. Total operating volume was $50 \mathrm{~mL}$.

$1.5 \mathrm{ml}$ samples were removed to determine the glucose concentration at the incubation time of $2,4,8,16,24,48,72$ hours. The liquid was tested for dissolved glucose and xylose content using an YSI 2700 Select Biochemistry Analyzer.

\subsection{Procedure: Activity Loss of Adsorbed Enzyme}

\subsubsection{Examine Relative Extents of Enzyme Activity Loss from Enzyme-substrate} Interaction and due to Thermal/Mechanical Mechanisms

Relative extents of enzyme activity loss were examined on substrate Solka Floc as an example. To determine enzyme activity loss due to thermal/mechanical mechanisms, 
experiments were run where enzyme underwent an initial incubation in a substrate free buffer solution. $0.6 \mathrm{~mL}$ of Spezyme CP cellulases was initially incubated for the times listed above without substrate, and $2 \mathrm{~g}$ substrate was added for a second incubation period for $1 \mathrm{~h}$. The activity of the cellulase was assayed. The above experiments were performed with duplicate samples and the measurements for each sample were repeated twice.

To determine enzyme activity loss from enzyme-substrate interaction, first, 0.1 , 0.2, 0.4, 0.8 and $1.2 \mathrm{~g}$ of Solka Floc substrate and $0.6 \mathrm{~mL}$ of Spezyme CP cellulases (104 $\mathrm{mg} / \mathrm{ml}$ or equal to $50 \mathrm{FPU} / \mathrm{mL}$ ) were added in the flasks and incubated for $2,4,8,16,24$, 48 and $72 \mathrm{~h}$. This gave concentrations of $300,150,75,37.5$ and 25 FPU/g cellulose. The glucose released in this period was recorded as $C_{1}$. Each set of conditions was run in four flasks and duplicate measurements were made for each sample at each time point.

A second incubation was performed as an activity assay with a second loading of substrate. Total substrate amount was brought up to two grams and incubated for 1 more hour. The total glucose released after the initial and second incubation was recorded as $\mathrm{C}_{2}$. Of the original four flasks, two were used as a control and run without adding fresh substrate in the second incubation. The glucose concentration increment in the control experiment during the second incubation was recorded as $\mathrm{C}_{3}$. The $\mathrm{C}_{3}$ value is used to quantify the amount of sugar released from the original substrate during the second incubation. This is an estimate to the amount that is released in the experimental flasks. Enzyme's activity following interaction with substrate is defined as the glucose concentration increment $(\mathrm{g} / \mathrm{L})$ as a result of the freshly added substrate in the second 
incubation, which is: $\mathrm{C}_{2}-\mathrm{C}_{1}-\mathrm{C}_{3}$. The procedure to determine the total activity loss as a function of incubating time is summarized in Table 3.1.

\subsubsection{Glucose Measurements}

The liquid was tested for dissolved glucose content using a YSI 2700 Select Biochemistry Analyzer. For sampling, the slurry was stirred under the laminar flow hood and $1.5 \mathrm{~mL}$ was removed and heated above $85^{\circ} \mathrm{C}$ for 10 minutes to stop the reaction. The sample was then centrifuged to separate the liquid out of the slurry.

\section{Table 3.1}

Summary of experimental procedure ofordetermining total deactivation of enzyme following incubation with different amounts of substrate.

\begin{tabular}{|c|c|c|}
\hline & Initial Incubation & Second Incubation \\
\hline Sample & $\begin{array}{l}\text { 1. Add initial loading of substrate }(0.1 \mathrm{~g}-1.2 \mathrm{~g}) \\
\text { 2. Add } 0.6 \mathrm{~mL} \text { enzyme in the concentration of } 50 \\
\text { FPU/ml (this gives } 15 \mathrm{FPU} / \mathrm{g} \text { cellulose when the } \\
\text { remaining substrate is added for the second } \\
\text { incubation) } \\
\text { 3. Complete initial incubation }(2,4,8,16,24,48,72 \\
\text { hours) } \\
\text { 4. Take } 1^{\text {st }} \text { sample, } \mathrm{C}_{1}\end{array}$ & $\begin{array}{l}\text { 1. Add second loading of } \\
\text { substrate (bring total up to } \\
2.0 \mathrm{~g} \text { ) } \\
\text { 2. Complete the second } \\
\text { incubation ( } 1 \text { hour for every } \\
\text { sample) } \\
\text { 3. Take } 2^{\text {nd }} \text { sample, } \mathrm{C}_{2}\end{array}$ \\
\hline Control & $\begin{array}{l}\text { 1. Add initial loading of substrate }(0.1 \mathrm{~g}-1.2 \mathrm{~g}) \\
\text { 2. Add } 0.6 \mathrm{~mL} \text { enzyme in the concentration of } 50 \\
\text { FPU/mi } \\
\text { 3. Complete initial incubation }(2,4,8,16,24,48,72 \\
\text { hours) } \\
\text { 4. Take } 1^{\text {st }} \text { sample, } \mathrm{C}_{1}\end{array}$ & $\begin{array}{l}\text { 1. Do not add substrate } \\
\text { 2. Complete the second } \\
\text { incubation ( } 1 \text { hour for every } \\
\text { sample) } \\
\text { 3. Take } 2^{\text {nd }} \text { sample, } C_{3}\end{array}$ \\
\hline
\end{tabular}

\subsection{Procedure: Scaled-up Separation of CBH1 from a Commercial Cellulase}

\section{Mixture to Study Hydrolysis and Inactivation Mechanisms}

\subsubsection{Preparation of Spezyme CP Sample}

To separate $\mathrm{CBH} 1$ from Spezyme CP cellulases, the initial crude enzyme sample was buffer exchanged to $\mathrm{pH} 7.6$ in a $10 \mathrm{mM}$ TEA (Triethanolamine)- $\mathrm{HCl}$ buffer by 
repeated ultrafiltration in $6 \mathrm{ml}$ Vivaspin centrifuge tubes in preparation for chromatography as suggested by Medve et al. (1998b).

\subsubsection{Protein Assay}

Unless stated otherwise, protein concentrations were determined at least in triplicate according to absorbance at $280 \mathrm{~nm}$ (Medve et al., 1998b), with a NanoDrop Spectrophotometer (ND-1000, NanoDrop Technologies, Inc. Wilmington, DE).

The total protein concentration in the Spezyme CP was determined by the software with the NanoDrop Spectrophotometer using the effective molecular weight and absorption coefficient of the mixtures. Since CBH1, CBH2 and EG2 account for $92 \%$ of total cellulase protein in the $T$. reesei cellulases, the effective molecular weight and absorption coefficient of the cellulase mixtures can be approximated by Equation (3.2):

$$
P=\frac{P \times X_{+}+P_{2} \times X_{2}+P \times X_{3}}{X_{1}+X_{2}+X_{3}}
$$

where $\mathrm{P}$ represents the effective molecular weight or absorption coefficient of cellulase mixtures; subscript 1,2 and 3 represents the major cellulase components $\mathrm{CBH} 1, \mathrm{CBH} 2$ and EG2, and $\mathrm{X}$ represents the relative abundance of the three major cellulase component. The molecular weights $(\mathrm{g} / \mathrm{mol})$, absorption coefficients $\left(\mathrm{mM}^{-1} \mathrm{~cm}^{-1}\right)$ at $280 \mathrm{~nm}$, and the relative abundance of each of the major proteins are: $64,000,78.8,60 \%(\mathrm{CBH} 1) ; 53,000$, 92.0, 20\% (CBH2); 48,000, 78.0, 12\% (EG2).(Medve et al., 1998b) Then the effective molecular weight and absorption coefficient of Spezyme CP cellulases are 59,522 $\mathrm{g} / \mathrm{mol}$ and $81,565 \mathrm{M}^{-1} \mathrm{~cm}^{-1}$, respectively, as calculated from Equation (3.2).

The $\mathrm{CBH}$ l concentration in the separation was estimated from the absorbance at $280 \mathrm{~nm}$, using a molecular weight of $64,000 \mathrm{~g} / \mathrm{mol}$ and absorption coefficient of 78.8 $\mathrm{mM}^{-1} \mathrm{~cm}^{-1}$ 


\subsubsection{Continuous Gradient Elution}

The separation of cellulases was first carried out using an AKTA FPLC (fast protein liquid chromatography) (Amersham Pharmacia Biotech; Uppsala, Sweden) as reported by Medve et al. (1998b) at $4{ }^{\circ} \mathrm{C}$. The FPLC system consisted of a pump (P-920), UV monitor (UPC-900), a valve (INV-907), a mixer (M-925) and a fraction collector (Frac-900/901). $29 \mathrm{mg}$ of Spezyme CP cellulases was loaded onto a $5 \mathrm{ml}$ HiTrap Q HP anion exchange column, the contents of which were equilibrated to $\mathrm{pH} 7$, and eluted with $120 \mathrm{ml} \mathrm{0-33 \%} 1 \mathrm{M}$ salt in $20 \mathrm{mM} \mathrm{TEA}-\mathrm{HCl}(\mathrm{pH} 7.0$ ) buffer at a flow rate of $3 \mathrm{ml} / \mathrm{min}$.

The initial sample contained total protein at $104 \pm 1 \mathrm{mg} / \mathrm{ml}$ according to absorbance at $280 \mathrm{~nm}$ and using $1 \mathrm{~A}(280)=1 \mathrm{mg} / \mathrm{ml}$ with a NanoDrop Spectrophotometer (ND-1000, NanoDrop Technologies, Inc. Wilmington, DE). The protein content measured here is in the range of reported values of $82 \mathrm{mg} / \mathrm{ml}$ (Kim et al., 2011) and 123 $\mathrm{mg} / \mathrm{ml}$ (Kumar and Wyman, 2008) for Spezyme CP cellulase as elsewhere. Unless specially mentioned, all tests in this work were repeated at least three times.

Decreasing the operating $\mathrm{pH}$ reduces binding of enzymes with higher PI to an anion column, and as a result can better purify $\mathrm{CBH} 1$ from other substances. $\mathrm{CBH} 1$ from previous step separations was applied to a lower $\mathrm{pH}$ condition $(\mathrm{pH}=6)$ to examine whether a second separation was needed to improve the purity of $\mathrm{CBH} 1$ separated in the first separation.

\subsubsection{Step Elution (with vacuum manifold) and Scale-up}

The ion exchange column ( $5 \mathrm{ml}$ HiTrap Q HP column) was connected to a VM 20 vacuum manifold (Sigma-Aldrich Co.; St. Louis, MO) to achieve a pressure differential for enzyme separation. A flow route of the separation system is shown in Figure 3.1a. 
This manifold system required step elution in place of the continuous gradient. Following loading of $29 \mathrm{mg}$ of $\mathrm{CBH} 1$ (in $10 \mathrm{mM}$ TEA-HCl pH 7.6 buffer) onto each anion column, $10 \mathrm{ml}$ of $0.1 \mathrm{M}, 15 \mathrm{ml}$ of $0.25 \mathrm{M}$, or $8 \mathrm{ml}$ of $0.33 \mathrm{M}$ sodium chloride in 20 mM TEA-HCl pH 7.0 buffer were applied to elute the protein successively following a wash of the column with $20 \mathrm{ml}$ of $20 \mathrm{mM}$ TEA- $\mathrm{HCl} \mathrm{pH} 7.0$ buffer. The protocol is summarized in Table 3.2. With this manifold system (Figure 3.1b), scale-up can be easily achieved by simply connecting several columns in parallel ( 5 columns were connected to vacuum manifold in this study).

\section{Table 3.2}

\section{Profile for step elution}

\begin{tabular}{clc}
\hline Step & \multicolumn{1}{c}{ Species } & $\begin{array}{c}\text { Quantity } \\
\text { (per column) }\end{array}$ \\
\hline 1 & Spezyme CP cellulases & $\sim 30 \mathrm{mg}$ \\
2 & $20 \mathrm{mM} \mathrm{TEA}-\mathrm{HCl} \mathrm{pH} \mathrm{7.0} \mathrm{buffer} \mathrm{(to} \mathrm{wash} \mathrm{column)}$ & $20 \mathrm{ml}$ \\
3 & $0.1 \mathrm{M}$ salt in 20 mM TEA-HCl pH 7.0 buffers & $10 \mathrm{ml}$ \\
4 & $0.25 \mathrm{M}$ salt in 20 mM TEA-HCl pH 7.0 buffers & $15 \mathrm{ml}$ \\
5 & $0.33 \mathrm{M}$ salt in 20 mM TEA-HCl pH 7.0 buffers & $8 \mathrm{ml}$ \\
\hline
\end{tabular}



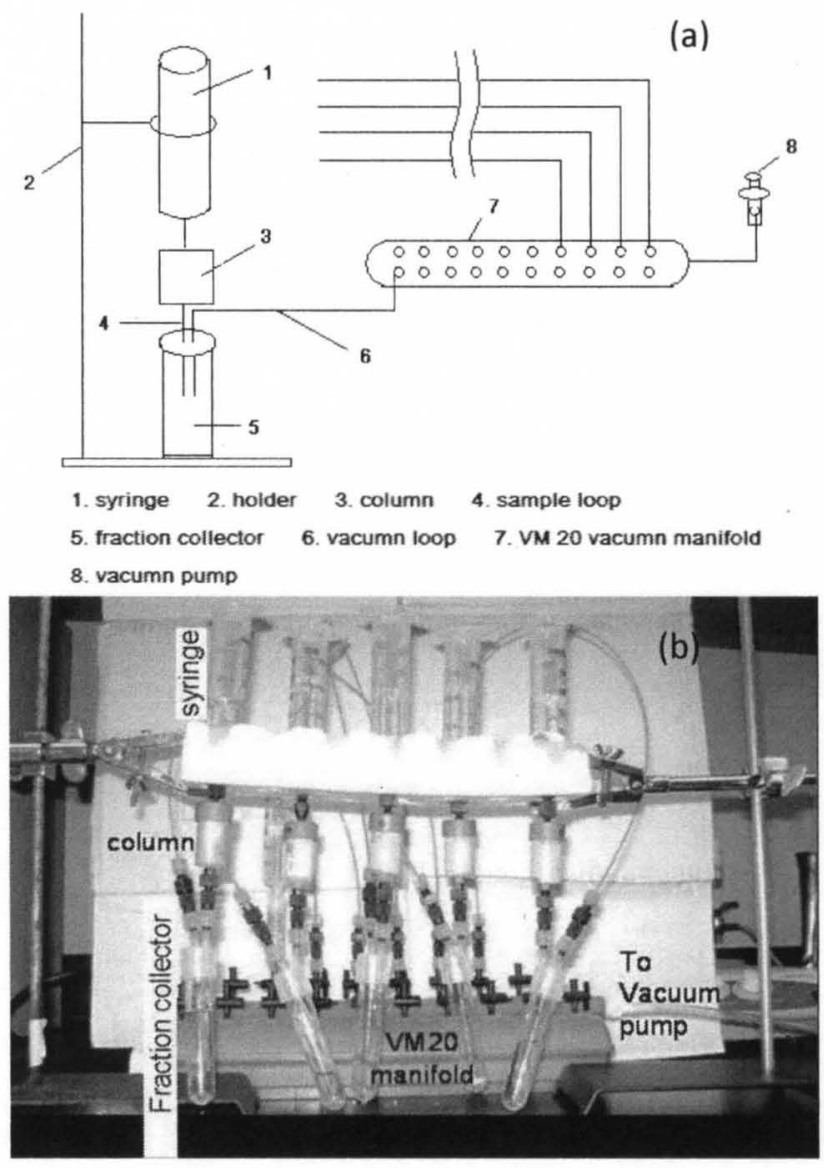

Figure 3.1. Scaled-up separation of $\mathrm{CBH} 1$ by a vacuum manifold system. (a) flow route of the separation system; (b) experimental set-up.

\subsubsection{SDS-PAGE Analysis}

The collected fractions were characterized by SDS-PAGE gel electrophoresis. The SDS-PAGE was run on a $10 \%$ tricine separating gel with a $4 \%$ tricine stacking gel and was applied with a $30 \mathrm{~mA}$ constant current using an AE-6450 dual mini slab kit system (ATTO Corporation; Tokyo, Japan) for about 3 hours. The protein was stained with coomassie brilliant blue as other report elsewhere (Kotchoni et al., 2006).

\subsection{6 pNPC Activity Assay}

pNPC was used to test the activity of CBH1. A volume of $200 \mu$ l cellulase sample at a concentration of $0.2 \mathrm{mg} / \mathrm{ml}$ was incubated with $800 \mu \mathrm{l}$ of $2.5 \mathrm{mmol} / \mathrm{l} \mathrm{pNPC}$ solution 
$(\mathrm{pH} 4.8)$ at $50{ }^{\circ} \mathrm{C}$ for $30 \mathrm{~min}$. The reaction was stopped by addition of $1 \mathrm{ml} 12.5 \%$ $\mathrm{Na}_{2} \mathrm{CO}_{3}$ solution. The concentration of $\mathrm{p}$-nitrophenol produced was determined by light absorbance at $410 \mathrm{~nm}$ using a NanoDrop Spectrophotometer (ND-1000, NanoDrop Technologies, Inc. Wilmington, DE). A standard curve was plotted by reading light absorbance at $410 \mathrm{~nm}$ for concentration standards of p-nitrophenol between 10-250 $\mathrm{mg} / \mathrm{ml}$.

To distinguish the pNPC activity induced by EGl, cellobiose in a concentration of $0.02 \mathrm{M}$ was added to the pNPC solution before incubation. With the addition of cellobiose, activity of $\mathrm{CBH} 1$ was inhibited. The remaining pNPC activity was due to EG1. The average of six measurements was reported.

\subsubsection{Stability of CBH1}

$\mathrm{CBH} 1$ at $0.2 \mathrm{mg} / \mathrm{ml}$ was incubated in a $2 \mathrm{ml}$ reaction volume for up to 2 days at $50{ }^{\circ} \mathrm{C}$ and $150 \mathrm{rpm}$ in an orbital shaker. A pNPC assay was used to determine the activity of $\mathrm{CBH} 1$. During incubation for $0.5,1,2,4,8,24$, or 48 -hour incubation, $0.2 \mathrm{ml}$ samples were continuously removed from the reaction, mixed with $800 \mu \mathrm{pNPC}$ at $2.5 \mathrm{mmol} / \mathrm{l}$, and incubated at $50{ }^{\circ} \mathrm{C}$ for $10 \mathrm{~min}$. The reaction was stopped by addition of $1 \mathrm{ml} 12.5 \%$ $\mathrm{Na}_{2} \mathrm{CO}_{3}$ solution. $\mathrm{CBHI}$ activities as a function of reaction time were normalized according to activity before reaction. The average of six measurements was reported.

\subsubsection{Adsorption of CBH1 on BMCC}

The apparent binding isotherms of $\mathrm{CBH} 1$ adsorbed on $\mathrm{BMCC}$ were determined at $0{ }^{\circ} \mathrm{C}$ using an ice-water bath with end-over-end mixing. $\mathrm{CBH} 1$ at concentrations of 0.1 , $0.2,0.4,0.6,0.8$ and $1.0 \mathrm{mg} / \mathrm{ml}$ were incubated with a $0.15 \%(\mathrm{~m} / \mathrm{v}) \mathrm{BMCC}$ solution for 45 minutes. The concentrations of free $\mathrm{CBH} 1$ were determined using the Bradford 
Protein Assay. The amounts of $\mathrm{CBH} 1$ adsorbed on BMCC were calculated by deducting amounts of free $\mathrm{CBH} 1$ from the total initial loadings. The average of six measurements was reported.

$0.1,0.2,0.3,0.6$ and $1.2 \mathrm{mg} / \mathrm{ml}$ bovine serum albumin (BSA) was incubated with BMCC as control. The non-specific adsorption of BSA on BMCC was determined and compared with $\mathrm{CBH} 1$ adsorption.

\subsubsection{Hydrolysis of BMCC}

Liu et al. (2009) used AFM (atomic force microscopy) height images of cellulose exposed to $\mathrm{CBHI}$ to observe cellulose size reduction during the reaction, which they claimed was the result of CBHI hydrolysis. We have carried out a similar analysis, where hydrolysis of BMCC by $\mathrm{CBH} 1$ was monitored in real-time by imaging with AFM to observe cellulose fiber height. BMCC was immobilized on APTES-treated mica via vapor deposition as reported elsewhere (Baker et al., 1998; Crampton et al., 2005). The freshly cleaved mica was placed in a small reaction chamber (i.e. $250 \mathrm{ml}$ glass beaker) with $0.5 \mathrm{ml}$ of APTES in a $1 \mathrm{ml}$ glass beaker inside the reaction chamber. The reaction chamber was allowed to equilibrate for 2 hours with the APTES to coat the mica. A volume of $5 \mu \mathrm{l} \mathrm{BMCC}$ suspension in a concentration of $0.75 \mu \mathrm{g} / \mathrm{ml}$ was introduced onto the APTES-mica surface for adsorption for 30 minutes. A low concentration of BMCC was used so that changes in height can be observed on a single fiber. The cellulose adsorbed mica was then gently washed with D.I. water. Enzyme was introduced onto the substrate by dropping a small volume of diluted CBH1 solution directly onto the cellulose substrate. Once the surface adsorption was completed, the cellulose surface was placed in a shallow glass petri dish containing a buffered solution at $\mathrm{pH} 4.8$. The weak 
buffering helps maintain the $\mathrm{pH}$ throughout the experiment but reduces the likelihood that salt from the buffer deposits onto the surface and disrupts the imaging process. The petri dish was placed into the AFM (model XE-100, Park Systems Inc., Santa Clara, CA). Images were acquired using the non-contact mode under water. Height, phase and error signals were measured with an All-in-One probe cantilever with a nominal force constant of $0.2 \mathrm{~N} / \mathrm{m}$ using scan rates between $0.15-0.25 \mathrm{~Hz}$.

\subsection{Procedure: Deactivation of Individual Cellulase Components}

\subsubsection{Effect of Incubating Time on Cellulase Deactivation}

$0.1 \mathrm{ml}$ Spezyme CP cellulase samples with $50 \mathrm{FPU} / \mathrm{ml}$ or $4.2 \mathrm{mg} \mathrm{CBH1}$ (corresponding to the $\mathrm{CBH} 1$ content in $0.1 \mathrm{ml}$ Spezyme CP cellulases based on $75 \mathrm{mg} / \mathrm{ml}$ cellulases and $56 \%$ of $\mathrm{CBH} 1$ content in Spezyme CP as reported elsewhere (Ye et al., 2011) were incubated in $100 \mathrm{ml}$ reaction volume Erlenmeyer flask for up to 2 days at 50 ${ }^{\circ} \mathrm{C}, 150 \mathrm{rpm}$ on an orbital shaker or without mixing. The $\mathrm{pH}$ of each flask was adjusted to 4.8 with citrate buffer. Samples were incubated for $2,4,8,24$, or 48 -hours.

\subsubsection{Effect of Mixing Intensity on Cellulase Deactivation}

$0.1 \mathrm{ml}$ Spezyme CP cellulase with $50 \mathrm{FPU} / \mathrm{ml}$ or $4.2 \mathrm{mg} \mathrm{CBH1}$ was incubated for one day at 50,150, and $250 \mathrm{rpm}$. A sample was incubated without mixing as a control. The other conditions were the same as in the previous section.

The fluid motion inside the orbiting Erlenmeyer flask was modeled using Fluent 12.1.2 (ANSYS, Inc. Canonsburg, PA), a commercial CFD software package, to determine shear stress by the fluid. A 3-D rendering of the flask was created in the preprocessor ICEM with dimensions and orbital parameters that mimicked the actual flask, which had a base diameter of $8.5 \mathrm{~cm}$, a neck diameter of $3.0 \mathrm{~cm}$, a length from base 
to neck of $10 \mathrm{~cm}$. The initial fluid height was $2.04 \mathrm{~cm}$. The orbital radius was $1.0 \mathrm{~cm}$. Three rotation rates were modeled: 50, 150, and $250 \mathrm{rpm}$. A mesh with 329,846 hexahedral computational cells was applied to the volume. The modeling technique, convergence criteria, grid optimization, and time needed to reach steady state for the transient solution have been described previously (Berson et al., 2008) and validated (Thomas et al., 2011).

\subsubsection{Effect of Enzyme Concentration on Cellulase Deactivation}

$0.15,0.3,0.6$ and $1.2 \mathrm{ml}$ Spezyme CP cellulase with $50 \mathrm{FPU} / \mathrm{ml}$ was incubated for 1 day at $250 \mathrm{rpm}$ or without mixing. Samples were removed (diluted to $5 \mathrm{FPU} / \mathrm{ml}$ ) to assay for total activity towards PASC. Reaction was run in $100 \mathrm{ml}$ volume. The other experimental conditions were the same as in the study of Effect of Incubating Time on Cellulase Deactivation.

\subsubsection{Activity Assay}

CBH1 activity was determined by pNPC assay. Endoglucanase activity was assayed by mixing $1 \mathrm{ml}$ enzyme solution removed during the incubation with $1 \mathrm{ml}$ containing $5.0 \%(\mathrm{w} / \mathrm{v}) \mathrm{CMCNa}$, and reacted for two more hours. Released glucose content was assayed using an YSI 2700 Select Biochemistry Analyzer. An average of six measurements was reported.

Total activity was assayed by mixing $1 \mathrm{ml}$ enzyme solution removed during the incubation with $1 \mathrm{ml}$ containing $5.0 \%(\mathrm{w} / \mathrm{v})$ PASC substrate, and reacted for two more hours. Released glucose content was assayed using an YSI 2700 Select Biochemistry Analyzer. 


\subsection{Procedure: Desorption of CBH1 at Reduced Activity}

\subsubsection{Deactivation by Mechanical Deactivation}

To study enzyme desorption at reduced activity, $\mathrm{CBH} 1$ activity was first suppressed by mechanical deactivation. $\mathrm{CBH} 1$ in a concentration of $0.2 \mathrm{mg} / \mathrm{ml}$ was incubated with $0.15 \%(\mathrm{w} / \mathrm{v}) \mathrm{BMCC}$ in a $2-\mathrm{ml}$ reaction volume micro-centrifuge tube at $50{ }^{\circ} \mathrm{C}$. Mechanical deactivation was induced by mixing at 150 or $300 \mathrm{rpm}$ on an orbital shaker. $0.2 \mathrm{ml}$ samples were removed from the reaction after incubating for $0.5,1,2,4,8$, or 24-hours, then assayed for $\mathrm{CBH} 1$ activity and fraction of free enzyme. An average of three measurements was reported unless otherwise specified.

\subsubsection{Deactivation by Competitive Inhibitor}

Either $20 \mathrm{mM}$ cellobiose or $0.25 \mathrm{M} \mathrm{GdnHCl}$ (Henriksson et al., 1996; Woodward et al., 1990a) was added to the reaction described in the previous section on a shaker platform at $150 \mathrm{rpm}$ to study desorption in the presence of a competitive inhibitor. Activity of $\mathrm{CBH} 1$ and the fraction of free enzyme were assayed.

\subsubsection{Deactivation by Low Reaction Temperature}

The reaction was run at $0{ }^{\circ} \mathrm{C}$ (using an ice-water bath) with end-over-end mixing for $0.5,1,2,4,8$, or 16 hours on a shaker platform at $150 \mathrm{rpm}$. Other reaction conditions were similar to that in section of deactivation by mechanical deactivation. The fraction of free enzyme was assayed.

\subsubsection{Deactivation by $\mathrm{K}_{2} \mathrm{PdCl}_{6}$ (Denaturant)}

Deactivation and desorption of $\mathrm{CBH} 1$ from $\mathrm{BMCC}$ was examined with 50 or 162.5 $\mu \mathrm{M}$ of $\mathrm{K}_{2} \mathrm{PdCl}_{6}$ (corresponding to $16: 1$ or $50: 1$ molar ratio of $\mathrm{K}_{2} \mathrm{PdCl}_{6}$ to $\mathrm{CBH} 1$ ), which was added and allowed to incubate for 30 minutes prior to initiating the reaction. 
Deactivated CBH1 was then incubated with $0.15 \%(\mathrm{w} / \mathrm{v}) \mathrm{BMCC}$ for another 40 minutes to allow adsorption to occur. The samples were centrifuged, supernatant was removed, and the solid was re-suspended in $2.0 \mathrm{ml}$ fresh citrate buffer $(\mathrm{pH}=4.8)$ in order to determine if the inactive adsorbed $\mathrm{CBH} 1$ can desorb from substrate. The fraction of free CBH1 was measured at 40,100, 220 and 480 minutes. Activity of $\mathrm{CBH} 1$ was determined using the pNPC assay.

\subsection{Procedure: Factors to Consider When Developing a Cellulose Hydrolysis}

\section{Process}

\subsubsection{Kinetic Modeling to Determine Activation Energy}

In order to examine the effects of reaction conditions such as temperature on cellulose hydrolysis, the activation energy of each reaction step needs to be determined first. Hydrolysis of Sigmacell were performed at three different temperatures: 50,35 , and $20^{\circ} \mathrm{C}$. Activation energies for the rate limiting steps were determined using an Arrhenius plot based on the kinetic model describing inactivation of adsorbed enzyme as the main effect for the rate reduction of cellulose hydrolysis. 


\section{CHAPTER IV}

\section{EFFECT OF ENZYME DEACTIVATION DUE TO ENVIRONMENTAL MECHANISMS AND VARIATION OF SUBSTRATE PROPERTIES ON CELLULOSE HYDROLYSIS}

\subsection{Extent of Total Cellulase Deactivation from the Reaction Environment}

The activity of total cellulases following 72 hours of incubation as assayed towards three different substrates is shown in Figure 4.1. Deactivation extents were insignificant on all three substrates. Activity loss assayed on cotton fiber was the least, with $12 \%$ deactivation over the 72 hour incubation; while a little more deactivation was observed on filter paper and Sigmacell, with $8-22 \%$ and $14-22 \%$ deactivation after 48-72 hours of incubation, respectively. For all tests here, only $\sim 20 \%$ or less deactivation was observed after 72 hours of incubation. Zhang et al., (2010) suggested that about $80 \%$ or more deactivation of cellulases from thermal/mechanical mechanisms within 12 hour would be needed to account for slow kinetics in cellulose hydrolysis with their mathematical modeling, implying that enzyme deactivation alone as determined here is not a universal reason that can account for the significant rate reduction in hydrolysis. Since these three substrates differ in properties and morphology, for example cotton fiber and Sigmacell are high crystalline cellulose while filter paper is more amorphous (Zhang and Lynd, 2004), it can be concluded here that substrate crystallinity and morphology did not affect deactivation. 


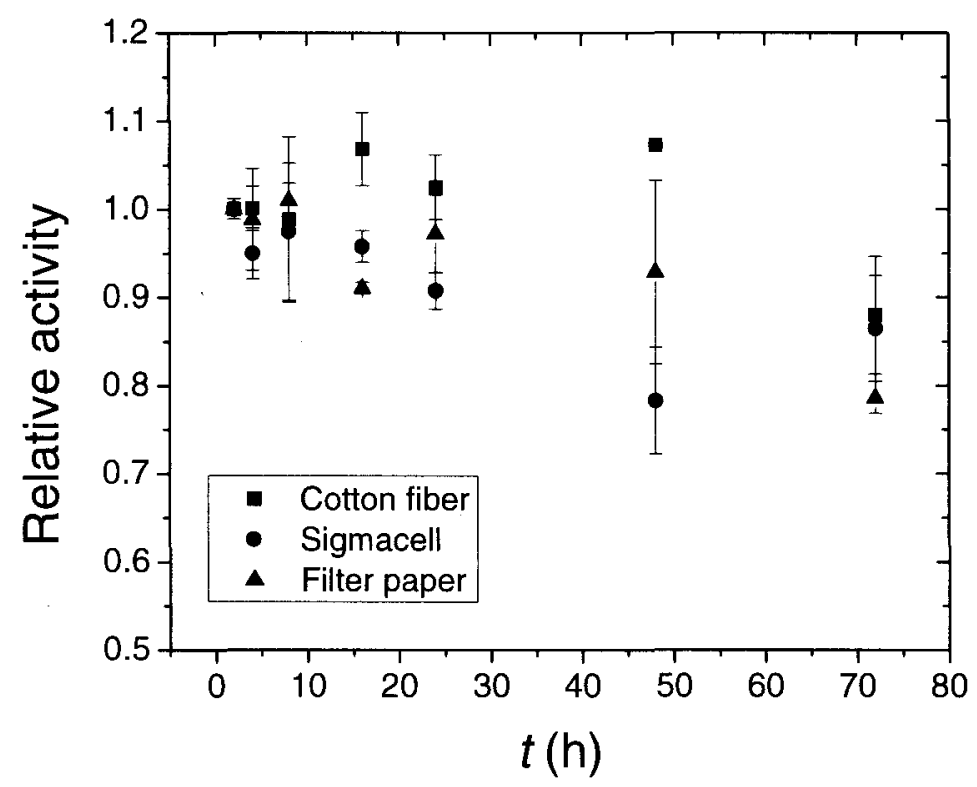

Figure 4.1. Activities of cellulases after 72 hours of incubation in buffer solution. Activities were normalized according to the activities after 2 hours of incubation.

\subsection{Effect of Varying Substrate Properties on Cellulose Hydrolysis}

Effect of varying substrate properties on cellulose hydrolysis was studies in two ways: First, effect of substrate property change during the reaction on hydrolysis was studied; Second, effect of initial properties of different substrates on hydrolysis was studied.

Figure 4.2 shows that XRD profiles of cellulose at different hydrolysis time overlapped with each other. The calculated $\mathrm{CrI}$ varied less than $1 \%$ during the 72 -hour incubation period. This finding is consistent with results reported elsewhere (Lenz et al., 1990; Ohmine et al., 1983; Puls and Wood, 1991), which suggested cellulose crystallinity is not likely to change and affect cellulose hydrolysis rate. 


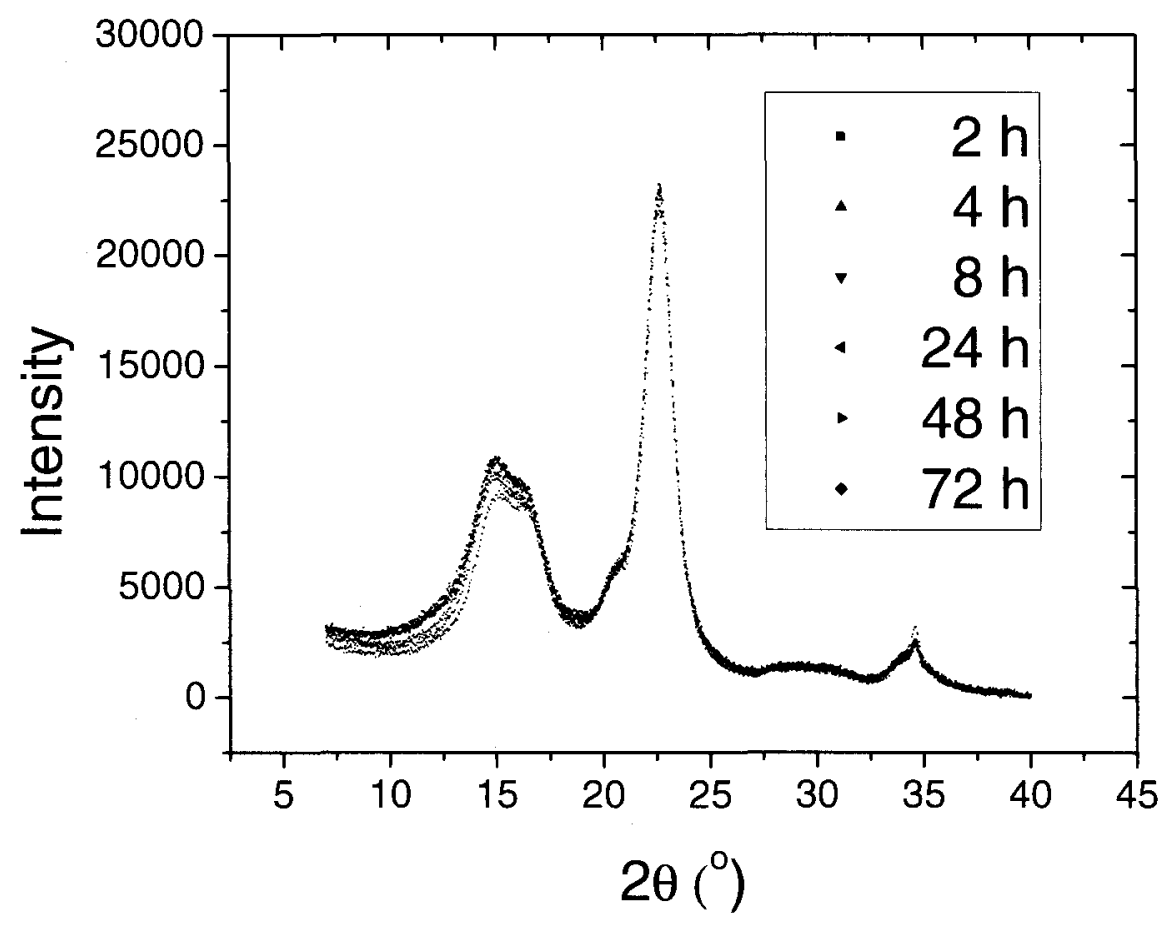

Figure 4.2. XRD profile of Sigmacell during 72-hour reaction.

Figure 4.3 shows changes of SSA, total pore volume and average pore size during the reaction. SSA generally increased during the 72-hour hydrolysis, from $1.512 \mathrm{~m}^{2} / \mathrm{g}$ at 2 hour to $2.753 \mathrm{~m}^{2} / \mathrm{g}$ at 72 hour, about 1.8 -fold increase (Figure $4.3 \mathrm{a}$ ). This finding agrees with the trend of SSA change during the reaction for Solka Floc as reported elsewhere (Lemos et al., 2003). Total pore volume increased about 2.6-fold during the same hydrolysis period, from $4.63 \mathrm{~mm}^{3} / \mathrm{g}$ at 2 hour to $12.2 \mathrm{~mm}^{3} / \mathrm{g}$ at 72 hour (Figure $4.3 \mathrm{~b}$ ). Meanwhile, average pore size increased from $11.56 \mathrm{~nm}$ at 2 hour to $17.16 \mathrm{~nm}$ at 72 hour (Figure 4.3c). Larger SSA at the later stage than beginning suggests that the substrate had a greater capacity for enzyme to adsorb as reaction goes on. Also, increasing pore volume and average pore sizes indicate that the structure of cellulose is more open for enzyme to attack. These findings about cellulose structures during hydrolysis are contradictory to 
the fact that hydrolysis rate slows down significantly as reaction goes on, implying that these physical features were not the main factors affecting cellulose hydrolysis rate.

Effect of initial substrate properties on hydrolysis was studied as in Table 4.1 and Figure 4.4. The CrI, SSA, total pore volume and average pore size were measured for three different cellulose substrates, Sigmacell Type-20, Solka Floc and Cellulose, Microcrystalline (Table 4.1). The CrI determined by XRD for these three substrates were 0.75-0.83, respectively, and increased in the order of Solka Floc, Cellulose, microcrystalline and Sigmacell Type-20. The range of SSA was $1.0534-1.8997 \mathrm{~m}^{2} / \mathrm{g}$, about 1.8-fold difference; Total volume of pores was $3.968-9.302 \mathrm{~m}^{2} / \mathrm{g}$, about 2.3 -fold difference; Average pore size was $13.664-21.030 \mathrm{~nm}$, about 1.5 -fold difference for these three substrates, respectively. Values of these properties increased in the order of Cellulose, microcrystalline, Solka Floc, and Sigmacell Type 20. 

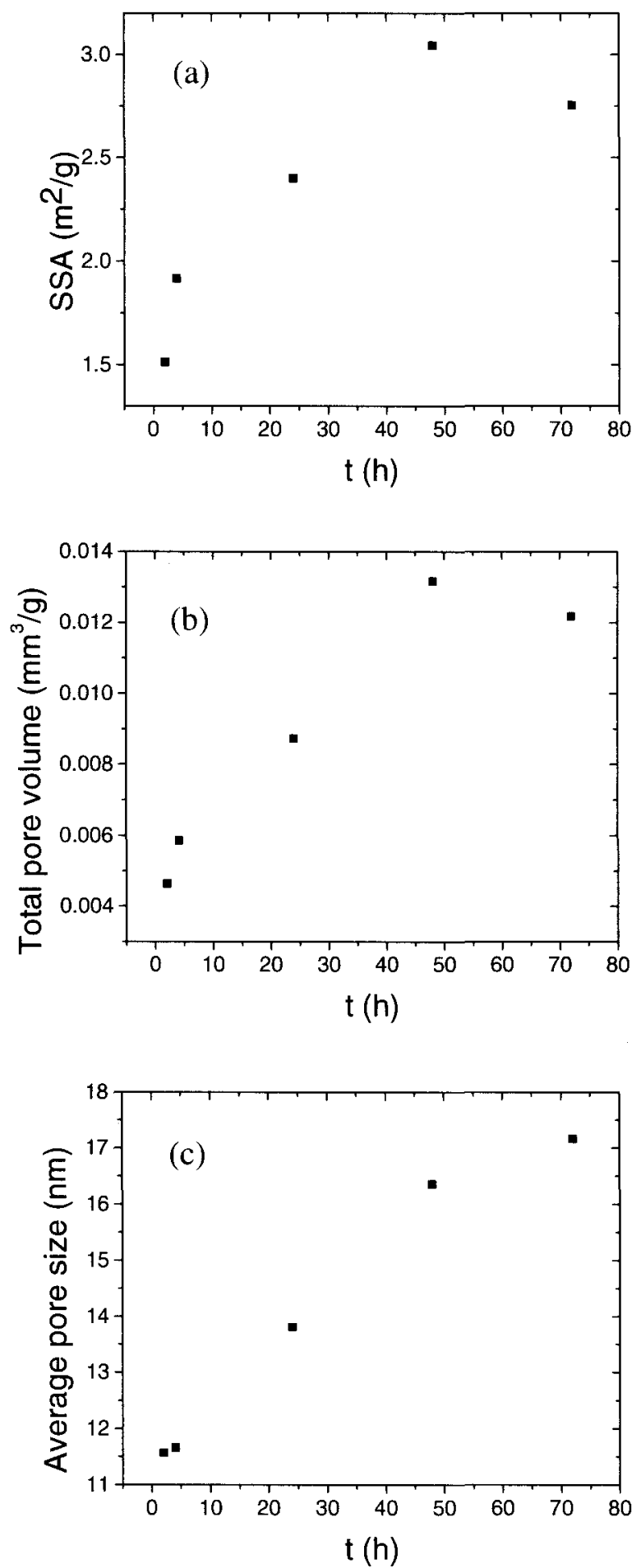

Figure 4.3. Change of (a) SSA, (b) pore volume and (c) average pore sizes during the reaction for Sigmacell. 
Table 4.1

Initial physical properties of different substrates

\begin{tabular}{lccc}
\hline Substrate & $\begin{array}{c}\text { Sigmacell } \\
\text { Type-20 }\end{array}$ & Solka Floc & Cellulose, \\
& 0.83 & 0.75 & Microcrystalline \\
\hline Crystallinity $(\mathrm{CrI})$ & $1.77-1.90$ & $1.67-1.68$ & $1.05-1.16$ \\
$\mathrm{SSA}\left(\mathrm{m}^{2} / \mathrm{g}\right)$ & $9.16-9.30$ & $5.73-5.89$ & $3.97-4.07$ \\
Pore volume $\left(\mathrm{mm}^{3} / \mathrm{g}\right)$ & $19.29-21.03$ & $13.67-14.15$ & $13.66-15.44$ \\
Average pore size $(\mathrm{nm})$ & & & \\
\hline
\end{tabular}

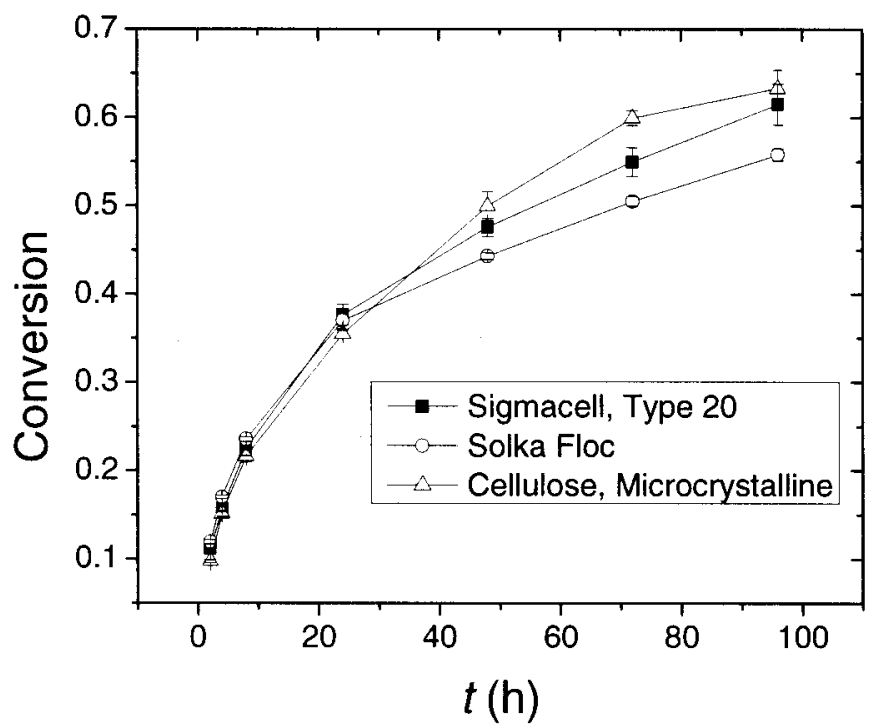

Figure 4.4. Comparison of hydrolysis of three different cellulose substrates.

$5 \%(\mathrm{w} / \mathrm{v})$ cellulose substrate and $0.75 \mathrm{ml}$ of Spezyme $\mathrm{CP}$ cellulases (corresponding to $50 \mathrm{FPU}$ (filter paper unit)/mL cellulases activity or $15 \mathrm{FPU} / \mathrm{g}$ cellulose) were incubated for up to 3 days. Enzymatic hydrolysis of various crystalline cellulose 
substrates is shown in Figure 4.4. The initial hydrolysis of different substrates is very fast, while the glucose concentration increment slows down quickly after about 8 hours. It was found that hydrolysis kinetics was similar for different substrates although physical properties varied. The conversions for different substrates differ mostly less than $10 \%$ at each time point. The finding here suggested that the differences in the physical properties of various cellulose substrates did not affect the hydrolysis rate of cellulose. This finding is consistent with that reported by Jalak and Valjamae (Jalak and Valjamae, 2010), who found a commonly apparent hydrolysis rate constant for several different substrates such as lignocellulose, Avicel, and amorphous cellulose when these substrates are hydrolyzed by cellobiohydrolase $1(\mathrm{CBH} 1)$.

\subsection{Summary}

In this chapter, some traditional factors considered to affect cellulose hydrolysis, such as enzyme deactiation due to the reaction environment and variation of substrate properties, were examined. Deactivation of total cellulases as assayed towards three different substrates here was only $\sim 20 \%$ or less after 72 hours of incubation, which suggests that the slow kinetics may not be a result of just enzyme deactivation from the reaction environment. Effects of physical property change during the reaction such as crystallinity, SSA, pore volume and average pore size on enzymatic hydrolysis of cellulose were then also studied. It was found that crystallinity of Sigmacell did not change during the reaction; while SSA, pore volume and average pore sizes increased, which is contradictory to the fact that hydrolysis rate slowed down significantly as reaction went on. Meanwhile, initial physical properties such as crystallinity, SSA, pore volume and average pore size of various substrates were characterized to study whether 
variance in these initial features affects hydrolysis. Hydrolysis kinetics for these substrates was similar although physical properties differ. The findings here imply that changes of these physical properties during the reaction and variance in initial physical properties of substrates also do not significantly account for the slow kinetics during hydrolysis of cellulose. Since both environmental and substrate considerations alone do not account for the slow kinetics, deactivation due to interactions between the enzyme and substrate should be considered. 


\section{CHAPTER V}

\section{ACTIVITY LOSS OF ADSORBED ENZYME}

\subsection{Cellulose Hydrolysis}

$0.1,0.2,0.4,1.2 \mathrm{~g}$ and $2 \mathrm{~g}$ of cellulose substrate and $0.6 \mathrm{ml}$ of Spezyme CP cellulases (50 FPU (filter paper unit)/mL cellulases activity) were incubated for up to 3 days. The substrate concentrations were purposefully kept low to prevent mass transfer and product inhibition effects. Hydrolysis of Solka Floc in concentrations of 1-20 g/L illustrates the slowdown in rate as the reaction proceeds (Figure 5.1). The initial release of product is very fast, while the glucose concentration increment slows down very quickly after about 8 hours. A range of $42-53 \%$ of the maximum achievable glucose in 72 hours was obtained within the first 8 hours of the saccharification, which is comparable to reported results at higher concentrations (Dasari and Berson, 2007).

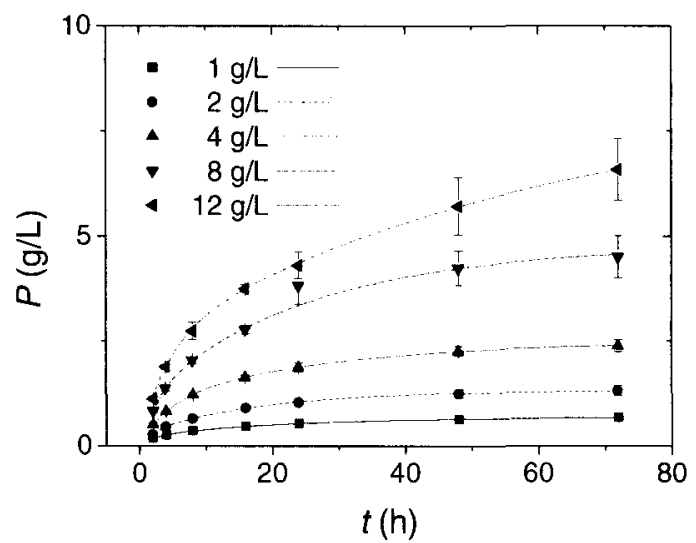

Figure 5.1. Glucose released during 72-hour incubation for Solka Floc. 


\subsection{Theoretical Modeling}

Model development begins with a simple rate equation for cellulose hydrolysis without the effect of cellulase activity loss, then builds to include a first order inactivation of adsorbed cellulase. Start with a minimal possible mechanism for cellulose hydrolysis:

$$
\begin{array}{cc}
k_{l} & k_{2} \\
E+S \Leftrightarrow & E S \Rightarrow E+P \\
k_{\cdot l} &
\end{array}
$$

which describes initial binding of enzyme and cellulose to form an active enzymesubstrate complex followed by the breakdown of the enzyme-substrate complex to form product $P$ and release enzyme from the substrate. In this minimal mechanism, the cellulase system is represented by a single enzyme. Product inhibition is neglected for simplicity since inhibition of cellulases by the final glucose product is insignificant in the loading range used here (Nidetzky and Steiner, 1993), with an inhibition constant of 69 g/L (383 mM) (Tolan and Foody, 1999).

A basic expression for the hydrolysis rate $(V)$ is given:

$$
V=\frac{d P}{d t}=k_{2} \times(E S)
$$

When cellulase adsorption is described using the Langmuir model, the concentration of initial enzyme-substrate complex (ES) can be expressed by Equation (5.3):

$$
(E S)=\frac{(E) \times A_{\max } \times(S)}{(E)+K_{d}}
$$

where $K_{d}[\mathrm{~g} / \mathrm{L}]$ is the dissociation constant, which for a simple binding mechanism is given by $k_{l} / k_{-l}$. $A_{\max }$ is the maximum adsorption sites per unit substrate $(\mathrm{g} / \mathrm{g})$.

The mass balance for enzyme is given by Equation (5.4): 


$$
(E S)+(E)=(E)_{0}
$$

where $(E)_{0}[\mu \mathrm{M}]$ is the concentration of total enzyme. Substitute for $(E)$ in Equation (5.3) and re-arrange to get:

$$
\left[A_{\max } \times(S)+K_{d}+(E)_{0}-(E S)\right] \times(E S)-(E)_{0} \times A_{\max } \times(S)=0
$$

Equation (5.5) has two roots for $(E S)$. Substrate concentrations were kept low in the experiments performed here, so the adsorbed enzyme $(E S)$ was negligible compared to $(E)_{0}$. Therefore, Equation (5.5) can be simplified to

$$
(E S)=\frac{(E)_{0} \times A_{\max } \times(S)}{A_{\max } \times(S)+K_{d}+(E)_{0}}
$$

Combining Equation (5.2) and Equation (5.6), the hydrolysis rate will be:

$$
V=\frac{d P}{d t}=k_{2} \times(E S)=k_{2} \times \frac{(E)_{0} \times A_{\max } \times(S)}{A_{\max } \times(S)+K_{d}+(E)_{0}}
$$

If a nominal $K_{m}$ is defined as

$$
K_{m}=\frac{K_{d}+(E)_{0}}{A_{\max }}
$$

and $V_{\max }$, the maximum rate, is defined as the product of $k_{2}$ and concentration of total enzyme $(E)_{0}$, then the hydrolysis rate can be written as in Equation (5.9):

$$
V=\frac{d P}{d t}=k_{2} \times(E S)=\frac{k_{2} \times(E)_{0} \times(S)}{K_{m}+(S)}=V_{\max } \times \frac{(S)}{K_{m}+(S)}
$$

If $V_{m a x}$ and (or) $K_{m}$ are constants, integration of the differential function of product with respect to time gives:

$$
\frac{P}{V_{\max }}-\frac{K_{m}}{V_{\max }} \times \ln \frac{1.1 \times(S)_{0}-P}{P}=t
$$

where the initial substrate concentration, $(S)_{0}$, can be related to the substrate concentration $(S)$ as in Equation (5.11) where 1.1 is the product to substrate mass ratio when cellulose is converted to glucose:

$$
(S)=(S)_{0}-\frac{(P)}{1.1}
$$


By rearranging Equation (5.10), a plot of $\frac{t}{P}$ versus $\frac{1}{P} \times \ln \frac{1.1 \times(S)_{0}-P}{P}$ is expected to give a straight line with intercept $-K_{m} / V_{\max }$ and slope $1 / V_{\max }$.

However, the data clearly does not fit this linearly for any of the substrate concentrations (Figure 5.2). It is speculated here that apparent $V_{\max }$, where $V_{\max }=(E)_{0} \times k_{2}$, is not constant if total enzyme becomes less available since adsorbed cellulases are inactivated during the reaction.

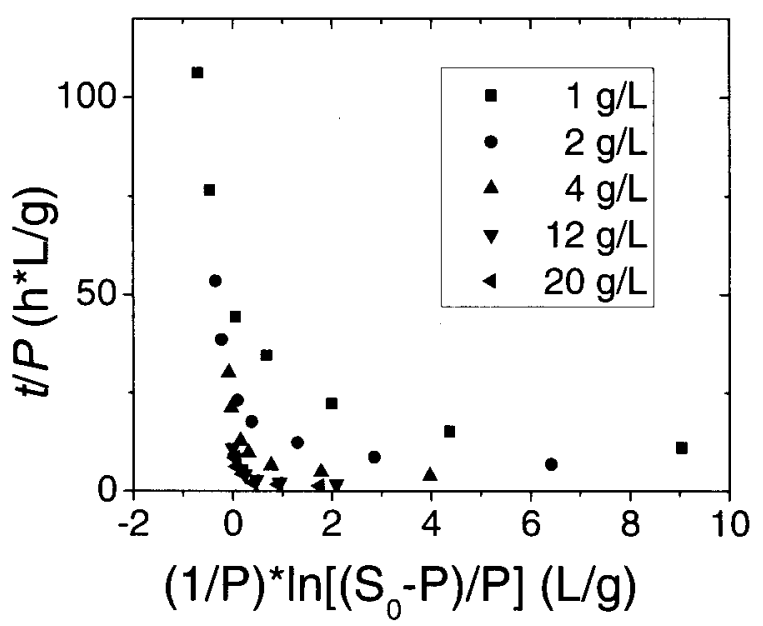

Figure 5.2. A plot of $\frac{t}{P}$ versus $\frac{1}{P} \times \ln \frac{1.1 \times(S)_{0}-P}{P}$ at substrate concentrations of 1$20 \mathrm{~g} / \mathrm{L}$.

Next, the real hydrolysis rate $\left(V_{r}\right)$, which considers cellulase activity loss, is defined relative to $V$ according to Equation (5.12):

$$
\frac{V_{r}}{V}=\frac{k_{2} \times(E S)_{\text {active }}}{k_{2} \times(E S)}=\frac{(E S)_{\text {active }}}{(E S)}
$$

The relation between $(E S)_{\text {active }}$, the active enzyme-substrate complex, and $(E S)$, the initial enzyme-substrate complex, is shown in Equation (5.13), which is similar to the forms in Fersht (1999):

$$
\frac{(E S)_{\text {active }}}{(E S)}=y_{0}+A_{0} \times \exp \left(\ln 2 \times \frac{-t}{t_{1 / 2}}\right)
$$


where $A_{0}$ is the extent of inactivation, $y_{0}$ is the residual activity of enzyme, and $t_{l / 2}$ is the half life. They can be related to the inactivation rate constant, $k_{f}$, and the reactivation rate constant, $k_{r}$, by the following equations:

$$
\begin{aligned}
& A_{0}=\frac{k_{f}}{k_{f}+k_{r}} \\
& y_{0}=\frac{k_{f}}{k_{f}+k_{r}} \\
& t_{1 / 2}=\frac{\ln 2}{k_{f}+k_{r}}
\end{aligned}
$$

Rearranging Equation (5.12) and combining with the expression for $\frac{(E S)_{\text {active }}}{(E S)}$ in Equation (5.13) and the expression for $V$ in Equation (5.9), the real hydrolysis rate $\left(V_{r}\right)$ becomes:

$$
\begin{aligned}
& V_{r}=V \times \frac{(E S)_{a c t i v e}}{E S} \\
& \quad=V_{\max } \times \frac{(S)}{K_{m}+(S)} \times\left[y_{0}+A_{0} \times \exp \left(\ln 2 \times \frac{-t}{t_{1 / 2}}\right)\right] \\
& V_{\text {max } \text { app }} \text { is defined according to Equation }(5.18): \\
& V_{\text {max }, \text { app }}=V_{\max } \times\left[y_{0}+A_{0} \times \exp \left(\ln 2 \times \frac{-t}{t_{1 / 2}}\right)\right]
\end{aligned}
$$

which indicates that the apparent $V_{\max }$ decreases with a first order exponential decay function of time due to inactivation of adsorbed enzyme. The real hydrolysis rate is then expressed as:

$$
V_{r}=\frac{d P}{d t}=V_{\max , a p p} \times \frac{(S)}{K_{m}+(S)}
$$

which describes the reduction of the real hydrolysis rate due to the inactivation of adsorbed enzyme. 


\subsection{Calculation of the Values of Rate Constants}

First, an empirical second order exponential growth equation (Equation 5.20) was used to fit product release as a function of reaction time for the data in Figure 5.1.

$$
P=P_{0}+A_{1} \times \exp \left(-\frac{t}{t_{1}}\right)+A_{2} \times \exp \left(-\frac{t}{t_{2}}\right)
$$

where $P$ is product released $(\mathrm{g} / \mathrm{L}), t$ is reaction time $(\mathrm{h}), P_{0}(\mathrm{~g} / \mathrm{L}), A_{l}(\mathrm{~g} / \mathrm{L}), A_{2}(\mathrm{~g} / \mathrm{L}), t_{l}(\mathrm{~h})$, and $t_{2}(\mathrm{~h})$ are empirical parameters. Values of the parameters are listed in Table 5.1. The fittings give $R^{2}$ greater than 0.995 for all concentrations of substrate. This equation was also used by Väljamäe et al. (1998), who found that the second order exponential growth equation fit their data best among different fitting functions they tried, although this is an empirical equation without physical meaning. Second order exponential growth fitting gave the best fit here as well among the following functions: first order exponential growth, sum of linear and first order exponential growth, and second order exponential growth.

Second, the product formation rate $\left(V_{r}\right.$ in Equation (5.19)) at different times is calculated by differentiation of Equation (5.20) with respect to time, and the substrate concentration $(S)$ at different times in the reaction is calculated for varying initial substrate concentrations $(S)_{0}$ by using Equation (5.11).

Third, Equation (5.19) was used to regress nonlinearly the $V_{\text {max.app }}$ and $K_{m}$ values at a certain time for varying initial substrate concentrations (Figure 5.3). The regressed value for $K_{m}$ is shown in Table 5.2. $K_{m}$ does not show a clear trend, so the average value $(16.03 \mathrm{~g} / \mathrm{L})$ is used to represent $K_{m}$ in the modeling under the assumption that binding characteristics of enzyme to substrate does not change during the reaction. This value for average $K_{m}$ yields a big standard deviation. Robinson and Tiedje (1983) point out that $K_{m}$ 
is sensitive to the accuracy of data collected at low substrate concentrations, especially at the late stage of hydrolysis, which is the case here.

\section{Table 5.1}

Parameters from data fitting to second order exponential growth from hydrolysis results in Figure 5.1.

\begin{tabular}{llllll}
\hline Substrate & 1 & 2 & 4 & 12 & 20 \\
concentration $(\mathrm{g} / \mathrm{L})$ & & & & & \\
\hline$P_{0}(\mathrm{~g} / \mathrm{L})$ & 0.700 & 1.345 & 2.470 & 8.310 & 10.12 \\
$A_{1}(\mathrm{~g} / \mathrm{L})$ & -0.208 & -0.396 & -0.823 & -2.242 & -2.737 \\
$t_{1}(\mathrm{~h})$ & 3.864 & 2.296 & 3.729 & 4.085 & 2.851 \\
$A_{2}(\mathrm{~g} / \mathrm{L})$ & -0.427 & -0.999 & -1.608 & -6.004 & -7.651 \\
$t_{2}(\mathrm{~h})$ & 25.61 & 19.92 & 23.93 & 57.67 & 44.01 \\
$R^{2}$ & 0.9995 & 0.9997 & 1.0000 & 0.9999 & 0.9956 \\
\hline
\end{tabular}




\section{Table 5.2}

$\underline{V}_{\max , a p p} \underline{\text { and } K_{m}} \underline{\text { as functions of reaction time. }}$

\begin{tabular}{crr}
\hline$t$ & $V_{\text {max }, a p p}$ & $K_{m}$ \\
$(\mathrm{~h})$ & $(\mathrm{g} /(\mathrm{L} \cdot \mathrm{h}))$ & $(\mathrm{g} / \mathrm{L})$ \\
\hline 2 & $1.40 \pm 0.18$ & $26.1 \pm 5.3$ \\
4 & $0.70 \pm 0.02$ & $15.7 \pm 0.8$ \\
8 & $0.32 \pm 0.02$ & $10.4 \pm 1.3$ \\
16 & $0.20 \pm 0.02$ & $11.2 \pm 1.9$ \\
24 & $0.20 \pm 0.01$ & $16.8 \pm 1.8$ \\
48 & $0.14 \pm 0.06$ & $18.4 \pm 12.6$ \\
72 & $0.07 \pm 0.05$ & $14.2 \pm 16.4$ \\
\hline
\end{tabular}

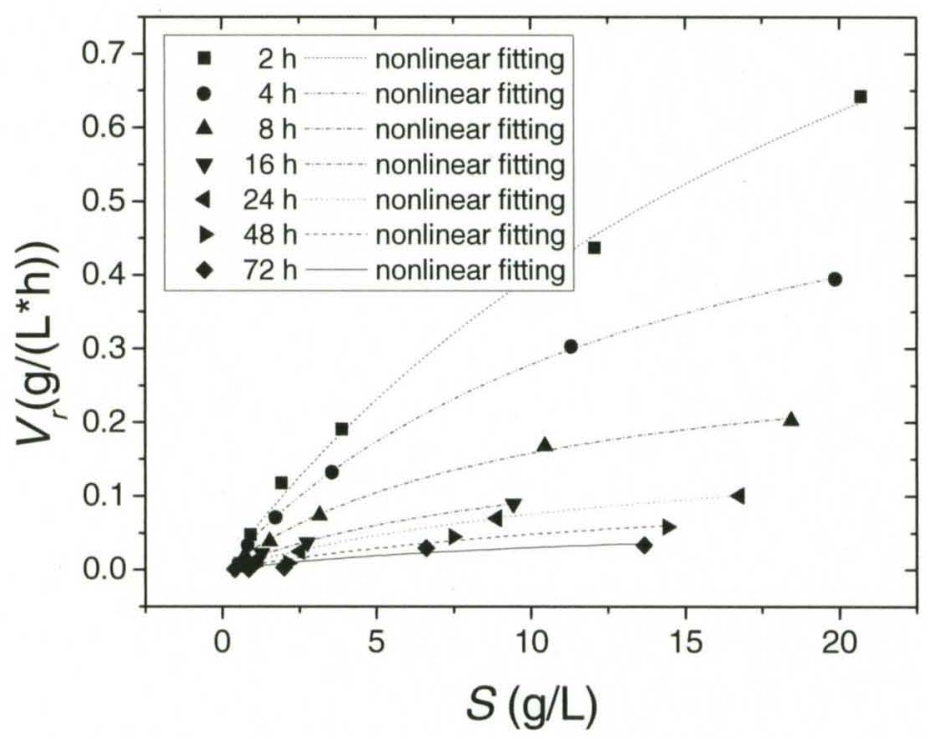

Figure 5.3. Regression of $V_{\max , a p p}$ and $K_{m}$ as a function of time. $V_{r}$ is calculated by differential of Equation (5.20), $S$ is calculated by Equation (5.11). Curves are nonlinearly regressed by Equation (5.19) to estimate $V_{\max , a p p}$ and $K_{m}$ as a function of reaction time. 
Figure 5.4 shows that regressed values of $V_{\max \text {,app }}$ decreas significantly as a function of reaction time, from about $1.5(\mathrm{~g} /(\mathrm{L} \cdot \mathrm{h}))$ at 2 hours to less than 0.1 at 72 hours, a more than $90 \%$ reduction during the 72 -hour reaction. This result is consistent with a similar curve showing significant decrease in observed catalytic constants reported by Jalak and Väljamäe (2010).

The curve in Figure 5.4 was fitted to Equation $(5.18)$, giving $2.96(\mathrm{~g} /(\mathrm{L} \cdot \mathrm{h}))$ for $V_{\max }, 0.053$ for $y_{0}, 0.95$ for $A_{0}$, and $1.75 \mathrm{~h}$ for $t_{1 / 2} . k_{2}$, the apparent hydrolysis rate, can be determined by $V_{\max }$ divided by the concentration of total enzyme $(E)_{0}$ as suggested by Equation (5.9). The molar mass of glucose is $180 \mathrm{~g} / \mathrm{mol}$, therefore $V_{\max }$ is equal to 0.016 $\mathrm{M} / \mathrm{h}$. Spezyme CP contains $82 \mathrm{mg}$ protein/mL as provided by Genencor (Kim et al., 2011). $0.6 \mathrm{~mL}$ of Spezyme $\mathrm{CP}$ cellulase added in a $100 \mathrm{~mL}$ reaction volume gives an enzyme concentration of $0.49 \mathrm{~g} / \mathrm{L}$. Assuming the average molecular weight of cellulases is $60,000 \mathrm{~g} / \mathrm{M}$, then the concentration of the total enzyme added is $8.2 \mu \mathrm{M}$. Therefore, $V_{\max }$ divided by the concentration of total enzyme $(E)_{0}$ gives a value of $k_{2}$ equal to $2.0 \times 10^{3} \mathrm{~h}^{-1}$ (or equal to $33 \mathrm{~min}^{-1}$ ). These values are comparable to the reported values of 3-30 $\mathrm{min}^{-1}$ reported by Klyosov (1988) and $19 \mathrm{~min}^{-1}$ by Kremer and Wood (1992) for cellulase incubated with Avicel.

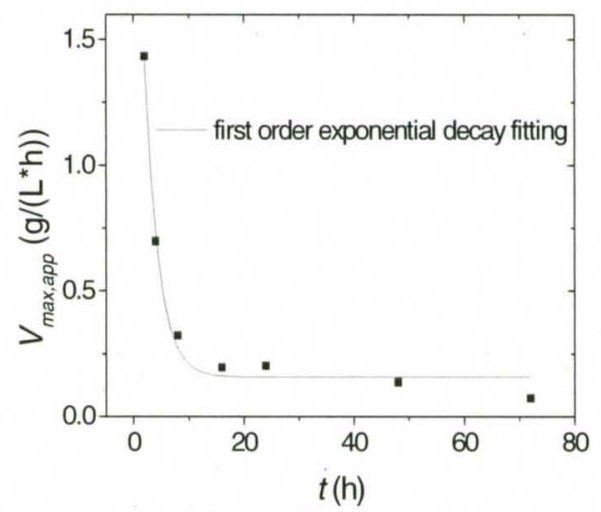

Figure 5.4. First order exponential decay fitting of $V_{\text {max,app }}$ as a function of reaction time to calculate the inactivation rate constant. 
When dissociation (enzyme release due to product formation) is likely to limit the hydrolysis process, the value of $k_{2}$ may reflect the dissociation rate constant multiplied by the processivity number (Jalak and Valjamae, 2010). Another possible explanation is that when dissociation is negligible compared to the adsorption rate constant, the initial hydrolysis rate can be written as in Equation (5.21) when $(S)$ is much smaller than $K_{m}$, so that free enzyme $(E)$ approaches total enzyme $(E)_{0}$ :

$$
V=\frac{d P}{d t}=k_{2} \times(E S)=\frac{k_{2} \times(E)_{0} \times(S)}{K_{m}+(S)} \approx \frac{k_{2}}{K_{m}} \times(E) \times(S)
$$

where $k_{2} / K_{m}$ is the apparent second order rate constant for the reaction of free enzyme with free substrate. If initial binding is negligibly reversible, the reaction rate constant of the diffusion controlled encounter of the enzyme and substrate will have a magnitude of at least $10^{9} \mathrm{M}^{-1} \mathrm{~s}^{-1}$ (Fersht, 1999), suggesting $k_{2} / K_{m}$ should be of this magnitude. $K_{m}$ is $16.03 \mathrm{~g} / \mathrm{L}$ glucan unit. The degree of polymerization of Solka Floc is about $600 \sim 800$ glucan/unit cellulose. The molar mass of cellulose will be $1.08 \sim 1.44 \times 10^{5} \mathrm{~g} / \mathrm{mol}$. Therefore, $K_{m}$ is about $1.1 \sim 1.5 \times 10^{-4} \mathrm{M}$ cellulose. $k_{2} / K_{m}$ then equals $\sim 2.9-4.0 \times 10^{3} \mathrm{M}^{-1} \mathrm{~s}^{-1}$, which is several orders of magnitude smaller than the diffusion limited rate constant, $10^{9}$ $\mathrm{M}^{-1} \mathrm{~s}^{-1}$. Therefore, there may be another event that occurs following enzyme adsorption, which limits the hydrolysis rate (more on this is discussed in the next section).

The values of $y_{0}, A_{0}$ and $t_{1 / 2}$ can be applied to Equations (5.14) - (5.16) to calculate the inactivation rate constant $\left(k_{f}\right)$ and reactivation rate constant $\left(k_{r}\right)$ for the adsorbed enzyme. $k_{f}$ and $k_{r}$ calculate to $0.38 \mathrm{~h}^{-1}$ and $0.021 \mathrm{~h}^{-1}$, respectively. The inactivation rate constant $\left(k_{f}\right)$ is an order lof magnitude arger than the reactivation rate constant $\left(k_{r}\right)$, therefore increasing amounts adsorbed enzyme becomes inactivated as the reaction proceeds. The inactivation rate constant calculated here for adsorbed enzyme is 
comparable to value of the inactivation rate constant reported by Howell and Mangat (1978) $\left(0.235 \mathrm{~h}^{-1}\right)$ and Converse et al. (1988) $\left(0.4 \mathrm{~h}^{-1}\right)$.

\subsection{Comparison of Theoretical Model Prediction to Experimental Hydrolysis}

\section{Results}

The proposed minimal theoretical model is summarized in Figure 5.5. After substituting for $A_{0}, y_{0}$ and $t_{1 / 2}$ in Equation (5.17) with $k_{f}$ and $k_{r}$ by Equation (5.14)-(5.16), and substituting for $V_{\max }$ in Equation (5.17) with $(E)_{0} \times k_{2}$, the rate of hydrolysis reaction becomes:

$$
\begin{aligned}
& V_{r}=k_{2} \times(E)_{0} \times \frac{(S)}{K_{m}+(S)} \times\left\{\frac{k_{r}}{k_{f}+k_{r}}+\frac{k_{f}}{k_{f}+k_{r}} \times \exp \left[-\left(k_{f}+k_{r}\right) \times t\right]\right\}
\end{aligned}
$$

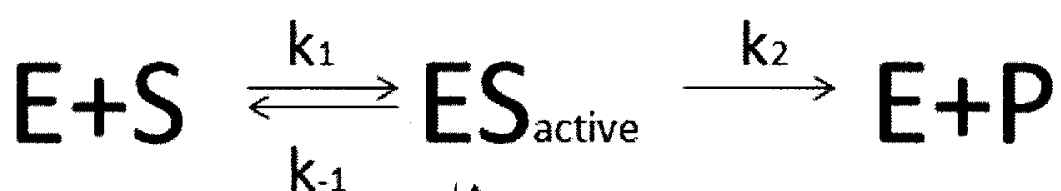

$$
\begin{aligned}
& k_{f} \downarrow k_{r} \\
& \text { ESinactive }
\end{aligned}
$$

Figure 5.5. Proposed minimal theoretical model to account for cellulose hydrolysis, which describes enzyme binding to substrate with association and dissociation rate constants $k_{l}$ and $k_{-l}$. Some active enzyme-substrate complex produces product with an apparent hydrolysis rate $k_{2}$ while the other becomes inactive with an inactivation rate constant $k_{f}$ and reactivation rate constant $k_{r}$. 
$P$ - $t$ curves were generated from Equation (5.22) using the values of $k_{2}, k_{f}, k_{r}$ and $K_{m}$ determined above and Equation (5.11). The curves generated from Equation (5.22) are shown in Figure 5.6(a), along with actual hydrolysis of Solka floc data. The theoretical conversion at 72 hours deviates by $2.9 \%, 2.8 \%, 9.9 \%,-1.4 \%, 6.4 \%$ from experimental results for substrate concentrations of $1.0,2.0,4.0,12.0$ and $20.0 \mathrm{~g} / \mathrm{L}$, respectively. The differences between predicted and experimental results are all within $10 \%$ or less, suggesting the theoretical modeling adequately accounts for Solka Floc hydrolysis, at least in this range of initial substrate concentrations. The same modeling method was also applied to account for the hydrolysis of Sigmacell as a substrate. Comparison of the estimated parameters for Solka Floc and Sigmacell are shown in Table 5.3. The rate constants $\left(k_{2}, k_{f}, k_{r}\right)$ for Sigmacell were within $2.5 \%$ of the values for Solka Floc. Furthermore, a common value of $V_{\max }$ implies that the rate-limiting intermediate step (discussed above in regards to the expected order of magnitude of $k_{2} / K_{m}$ ) would occur for any substrate type. One possibility may be an isomerization of enzyme following adsorption, which is suggested since it is known to occur in other enzyme-substrate systems, such as in the reaction of triosephosphate isomerase (Fersht, 1999). This finding is particularly noteworthy, especially if the rate-limiting step can be identified. Jalak and Väljamäe (2010) also reported that a common apparent hydrolysis rate constant was found for several different substrates such as lignocellulose, Avicel, and amorphous cellulose when these substrates were incubated with a major cellulase, $\mathrm{CBH} 1$, from Trichoderma reesei.

Glucose released from hydrolysis of Sigmacell was higher than from Solka Floc during the same incubation time (Figure 5.6b). For example, after a 72-hour incubation 
glucose released was $41 \%, 44 \%, 48 \%, 24 \%$ and $41 \%$ higher than that for Solka Floc at substrate concentrations of $1,2,4,12$ and $20 \mathrm{~g} / \mathrm{L}$, respectively. This is consistent with the lower $K_{m}$ value for Sigmacell (an average value of $6.23 \mathrm{~g} / \mathrm{L}$ from the regression) compared to Solka Floc $(16.03 \mathrm{~g} / \mathrm{L})$ since $K_{m}$ appears in the denominator of Equation (5.9).

(a)

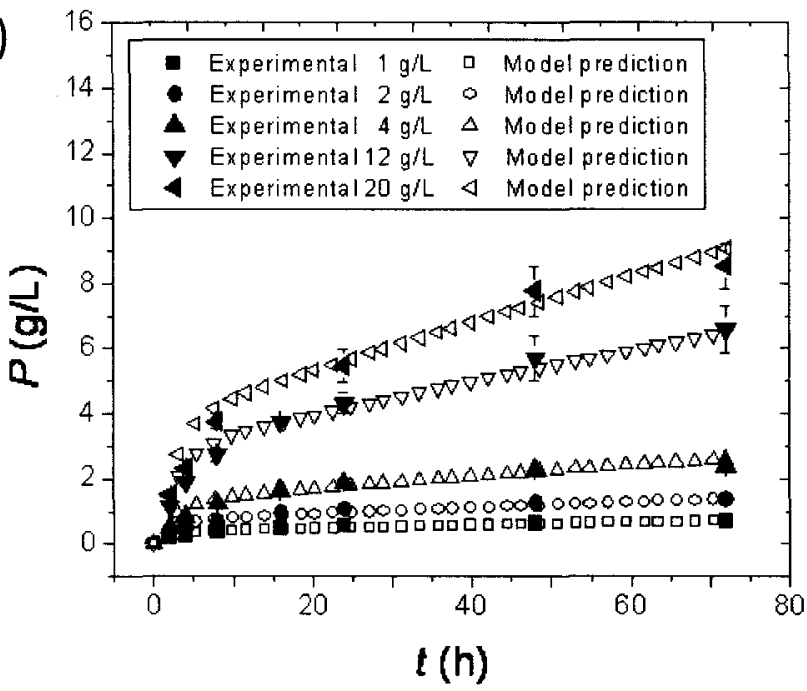

(b)

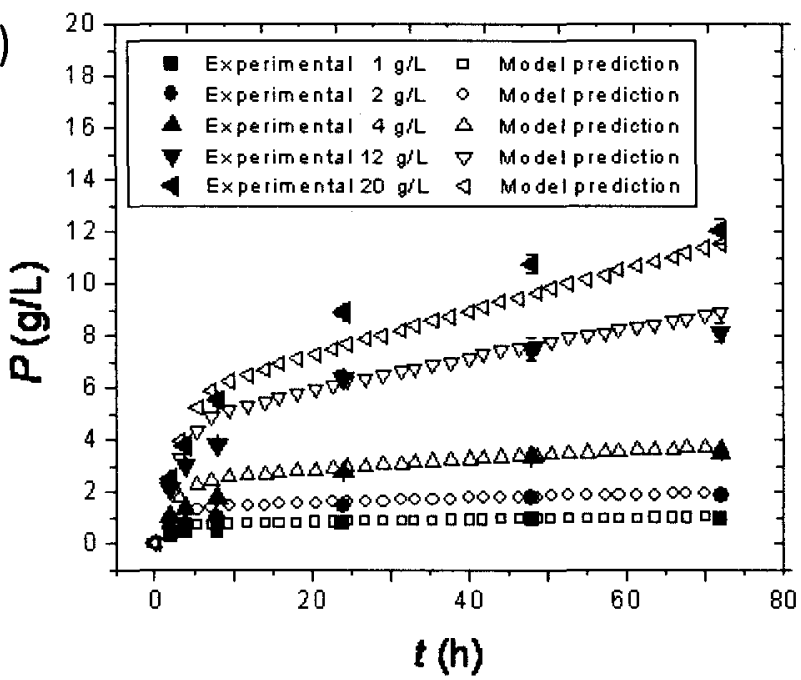

Figure 5.6. Comparison of measured and predicted glucose released. (a) Solka Floc; (b) Sigmacell. 


\section{Table 5.3}

Comparison of estimated parameters for Solka Floc and Sigmacell.

\begin{tabular}{lrr}
\hline Substrate & Solka Floc & \multicolumn{2}{l}{ Sigmacell } \\
\hline$V_{\max }(\mathrm{g} /(\mathrm{L} \cdot \mathrm{h}))$ & 2.96 & 2.83 \\
$y_{0}$ & 0.05 & 0.04 \\
$A_{0}$ & 0.95 & 0.96 \\
$t_{1 / 2}(\mathrm{~h})$ & 2.52 & 2.50 \\
$K_{m}(\mathrm{~g} / \mathrm{L})$ & 16.03 & 6.23 \\
$k_{2}\left(\mathrm{~min}^{-1}\right)$ & 33 & 32 \\
$k_{f}\left(\mathrm{~h}^{-1}\right)$ & 0.38 & 0.38 \\
$k_{r}\left(\mathrm{~h}^{-1}\right)$ & 0.02 & 0.02 \\
\hline
\end{tabular}

The theoretical conversion at 72 hours for Sigmacell deviates by $1.2 \%, 3.6 \%$, $5.4 \%, 9.5 \%$, and $-4.3 \%$ from experimental results for initial substrate concentrations of 1.0, 2.0, 4.0, 12.0 and $20.0 \mathrm{~g} / \mathrm{L}$, respectively, which like the Solka Floc, are also within $10 \%$ or less of experimental results.

\subsection{Relative Extents of Enzyme Activity Loss for Enzyme-Substrate Interactions and Thermal/Mechanical Mechanisms}

The activity loss of cellulases as a result of themal/mechanical deactivation, from incubating in substrate-free soultions, is shown in Figure 5.7. The activity slowly declined during the incubation; activity loss was about $20 \%, 35 \%$ and $40 \%$ after 24,48 
and 72 hours, respectively. The activity was fitted to a first order exponential model, Equation (5.23), which is comparable to Equation (5.13),

$$
\text { Activity }=y_{0-t / m}+A_{0-t / m} \times \exp \left(\ln 2 \times \frac{-t}{t_{1 / 2-t / m}}\right)
$$

where the subscript $-t / m$ stands for deactivation from thermal/mechanical mechanisms. From the fitting function, $\mathrm{y}_{0-\mathrm{t} / \mathrm{m}}=0.553, \mathrm{~A}_{0-\mathrm{t} / \mathrm{m}}=0.389$, and $\mathrm{t}_{1 / 2-\mathrm{t} / \mathrm{m}}=21.5 \mathrm{~h}$. Modelling by Levine et al (2010) suggested that an enzyme half-life due to thermal deactivation of about 4.3 hours or less for endoglucanase 2 or 10.6 hours or less for cellobiohydrolase 1 would be needed to account for the slow kinetics of cellulose hydrolysis. The 21.5 hour value determined here, therefore, implies that enzyme deactivation due to thermal/mechanical mechanisms does not account for the significant rate reduction during enzymatic hydrolysis of cellulose.

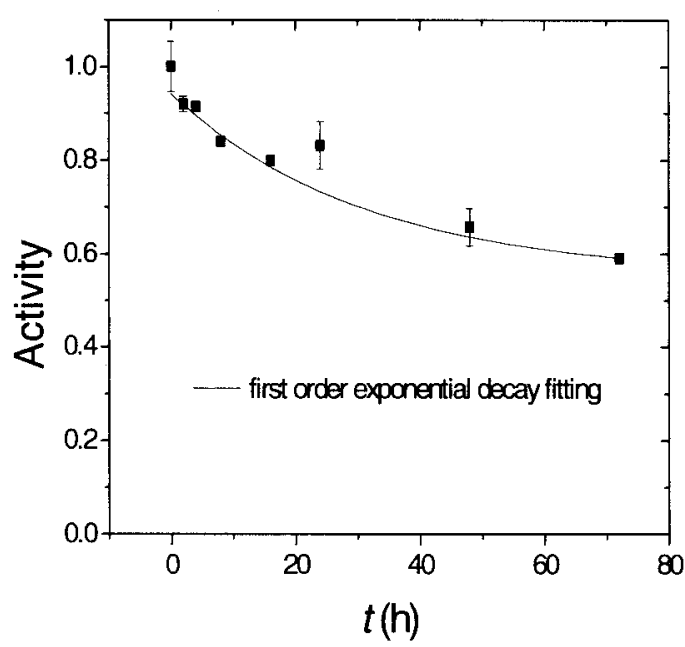

Figure 5.7. Activity of cellulase on Solka Floc following incubation in buffer solution for 2-72 hours. All data were nomalized according to the 1 hour cellulase activity without initial incubation. 
The deactivation rate constant, $\mathrm{k}_{\mathrm{f}-\mathrm{t} \mathrm{m}}$, solved from $\mathrm{A}_{0-\mathrm{v} / \mathrm{m}}=0.389$ and $\mathrm{t}_{1 / 2-\mathrm{v} \mathrm{m}}=21.5$ $\mathrm{h}$ with a relation between Equations 5.14-5.16 was $0.0123 \mathrm{~h}^{-1}$, is more than 30 times smaller than the inactivation rate constant $\left(\mathrm{k}_{\mathrm{f}}=0.38 \mathrm{~h}^{-1}\right)$ for adorbed enzyme determined previously, further confirming that enzyme deactivation due to thermal/mechanical mechanisms is not the main cause for the slow kinetics of cellulose hydrolysis.

Next, activity loss of cellulases due to interaction with substrate was determined (Figure 5.8). Activity decreased quickly up to $\sim 24$ hours. For example, at 24 hours, remaining activity was about $60 \%$ after interaction with $1 \mathrm{~g} / \mathrm{L}$ substrate and about $10 \%$ after interaction with $12 \mathrm{~g} / \mathrm{L}$ substrate. This compares to about $80 \%$ remaining without any interaction with substrate (Figure 5.7). After 24 hours, activity of cellulases following interaction with substrate decreased slowly, dropping to $45 \%$ and $10 \%$ of its original value within 72 hours for the lowest $1 \mathrm{~g} / \mathrm{L}$ and highest $12 \mathrm{~g} / \mathrm{L}$ concentrations tested. In summary, the more substrate present, the higher the percentage of cellulase becomes inactivated, further implying that enzyme-substrate interactions cause loss of activity.

The relative extent of activity loss due to thermal/mechanical mechanisms $\left(\mathrm{P}_{-t / \mathrm{m}}\right)$ in the total activity loss at a specific initial substrate concentration and time point can be calculated by equation (5.24):

$$
\mathrm{P}_{-\mathrm{t} / \mathrm{m}}=\frac{1-\frac{A_{-t / m}}{A_{i-t / m}}}{1-\frac{A_{s}}{A_{i, s}}}
$$

where $A_{-t m}$ is the cellulase activity at a certain time during incubation in a substrate free buffer solution, $A_{s}$ is the activity of cellulases at a certain time following interaction with substrate, $A_{i-t / m}$ is the initial cellulases activity without previous incubation in a buffer 
solution, and $\mathrm{A}_{\mathrm{i}, \mathrm{s}}$ is the initial cellulases activity with a certain concentration of substrate. Relative extent of activity loss due to enzyme-substrate interactions $\left(\mathrm{P}_{\mathrm{E}-\mathrm{S}}\right)$, which may represent inactivation of adsorbed enzyme, is calculated by:

$$
\mathrm{P}_{\mathrm{E}-\mathrm{S}}=1-\mathrm{P}_{-\mathrm{t} / \mathrm{m}}
$$

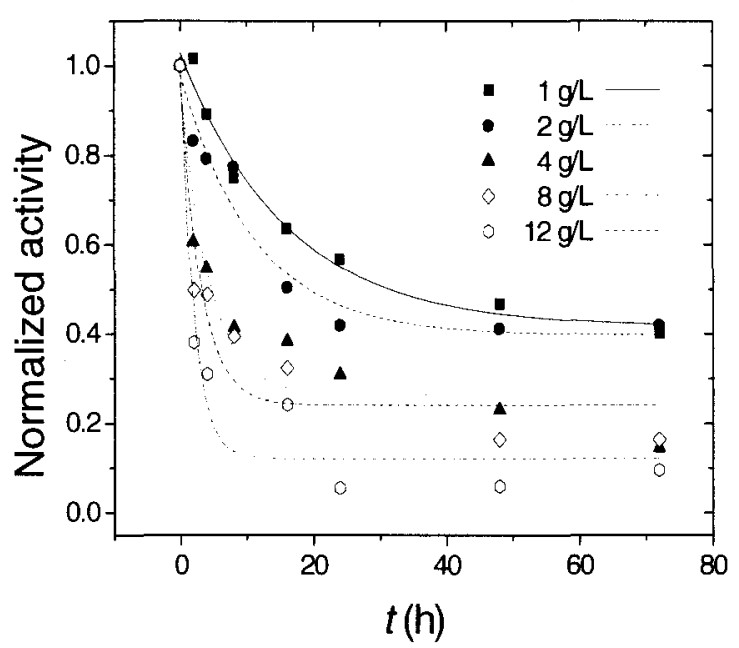

Figure 5.8. Activity of cellulase following interaction with different amounts of substrate during the initial incubation. All data were nomalized by the 1-hr cellulase activity without initial incubation (Defined as $C_{2}$ in the Methods Section). Curves are fit to a $1^{\text {st }}$ order exponential decay.

Figure 5.9 shows the comparison of relative extents of activity loss at three selected incubation time points: 4,16 , and 48 hours of the first incubation. At all three time points, the more initial substrate added, the more activity loss from inactivation of adsorbed enzyme. Except for the case of cellulases incubated with just $1 \mathrm{~g} / \mathrm{L}$ substrate, the dominating effect in activity loss is inactivation of adsorbed enzyme (as opposed to thermal/mechanical mechansims). For example, inactivation of adsorbed enzyme has a 
relative extent of $62 \%$ for an initial substrate concentration of $2 \mathrm{~g} / \mathrm{L}$ and $89 \%$ for $12 \mathrm{~g} / \mathrm{L}$ at 4 hours.

Relative activity loss due to thermal/mechanical mechanisms increased as the reaction proceeded; the activity loss from enzyme-substrate interactions decreased from $62 \%$ of total activity loss at $4 \mathrm{~h}$ to $42 \%$ at $48 \mathrm{~h}$ for an initial substrate concentration of $2 \mathrm{~g} / \mathrm{L}$ and from $89 \%$ at $4 \mathrm{~h}$ to $64 \%$ at $48 \mathrm{~h}$ for $12 \mathrm{~g} / \mathrm{L}$. Activity loss due to enzymesubstrate interactions levels off at about 10 hours (with the highest substrate concentration of $12 \mathrm{~g} / \mathrm{L}$ tested here) to 30 hours (with the lowest substrate concentration of $1 \mathrm{~g} / \mathrm{L}$ tested here) (Figure 5.8). However, activity loss due to thermal/mechanical mechanisms is lower compared with that due to enzyme-substrate interactions; for example there was only $20 \%$ activity loss in substrate free buffer solution at 24 hours versus $90 \%$ with $12 \mathrm{~g} / \mathrm{L}$ substrate. This trend continued throughout the 72 hour incubation. In summary, loss of cellulase activity, especially during the early part of the incubation, is mainly from enzyme-substrate interactions, which is likely caused from inactivation of adsorbed enzyme.

\subsection{Determination of Apparent Inactivation Rate Constant from Enzyme-Substrate}

\section{Interactions}

Comparing rate constants between enzyme-substrate interactions and thermal/mechanical mechanisms provides another means for quantifying the relative extent of deactivation. Activity of cellulases in Figure 5.8 was fitted to a first order exponential decay model like in Equation (5.13). Parameters for the first order exponential decay fitting of activity of cellulases following interaction with substrate are listed in Table 5.4, where $\mathrm{y}_{\mathrm{app}}, \mathrm{A}_{\mathrm{app}}$ and $\mathrm{t}_{1 / 2, \mathrm{app}}$ are apparent residue activity, apparent 

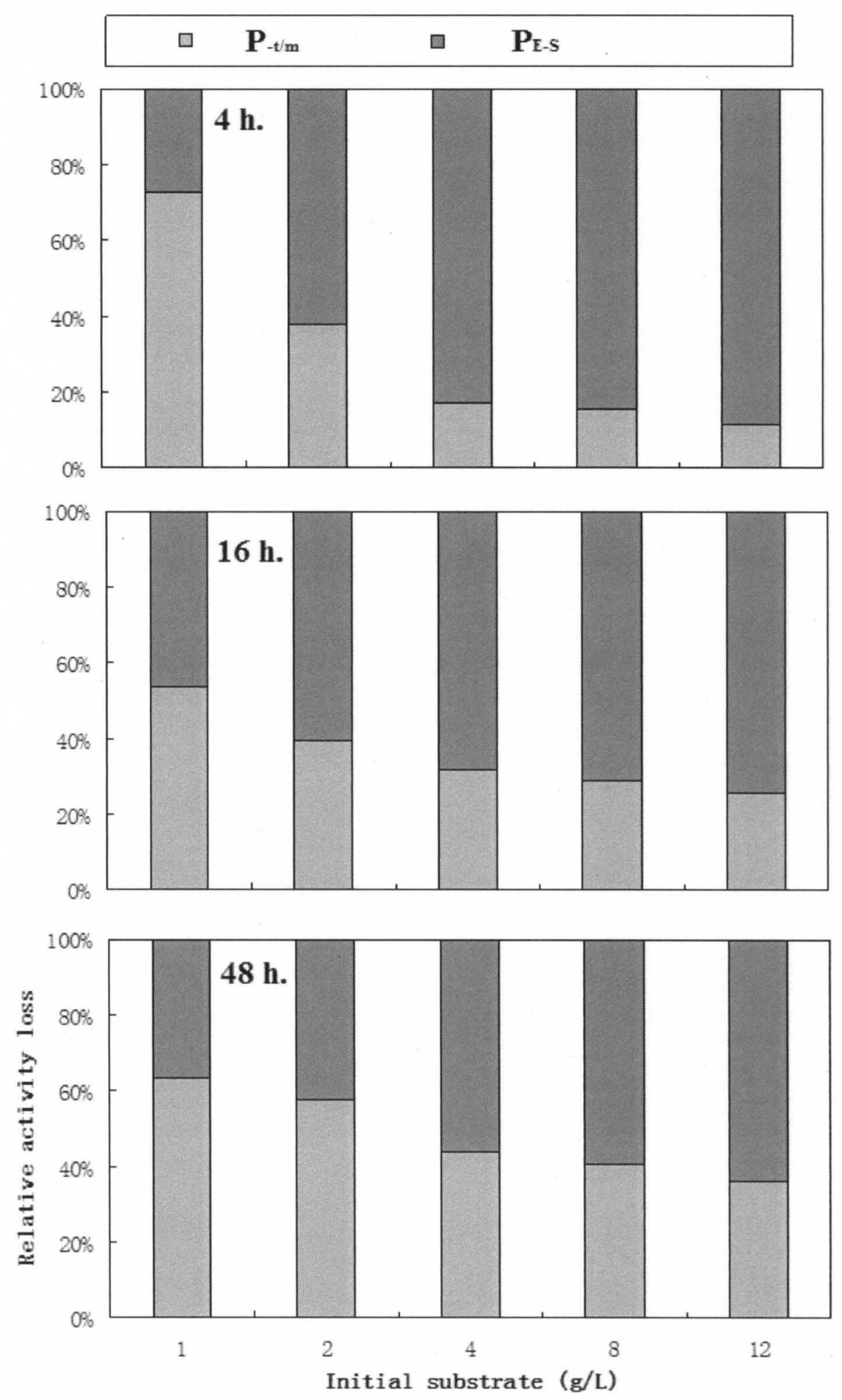

Figure 5.9. Relative extents of cellulase activity loss between enzyme-substrate interactions and thermal/mechanical mechanisms. 


\section{Table 5.4}

Parameters from the first order exponential decay fitting of activity of cellulases following interaction with substrate.

\begin{tabular}{cccccc}
\hline Initial & & & & & \\
substrate & 1 & 2 & 4 & 8 & 12 \\
$(\mathrm{~g} / \mathrm{L})$ & & & & & \\
\hline$y_{\text {app }}$ & $0.415 \pm 0.033$ & $0.397 \pm 0.040$ & $0.264 \pm 0.047$ & $0.241 \pm 0.060$ & $0.121 \pm 0.044$ \\
$A_{\text {app }}$ & $0.613 \pm 0.038$ & $0.583 \pm 0.053$ & $0.68 \pm 0.093$ & $0.719 \pm 0.118$ & $0.869 \pm 0.099$ \\
$t_{1 / 2, \text { app }}(\mathrm{h})$ & $11.01 \pm 1.92$ & $7.72 \pm 1.93$ & $2.63 \pm 0.94$ & $2.13 \pm 0.80$ & $1.37 \pm 0.38$ \\
$R^{2}$ & 0.98206 & 0.95976 & 0.91989 & 0.90454 & 0.95141 \\
\hline
\end{tabular}

inactivation extent, and apparent half life following inactivation due to enzyme-substrate interactions, respectively. The apparent half-lifes are $11.01,7.72,2.63,2.13$ and $1.37 \mathrm{hrs}$ and apparent residual activity are $41.5 \%, 39.7 \%, 26.4 \%, 24.1 \%$ and $12.1 \%$ following an initial incubation with cellulose in concentrations of $1.0,2.0,4.0,8.0,12.0 \mathrm{~g} / \mathrm{L}$, respectively. Both half-life and residue activity were reduced significantly by addition of substrate in increasing amounts. This is a clear indication of cellulase activity loss due to enzyme-substrate interactions. The apparent inactivation extent following enzymesubstrate interactions generally increased as a function of increasing substrate concentration. Equation (5.13) can be re-arranged to determine the inactivated enzymesubstrate complex, $(\mathrm{ES})_{\text {inactive, }}$ as a fraction of the total intial enzyme-substrate complex:

$$
\frac{(E S)_{\text {inactive }}}{(E S)}=\frac{(E S)-(E S)_{\text {active }}}{(E S)}=A_{0}\left[1-\exp \left(\ln 2 \times \frac{-t}{t_{1 / 2}}\right)\right]
$$

Combining Equation (5.6) and (5.26) and normalizing by $(\mathrm{E})_{0}$ gives 


$$
\frac{(E S)_{\text {inactive }}}{(E)_{0}}=\frac{A_{\max } \times S}{(E)_{0}+K_{d}+A_{\max } \times S} \times A_{0}\left[1-\exp \left(\ln 2 \times \frac{-t}{t_{1 / 2}}\right)\right]
$$

Apparent inactivation extent $\mathrm{A}_{\mathrm{app}}$ therefore can be defined as:

$$
A_{a p p}=\frac{A_{\max } \times S}{(E)_{0}+K_{d}+A_{\max } \times S} \times A_{0}
$$

The apparent inactivation rate constant $\mathrm{k}_{\mathrm{f}, \text { app }}$ can be calculated from:

$$
k_{f . a p p}=\frac{A_{a p p}}{\ln 2 \times t_{1 / 2}}
$$

$\mathrm{k}_{\mathrm{f} \text {,app }}$ increased with increasing initial substrate concentration (Figure 5.10), from about $0.0386 \mathrm{~h}^{-1}$ for $1 \mathrm{~g} / \mathrm{L}$ initial substrate to $0.440 \mathrm{~h}^{-1}$ for $12 \mathrm{~g} / \mathrm{L}$ initial substrate. The values are 3-36 times higher compared to $\mathrm{k}_{\mathrm{f}-\mathrm{t} / \mathrm{m}}$, which further confirms the finding that activity loss due to enzyme-substrate interactions is more significant than from thermal/mechanical mechanisms.

$\mathrm{k}_{\mathrm{f} \text {,app }}$ can be related to the inactivation rate constant $\left(\mathrm{k}_{\mathrm{f}}\right)$ for adsorbed enzyme by:

$$
k_{f}=\frac{A_{0}}{\ln 2 \times t_{1 / 2}}=\frac{A_{a p p}}{\ln 2 \times t_{1 / 2}} \times \frac{(E)_{0}+K_{d}+S \times A_{\max }}{S \times A_{\max }}=k_{f, u p p} \times \frac{(E)_{0}+K_{d}+S \times A_{\text {max }}}{S \times A_{\max }}
$$

Furthermore, when the enzyme concentration is overloaded compared to substrate, and when combining with Equation (5.8), Equation (5.30) can be simplified as:

$$
k_{f}=k_{f, a p p} \times \frac{(E)_{0}+K_{d}}{S \times A_{\max }}=\frac{k_{f, a p p}}{S} \times K_{m}
$$

When $\mathrm{k}_{\mathrm{f} \text {,app }}$ is plotted against substrate concentration, the ratio between $\mathrm{k}_{\mathrm{f} \text {,app }}$ and $\mathrm{S}$ (Figure 5.10 ) is $0.035 \mathrm{l} /(\mathrm{g} \cdot \mathrm{h}) . \mathrm{K}_{\mathrm{m}}$ is $16.03 \mathrm{~g} / \mathrm{L}$, resulting in $\mathrm{k}_{\mathrm{f}}$ equal to $0.56 \mathrm{~h}^{-1}$. The value calculated here is comparable to $0.38 \mathrm{~h}^{-1}$, which was derived previously in the section Calculation of the Values of Rate Constants. This value is 46 times greater than the inactivation rate constant for enzyme deactivation due to thermal/mechanical mechnisms $\left(\mathrm{k}_{\mathrm{f}-\mathrm{t} / \mathrm{m}}=0.0123 \mathrm{~h}^{-1}\right.$ in the section of Relative Extents of Enzyme Activity Loss for 
Enzyme-Substrate Interactions and Thermal/Mechanical Mechanisms), further evidence that inactivation of adsorbed enzyme from enzyme-substrate interactions is more significant than from thermal/mechanical mechanisms. The result here is also comparable to values reported by Converse et al., (1988) $\left(0.4 \mathrm{~h}^{-1}\right)$ and Howell and Mangat (1978) $\left(0.235 \mathrm{~h}^{-1}\right)$ for inactivation of adsorbed enzyme.

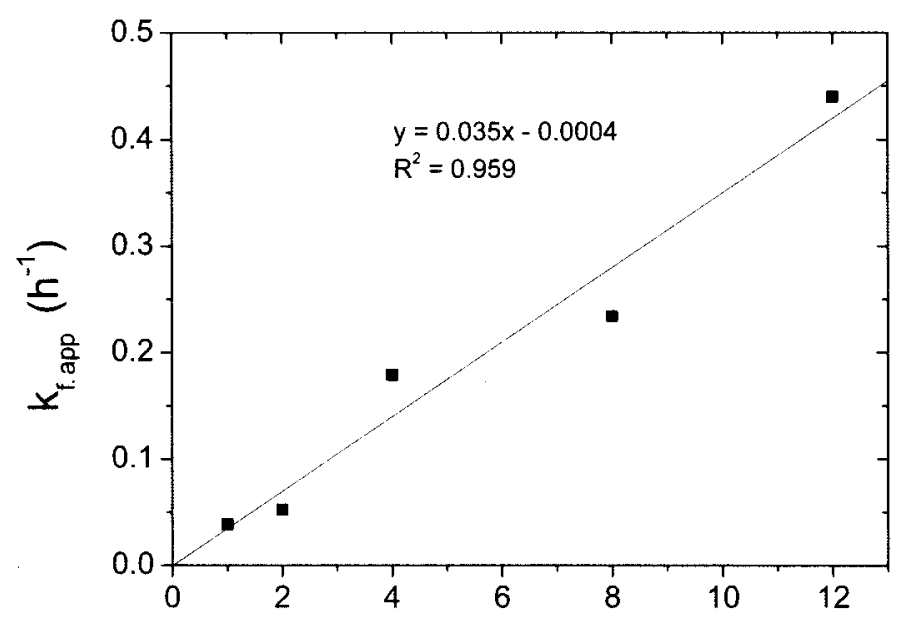

Concentration of substrate in initial incubation $(\mathrm{g} / \mathrm{L})$

Figure 5.10. A plot of apparent inactivation rate constantant $k_{f, a p p}$ versus substrate concentration to calculate the inactivation rate of adsorbed enzyme, $k_{f}$.

\subsection{Summary}

A mathematical model incorporating a first order inactivation of adsorbed cellulases was developed that accurately describes cellulose hydrolysis kinetics. The enzyme's apparent maximum rate decreases with a first order exponential decay function of time, and it is speculated here that this is due to inactivation of adsorbed enzyme. The model predicted enzymatic hydrolysis results within $10 \%$ of experimental results for both Solka Floc and Sigmacell substrates. The apparent hydrolysis rate $\left(k_{2}\right)$ and inactivation rate $\left(k_{f}\right)$ constants were $33 \mathrm{~min}^{-1}$ and $0.0063 \mathrm{~min}^{-1}\left(0.38 \mathrm{~h}^{-1}\right)$, respectively, comparable to 
values reported elsewhere. The rate constants were within $5 \%$ for the two different substrates, further strengthening the value of the model, and implying a common but yet undefined rate-limiting step associated with loss of enzyme activity likely exists in the pathway of cellulose hydrolysis.

The relative extents of activity loss due to enzyme-substrate interactions and deactivation from thermal/mechanical mechanisms were compared, and enzyme-substrate interactions contributed more towards the overall deactivation than did thermal/mechanical mechanisms, especially during the initial hours. Regarding enzymesubstrate interactions, the decrease in activity was seen to be a function of both time and initial substrate concentration, with the activity dropping to $45 \%$ of its original value within 72 hours for $1 \mathrm{~g} / \mathrm{L}$ and dropping to $10 \%$ of its original value for $12 \mathrm{~g} / \mathrm{L}$. Three independent metrics were compared to quantify the relative extent of deactivation: (1) Relative deactivation due to enzyme-substrate interactions was $62 \%$ (for $2 \mathrm{~g} / \mathrm{L}$ initial substrate) and $89 \%(12 \mathrm{~g} / \mathrm{L})$ at 4 hours, and $42 \%(2 \mathrm{~g} / \mathrm{L})$ and $64 \%(12 \mathrm{~g} / \mathrm{L})$ at 48 hours. (2) The apparent half-life of enzyme following interaction with substrate $\left(\mathrm{t}_{1 / 2, \text { app }}\right)$ was 1.37 11.01 hours, which is much shorter than the half life as a result of thermal/mechanical deactivation $\left(\mathrm{t}_{1 / 2-\mathrm{t} / \mathrm{m}}\right)$, which was 21.5 hours. (3) The apparent inactivation rate constant for enzyme-substrate interactions $\left(\mathrm{k}_{\mathrm{f}, \text { app }}\right)$ was about 3-36 times higher compared to the deactivation rate constant of thermal/mechanical mechanisms $\left(\mathrm{k}_{\mathrm{f}-\mathrm{t} / \mathrm{m}}\right)$. It is concluded here that enzyme-substrate interactions is the main cause of activity loss of cellulases and contributes significantly to the slow kinetics of cellulose hydrolysis. 


\section{CHAPTER VI}

\section{SCALED-UP SEPARATION OF CBH1 FROM A COMMERCIAL CELLULASE MIXTURE TO STUDY HYDROLYSIS AND INACTIVATION MECHANISMS}

\subsection{Assay of Total Protein Concentration in the Spezyme CP cellulases}

With the NanoDrop Spectrophotometer, the total protein concentration in the Spezyme CP cellulases was determined to be $75 \pm 1 \mathrm{mg} / \mathrm{ml}$ by absorbance at $280 \mathrm{~nm}$ using the effective molecular weight and absorption coefficient of $59,522 \mathrm{~g} / \mathrm{mol}$ and $81,565 \mathrm{M}^{-1} \mathrm{~cm}^{-1}$, respectively, for the Spezyme CP cellulases. This value is comparable to $82 \mathrm{mg} / \mathrm{ml}$ (Kim et al., 2011) as provided by Genencor International, Inc.

\subsection{Identification of $\mathrm{CBH} 1$ in the Spezyme $\mathrm{CP}$ cellulases}

CBH1, molecular weight equal to $64,000 \mathrm{~g} / \mathrm{mol}$, is the major component of Spezyme CP cellulases (Kabel et al., 2006), and was identified by SDS-PAGE (Figure 6.1). $\mathrm{CBH} 1$ was represented by the band with the highest intensity between the molecular marker weights of 66 and $55 \mathrm{kDa}$. The next highest molecular weight is EG1 at 55,000. If the major band were EG1, then there would have to be another band above it representing $\mathrm{CBH} 1$. The fraction of $\mathrm{CBH} 1$ is $\sim 60 \%$ compared to less than $8 \%$ for $\mathrm{EG} 1^{1}$, so that band would have to be more prominent. The fraction of $\mathrm{CBH} 1$ of the total Spezyme CP proteins was determined to be $56 \pm 9 \%$ by processing the images of the five enzyme loadings shown in Figure 6.1. Proteins were quantified by densitometry of the 
coomassie-stained gel, using ImageJ software (Mizunoya et al., 2008). The fraction determined here is comparable with reported $60 \pm 5 \%$ content of $\mathrm{CBH} 1$ in total cellulase proteins from T. reesei cellulase system, ${ }^{1}$ from which the Spezyme CP cellulase is made.

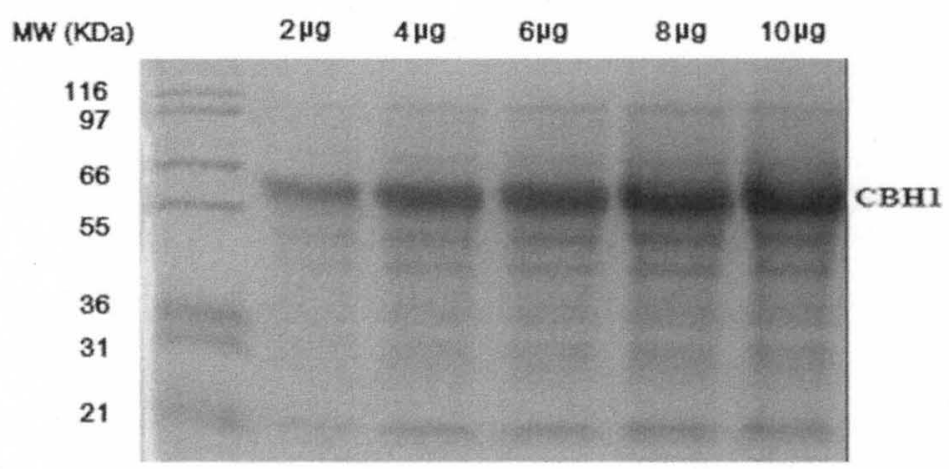

Figure 6.1. SDS-PAGE of the crude Spezyme CP cellulases. The molecular weight of each band is indicated on the left. The amount of protein loaded in each well is indicated above the gel.

\subsection{Continuous Gradient Elution}

CBH1 was first separated with the anion exchange column at $\mathrm{pH} 7$ by continuous gradient elution with a FPLC system. The chromatography result is shown in Figure 6.2a. Since $\mathrm{CBH} 1$ has the lowest $\mathrm{pI}$ value among cellulases from $T$. reesei, it is expected that it would bind to an anion column most tightly, and as a result would eluted at the highest ionic strength (in the third peak here). Enzymes were recovered from each of the three peaks, and the compositions of enzymes in each pool were characterized by SDS-PAGE (Figure 6.2b). Enzyme recovered in the third peak appears as a single band and had a molecular weight corresponding to $\mathrm{CBH} 1$, as was identified in Figure 6.1. The protein yield, $70 \%$ for $\mathrm{CBH} 1$, was calculated as the amount of protein present in the desired pool divided by the amount of $\mathrm{CBH} 1$ present in the initial crude mixture. The separated $\mathrm{CBH} 1$ was further applied to the same column, but at a lower $\mathrm{pH}$ of 6 , to examine whether its 
purity could be further improved by a second separation. $\mathrm{CBH} 1$ exhibited a single large symmetric peak (Figure 6.2c), confirming good purity of $\mathrm{CBH}$ l from the initial separation run at $\mathrm{pH} 7$.

\subsection{Step Elution and Scale Up}

From Figure $6.2 \mathrm{a}$ it was estimated that $\mathrm{CBH} 1$ began to elute at a salt concentration of $0.25 \mathrm{M}$. A step elution profile was developed as follows. A buffer with a salt concentration of $0.25 \mathrm{M}$ was used to elute the contaminants appearing in the first and second peaks in a continuous gradient elution, while $\mathrm{CBH} 1$ was recovered by a buffer with a salt concentration of $0.33 \mathrm{M}$. A large amount of elution buffer with $0.25 \mathrm{M}$ salt causes loss of $\mathrm{CBH} 1$ in the undesired fraction. Therefore, buffer with $0.10 \mathrm{M}$ salt was first used to elute some easily removable contaminants. In this way, the contaminants could still be effectively removed while most of the $\mathrm{CBH} 1$ could be recovered in the fraction eluted with $0.33 \mathrm{M}$ salt. The yield of $\mathrm{CBH} 1$ was calculated using Equation 6.1.

$$
\text { Yield of } C B H 1=\frac{C B H 1 \text { Concentration } \times \text { Volume of } C B H 1 \text { fraction }}{\text { Initial loading of Spezyme } C P \times \text { Content of } C B H 1}
$$

The yields of CBH1 separated from the vacuum manifold system and FPLC are summarized in Table 6.1 . The yield differed by less than $6 \%$ between the vacuum manifold system and the FPLC system. 

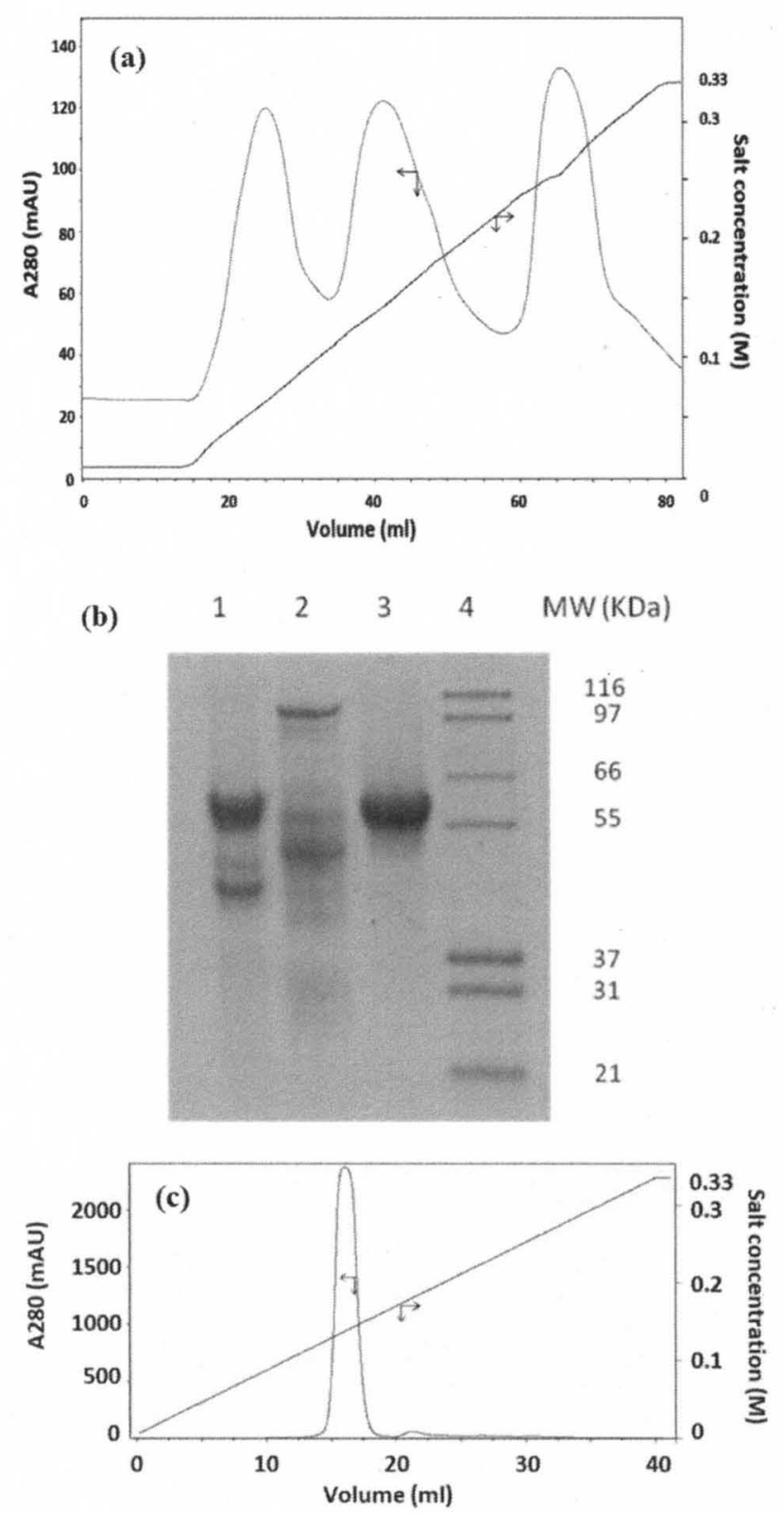

Figure 6.2. Separation of CBH1 by a FPLC system. (a) Separation of CBH1 from Spezyme CP cellulases with a continuous salt gradient at $\mathrm{pH}$ 7. (b) SDS-PAGE of the fractions collected in the three peaks as shown in (a) Lanes contain: (1): fractions in $1^{\text {st }}$ peak, (2) fractions in $2^{\text {nd }}$ peak, (3) fractions in $3^{\text {rd }}$ peak, and (4) molecular weight marker. (c) The separated $\mathrm{CBH} 1$ was applied at $\mathrm{pH}=6$ to examine its purity and whether a second separation is needed. 


\section{Table 6.1}

Comparison of protein yields of CBH1 separated by FPLC, a single column vacuum system, and scaled-up vacuum manifold system. Initial loading of Spezyme CP cellulases was $40 \mathrm{mg}$ to each column.

\begin{tabular}{|c|c|c|c|c|c|c|c|c|}
\hline \multirow[t]{2}{*}{ Test } & \multicolumn{5}{|c|}{ Protein Yield of CBH1 (\%) } & \multirow{2}{*}{$\begin{array}{c}\text { Total activity } \\
(\mathrm{U} / \mathrm{mg})\end{array}$} & \multirow{2}{*}{$\begin{array}{l}\text { Activity due to } \\
\text { EG1 (U/mg) }\end{array}$} & \multirow{2}{*}{$\begin{array}{l}\text { Specific pNPC } \\
\text { Activity }(\mathrm{U} / \mathrm{mg})\end{array}$} \\
\hline & Column & Column & Column & Column & Column & & & \\
\hline FPLC & $70 \pm 5$ & - & - & - & - & $0.059 \pm 0.002$ & $0.012 \pm 0.001$ & $0.047 \pm 0.002$ \\
\hline Vacuum manifold (scale-up) & $70 \pm 2$ & $68 \pm 0$ & $68 \pm 1$ & $71 \pm 0$ & $64 \pm 0$ & $0.074 \pm 0.007$ & $0.021 \pm 0.006$ & $0.053 \pm 0.001$ \\
\hline
\end{tabular}


The purity of $\mathrm{CBH} 1$ separated from the manifold system was compared with that of $\mathrm{CBH} 1$ separated from the FPLC system (Figure 6.3a). CBH1 separated by both methods showed a single band on the SDS-PAGE gel, which suggests good purity of CBH1 separated by either method. With 5 columns connected in parallel, a total of $55 \mathrm{mg}$ CBH1 was separated from $145 \mathrm{mg}$ Spezyme CP cellulase at once. In the scale-up separation, both the yields (Table 6.1) and purities of CBH1 (Figure 6.3b) were repeatable and comparable to a single column separation. There are 20 ports available for the connection of columns in the VM 20 vacuum manifold, so scale-up can be performed with this system for three to four times the volume tested here. Not all 20 columns can run in parallel at one time since $2-4$ ports are needed to adjust the vacuum pressure, depending on how many columns are in use.

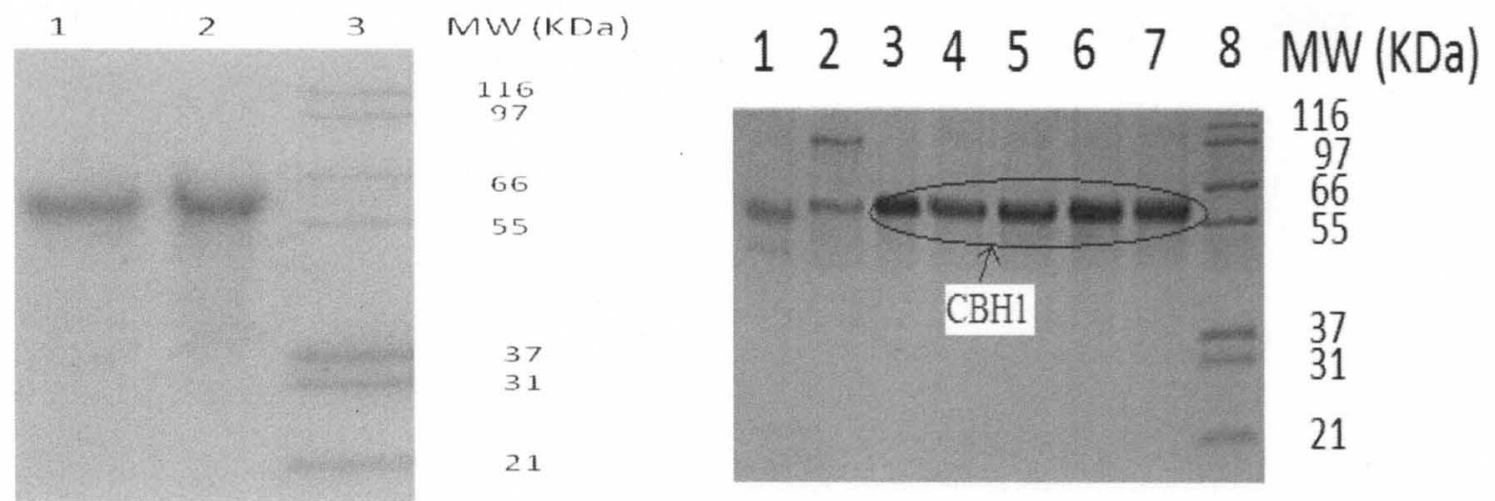

Figure 6.3. Examination of the purity of $\mathrm{CBH} 1$ separated by the vacuum manifold system. (a) Comparison of SDS-PAGE of CBH1 separated by FPLC and vacuum manifold. Lanes contain: (1): CBH1 separated by FPLC, (2) CBH1 separated by vacuum manifold, and (3) molecular weight marker. (b) SDS-PAGE of the scaled-up separation by step elution. Lanes contain: (1) fraction eluted by buffer with $0.1 \mathrm{M}$ salt, (2) fraction eluted by $0.25 \mathrm{M}$ salt buffer, (3)-(7) fractions eluted by $0.33 \mathrm{M}$ salt buffer and 5 columns in parallel, and (8) molecular weight marker. 
Medve et. al.'s separation procedure required about 46 minutes as calculated from their elution volume of $137 \mathrm{ml}$ with a flow rate of $3 \mathrm{ml} / \mathrm{min}$ and about 65 minutes as calculated from their elution volume of $520 \mathrm{ml}$ with a flow rate of $8 \mathrm{~mL} / \mathrm{min}$. The time for separation with the vacuum manifold system presented here is about 33 minutes as calculated from a total elution volume of $33 \mathrm{~mL} /$ column with a flow rate of $1 \mathrm{~mL} / \mathrm{min}$, plus an additional approximately 10 minutes total for addition of buffer between each step elution. The nature of the parallel manifold system results in separations on a larger scale in about the same order of time as the smaller-scale FPLC, and the required time is maintained on further scale-up.

\section{5 pNPC assay}

It is difficult to remove EG1 completely (estimated about $1-2 \%$ contaminant) from $\mathrm{CBH} 1$ since $\mathrm{EGl}$ has a pI closer to $\mathrm{CBH} 1$ than any of the other cellulase components. EG1 and CBH1 have significant sequence homology (45\% identity) (Zhang and Lynd, 2004) but EG1 has a 30-times higher pNPC activity than CBH1 (Takashima et al., 1998; Takashima et al., 1996). A small contaminant of EG1 in a separated CBH1 sample may give an overestimate of the specific pNPC activity for CBH1 in this assay. Since CBH1 is strongly inhibited by cellobiose, which has a $\mathrm{K}_{\mathrm{i}}$ of $20 \mu \mathrm{M}$ (Henriksson et al., 1996) and EGl displays less inhibition by cellobiose (Du et al., 2010). $0.02 \mathrm{M}$ cellobiose was added during the reaction to completely inhibit $\mathrm{CBH} 1$ activity in the pNPC assay, so that any activity due to EG1 would stand out. The specific pNPC activity for $\mathrm{CBH} 1$ is determined from Equation (6.2):

$$
\text { Specific activity of } C B H 1=\frac{C_{p(-c)}-C_{p(+c)}}{\text { Reaction time } \times \text { Concentration of } C B H 1}
$$


where $\mathrm{C}_{\mathrm{p}(-\mathrm{c})}$ is the concentration of $\mathrm{p}$-nitrophenol generated without addition of cellobiose, and $\mathrm{C}_{\mathrm{p}(+\mathrm{c})}$ is the concentration of p-nitrophenol generated following addition of cellobiose. The specific $\mathrm{CBH} 1$ activity along with EG1 and total activities are summarized in Table 6.2. The specific activity of $\mathrm{CBH} 1$ separated from the vacuum manifold system $(0.052$ $\mathrm{U} / \mathrm{mg})$ was similar to that separated by FPLC $(0.047 \mathrm{U} / \mathrm{mg})$. These values are similar to other report elsewhere. Takashima et al. (1996) reported the specific pNPC activity of CBH1 separated by expressing a CBH1 gene in Aspergillus oryzae to be $0.0543 \mathrm{U} / \mathrm{mg}$.

An ammonium acetate $(\mathrm{pH} 7)$ buffer was used to examine whether the TEA-HCl buffer used here had an adverse effect on $\mathrm{CBH} 1$ activity. The $\mathrm{CBH} 1$ separated by the FPLC system with an ammonium acetate buffer showed a similar specific pNPC activity $(0.039 \mathrm{U} / \mathrm{mg})$ as the $\mathrm{CBH} 1$ separated using the TEA-HCl buffer, which suggests that the TEA-HCl buffer, which was also used by Medve et al. (1998b) in their separation, does not adversely affect CBH1 activity.

\subsection{Stability of CBH1}

The stability of $\mathrm{CBH} 1$ at $50{ }^{\circ} \mathrm{C}$ with stirring at $150 \mathrm{rpm}$ was tested for 2 days (Figure 6.4). The normalized activity of $\mathrm{CBH} 1$ did not decrease significantly in the first 8 hours, and about $85 \%$ of the initial activity was retained following 2 days of incubation. Therefore, there was no significant deactivation of $\mathrm{CBH} 1$ at the tested conditions.

\subsection{Adsorption of CBH1 on BMCC}

Binding isotherms of $\mathrm{CBH} 1$ on $\mathrm{BMCC}$ were measured to determine the affinity of separated $\mathrm{CBH} 1$ for substrate (Figure 6.5). As $\mathrm{CBH} 1$ loading increased, bound $\mathrm{CBH} 1$ increased until reaching a plateau of about $4 \mu \mathrm{mol} / \mathrm{g} \mathrm{BMCC}$. In the control test, adsorption of BSA on BMCC was much smaller as compared with $\mathrm{CBH} 1$ adsorption, 
with less adsorbed protein on $\mathrm{BMCC}$ and more protein free in solution. BSA is negatively charged at $\mathrm{pH} \mathrm{7,} \mathrm{and} \mathrm{showed} \mathrm{minimal} \mathrm{and} \mathrm{concentration-independent} \mathrm{binding}$ to BMCC.

The binding isotherms of $\mathrm{CBH} 1$ were regressed using a 'Langmuir-type' model:

$$
E_{a}=\frac{A_{\max } \times K_{a} \times E_{f}}{1+K_{a} \times E_{f}}
$$

where $E_{a}$ is the concentration of bound $\mathrm{CBH} 1, \mathrm{~A}_{\max }$ is the maximum adsorption capacity $(\mu \mathrm{mol} / \mathrm{g} \mathrm{BMCC}), \mathrm{K}_{\mathrm{a}}$ is the association constant $(\mathrm{L} / \mu \mathrm{mol})$, and $\mathrm{E}_{\mathrm{f}}$ is the concentration of free CBH1.

With a nonlinear regression, the values of $A_{\max }$ and $K_{a}$ were found to be $3.69 \pm$ $0.24 \mu \mathrm{mol} / \mathrm{g} \mathrm{BMCC}$ and $5.55 \pm 2.34 \mu \mathrm{M}^{-1}$, respectively. The results here are comparable with the findings of Srisodsuk et al. (1993) who reported an $\mathrm{A}_{\max }$ of $4.2 \mu \mathrm{mol} / \mathrm{g} \mathrm{BMCC}$ and $\mathrm{K}_{\mathrm{a}}$ of $7.14 \mu \mathrm{M}^{-1}$ for a CBH1 expressed in a $E$. coli strain.

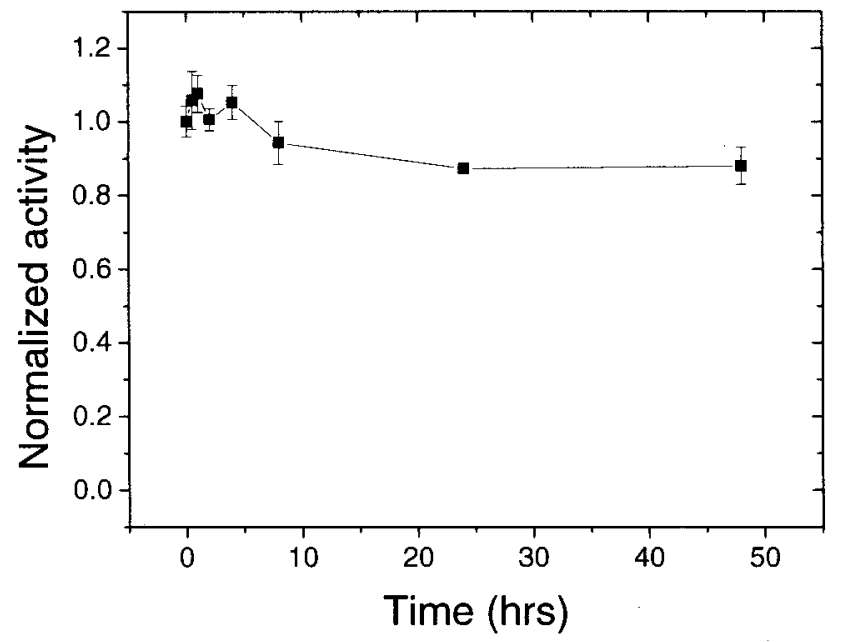

Figure 6.4. Stability of $\mathrm{CBH} 1$ at $50{ }^{\circ} \mathrm{C}$ and $150 \mathrm{rpm}$. All data were normalized according to the initial pNPC activity. 


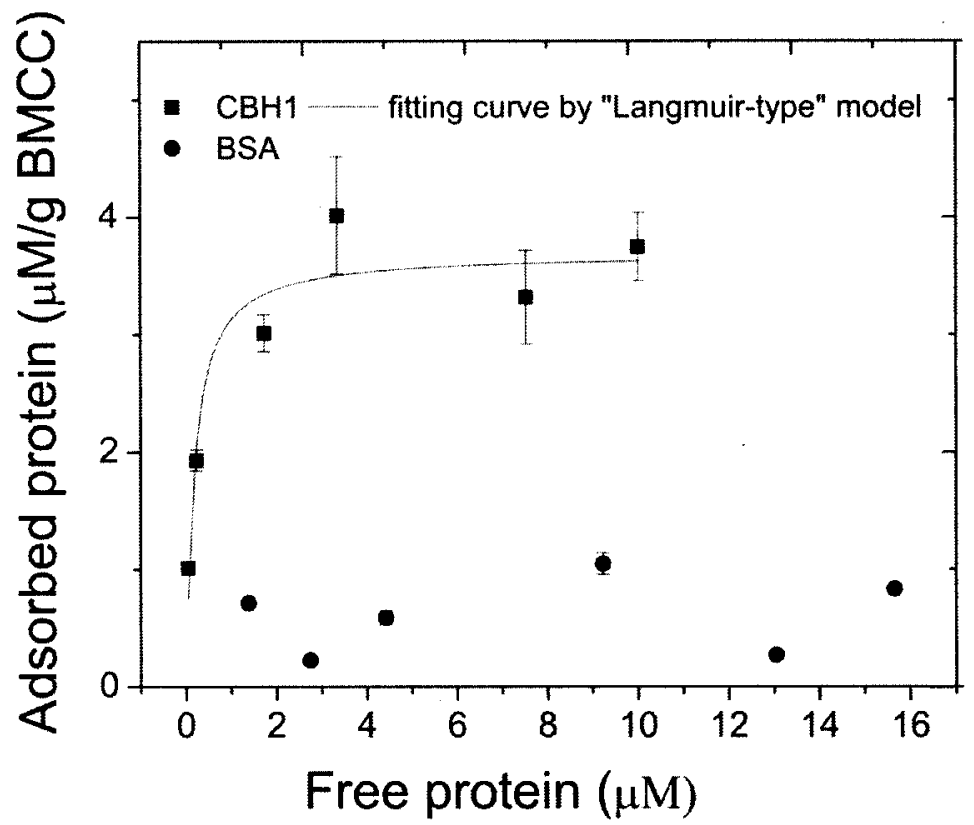

Figure 6.5. Binding isotherms of $\mathrm{CBH} 1$ and $\mathrm{BSA}$ on $\mathrm{BMCC}$ at $0{ }^{\circ} \mathrm{C} . \mathrm{CBH} 1$ and $\mathrm{BSA}$ at concentrations of $0.1,0.2,0.4,0.6,0.8$ and $1.0 \mathrm{mg} / \mathrm{ml}$ were incubated with $0.15 \%(\mathrm{~m} / \mathrm{v})$ BMCC solution for 45 minutes. The concentrations of free protein were determined by the Bradford Protein Assay. The amounts of protein adsorbed on BMCC were calculated by deducting amounts of free $\mathrm{CBH} 1$ from the initial total loadings.

\subsection{Hydrolysis of BMCC}

Figure 6.6a-d shows the changing height of an imaged BMCC fiber throughout the hydrolysis reaction. The width of the fiber is $\sim 1 \mu \mathrm{m}$, which is 25 times greater than the width of an individual fibril of $40 \mathrm{~nm}$ (Jervis et al., 2005), so it is likely that the imaged fiber is a bundle of individual fibrils. The initial maximum height of the bundle of fibrils is $\sim 45 \mathrm{~nm}$. During the reaction (Figure 6.6b-6d) a reference point on the mica surface was marked with a cursor. A horizontal line was drawn across this reference point so that a comparison of fiber height at the same location can be made over time. Another cursor was set at the left edge of the fiber. During the reaction the height of the fiber was 
reduced to $\sim 30 \mathrm{~nm}$ after 45 minutes (Figure 6.6b), $\sim 15 \mathrm{~nm}$ after 1.5 hours (Figure 6.6c), $\sim 8 \mathrm{~nm}$ after 2.5 hours (Figure 6.6d) and almost nothing remained after 3 hours. Hydrolysis of BMCC cellulose by the separated $\mathrm{CBH} 1$ was fast, confirming that the CBH1 after separation retained a high activity towards crystalline cellulose and, therefore, is useful for studying various aspects of cellulose hydrolysis such as binding and kinetics.

Only the height of the BMCC fiber changed during the reaction, and not the width. This indicates that CBHI tends to hydrolyze cellulose only from certain surfaces, which is consistent with other observations that the binding domain of cellulases only binds to certain surfaces on crystalline cellulose (Lehtio et al., 2003; Liu Y. S., 2010; Tormo et al., 1996).

\subsection{Inactivation of Adsorbed Enzyme}

Crowding of adsorbed enzyme (highlighted in circles) was visualized on phase images using AFM (Figure 6.7). In Figure 6.7, the images at 45, 90 and 150 minutes are related to the topography images at the same time points. The width of the fiber (indicated by the arrow) is $\sim 1 \mu \mathrm{m}$ as observed in the topography image (Figure 6.6). It is, therefore, estimated here that the dimension of the crowding is on the order of $\sim 100 \mathrm{~nm}$, which is much larger than a single CBH1 molecule with dimensions of of 4 by $18 \mathrm{~nm}$. The crowding is likely due to jamming of CBH1 as reported by Igarashi et al. (2011), which prevented $\mathrm{CBH} 1$ from proceeding along the substrate surface and causing inactivation of adsorbed enzyme. The finding here helps support the hypothesis of the inactivation step of adsorbed enzyme as proposed in Chapter V. 

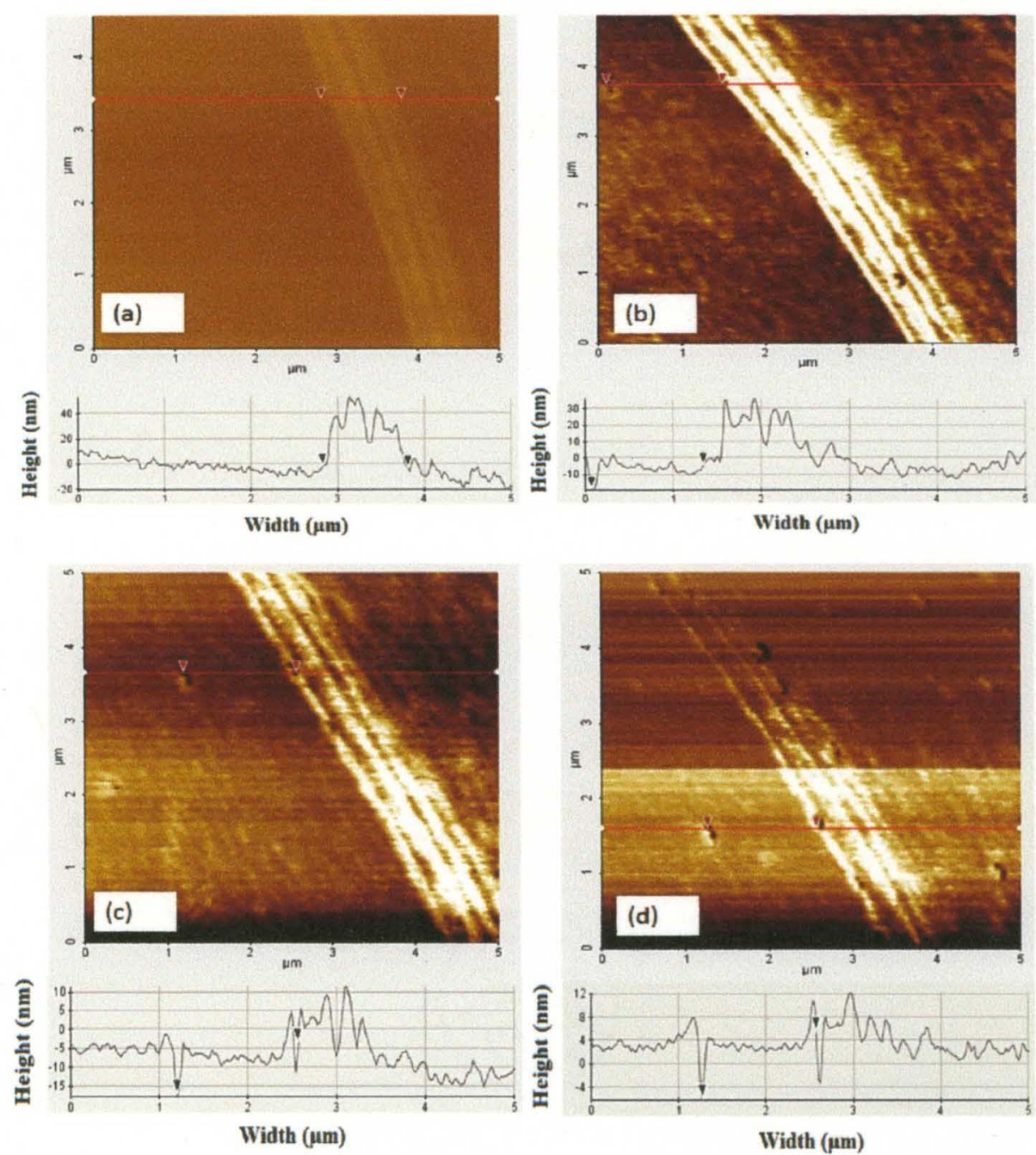

Figure 6.6. Height change of cellulose fiber during the reaction. (a) Height of cellulose fiber before reaction. The fiber is pointed out by a pair of cursors. (b) Height of cellulose fiber after 45 minutes of reaction. A reference point on the mica surface was marked with a cursor. A horizontal line was drawn across this reference point so that a comparison of fiber height at the same location can be made over time in the following reaction. Another cursor was set at the left edge of the fiber. (c) Height of cellulose fiber after 1.5 hours of reaction (Note that the baseline of height for mica surface is about $-5 \mathrm{~nm}$ in this figure). (d) Height of cellulose fiber after 2.5 hours of reaction (Note that the baseline of height for mica surface is about $4 \mathrm{~nm}$ in this figure). 


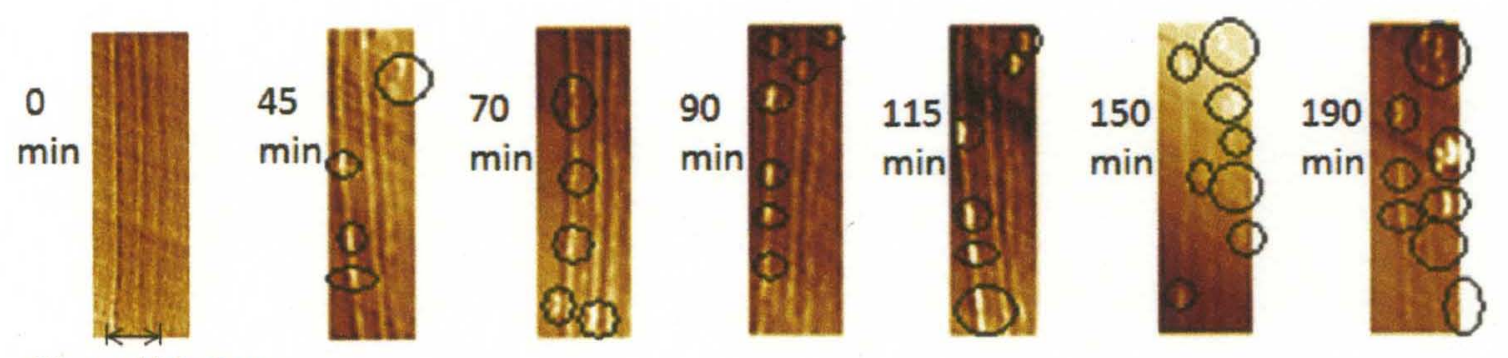

Fiber width $1 \mu \mathrm{m}$

Figure 6.7 Phase images of inactivation of $\mathrm{CBH} 1$ on a $\mathrm{BMCC}$ substrate surface. Arrows point to the edge of the fiber. The phase images at 45,90 and 150 minutes are related to the topography images at the same time points. Crowding of enzyme is highlighted in circles

\subsection{Summary}

CBH1 separation from Spezyme CP cellulases was successfully scaled-up by incorporating a vacuum manifold system and step elution to an ionic chromatography method. The $\mathrm{CBH} 1$ separated by this technique exhibited comparable purity and yield to CBH1 separated on a smaller scale by a conventional FPLC system. With five columns running in parallel, about about $55 \mathrm{mg}$ CBH1 was separated from $145 \mathrm{mg}$ Spezyme CP cellulases at once, and the system can be easily scaled-up further by adding additional columns. Separated CBH1 was identified as a single band on the SDS-PAGE gel, and showed good stability during a 2-day incubation at $50{ }^{\circ} \mathrm{C}$. It had a maximum adsorption at $0{ }^{\circ} \mathrm{C}$ on $\mathrm{BMCC}$ of about $4 \mu \mathrm{mol} / \mathrm{g}$, and a $\mathrm{K}_{\mathrm{a}}$ of $5.55 \mu \mathrm{M}^{-1}$. The activity of $\mathrm{CBH} 1$ towards pNPC from the scaled-up system $(0.052 \mathrm{U} / \mathrm{mg})$ was comparable to that measured in a FPLC $(0.047 \mathrm{U} / \mathrm{mg})$ and as reported elsewhere.

The results suggest that $\mathrm{CBH} 1$ separated by this system is of good quality for studying $\mathrm{CBH} 1 /$ substrate interactions, and this separation protocol can facilitate research in the investigation of $\mathrm{CBH} 1$ interactions with cellulose by providing large-scale 
quantities of purified $\mathrm{CBH} 1$, which is an important component in the study of enzymatic hydrolysis of cellulose. Moreover, the vacuum manifold system can be setup for less than $10 \%$ of the cost of a FPLC system.

The CBH1 was then used to examine hydrolysis and inactivation mechanisms on BMCC substrate using AFM imaging. The degradation of $\mathrm{BMCC}$ by $\mathrm{CBH} 1$ was fast as determined by real-time AFM imaging. The maximum fiber height was reduced from 45 $\mathrm{nm}$ initially to about $8 \mathrm{~nm}$ after 2.5 hours of enzymatic hydrolysis, which is a reduction of about $80 \%$, confirming good activity of separated CBH1. Only the height of the BMCC fiber changed during the reaction, indicating that CBHI tends to bind and hydrolyze cellulose from certain surfaces. Crowding of adsorbed $\mathrm{CBH} 1$ on the substrate surface was observed in phase images, which provided supporting evidence for the inactivation of adsorbed enzyme proposed in Chapter V. 


\section{CHAPTER VII}

\section{DEACTIVATION OF INDIVIDUAL CELLULASE COMPONENTS}

\subsection{Effect of Incubating Time on Cellulase Deactivation}

The effect of incubation time on cellulase deactivation was studied for two cases, with mixing (150 rpm as an example) and without mixing. The $\mathrm{CBH}$, endoglucanases, and total activities were all normalized according to their maximum values, regardless of mixing or no mixing. The maximum values occurred at 4 hours with mixing for $\mathrm{CBH} 1$ and total cellulase, and at 4 hours without mixing for endoglucanases.

With mixing, activities of $\mathrm{CBH} 1$, endoglucanases, and total cellulases all increased to a peak level before eventually decreasing (Figure 7.1a), which is likely indicative of an acclimation process for the cellulases before deactivation begins to occur. Activities then decrease before becoming stable by 24 hours. CBH1 and total activities both peaked at 4 hours while endoglucanases activity peaked at 8 hours, implying that total activity may be more directly influenced by $\mathrm{CBH} 1$ than by endoglucanases. The extents of activity loss were $35 \%$ for $\mathrm{CBH} 1$ and $20 \%$ total cellulases after 48 hours of incubation, while endoglucanase activity did not decrease much, only $8 \%$ after 48 hours, further implying that the decrease in total cellulase activity is more closely related to the decrease of $\mathrm{CBH} 1$ activity. This may simply be because $T$. Reesei cellulases contain

much more CBH1 (about 56\%) (Ye et al., 2011) than endoglucanases (about 10\%) 
(Takashima et al., 1998). Gunjikar et al. (2001) also found that exoglucanase was the component most prone to de-activation and could account for the overall loss in cellulase activity.

Without mixing, activities of $\mathrm{CBH} 1$, endoglucanases, and total cellulases also first increased before eventually decreasing and then leveled off by 24 hours, indicating a similar acclimation process for the cellulases (Figure 7.1b). Without mixing, the maximum $\mathrm{CBH} 1$ and total activities were about $84 \%$ and $93 \%$ of those with mixing, respectively, which suggests that mixing (at $150 \mathrm{rpm}$ ) had little effect on activity of $\mathrm{CBH} 1$ and thus total cellulase activity. Without mixing, the extents of activity loss were $35 \%$ for $\mathrm{CBH} 1,8 \%$ for endoglucanases and $22 \%$ for total cellulases after 48 hours of incubation, while with mixing the extents of activity loss were $35 \%, 8 \%$ and $20 \%$ for $\mathrm{CBH} 1$, endoglucanases and total cellulases, respectively, further implying that long-term deactivation of $\mathrm{CBH} 1$ and total cellulases were independent of mixing, at least at this intensity.

The deactivation extent for total cellulases was only about $20 \%$ after 48 hours of incubation both with and without mixing, which suggests that the slow kinetics may not be a result of just enzyme deactivation. Levine et al (2010) concluded that an enzyme half-life (due to thermal deactivation) much shorter than reported would be needed to account for the slow kinetics of cellulose hydrolysis, also implying that enzyme deactivation alone does not account for the slow kinetics. Hatfield (2010) reported that cellulase deactivation from enzyme-substrate interactions was more significant than from mechanisms related to the incubating environment. 

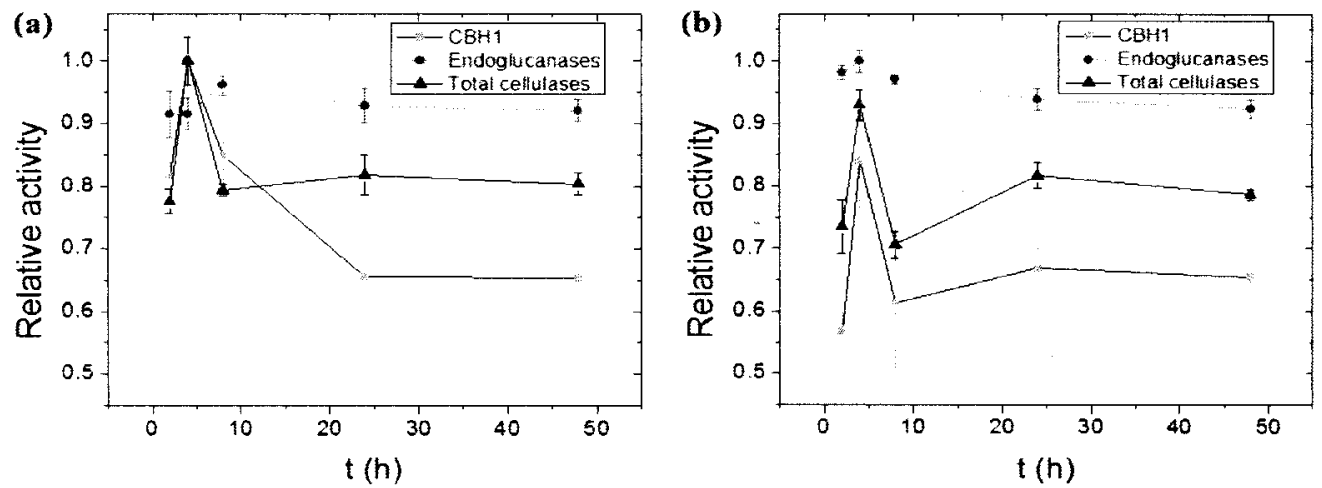

Figure 7.1. (a). Activities of cellulases after incubation at $150 \mathrm{rpm}$. (b). Activities of cellulases after incubation (without mixing). pNPC and PASC activities were normalized according to the activities after 4 hours of incubation at $150 \mathrm{rpm}$; CMC activity was normalized according to the activity after 4 hours of incubation without mixing.

\subsection{Effect of Mixing Intensity on Cellulase Deactivation}

The effect of mixing speed, and hence shear exposure, on cellulase deactivation is shown in Figure 7.2. Endoglucanases activity did not change significantly with rotating speed, but $\mathrm{CBH} 1$ activity was $20-25 \%$ higher at $250 \mathrm{rpm}$ compared to lower speeds. Similarly, total cellulase activity was highest at $250 \mathrm{rpm}$, which is consistent with the correlation between $\mathrm{CBH} 1$ activity and total cellulases activity.

The time-dependent change of $\mathrm{CBH} 1$ activity is compared for different mixing speeds in Figure 7.3. The peak values of $\mathrm{CBH} 1$ activity clearly increased with mixing speed. The peak value at $150 \mathrm{rpm}$ was $16 \%$ higher than that without mixing while the peak value at $250 \mathrm{rpm}$ was $26 \%$ higher than without mixing. This general trend was maintained for the first 24 hours. After that relative activity remained highest $(79 \%)$ at $250 \mathrm{rpm}$, while relative activity converged for $150 \mathrm{rpm}$ and no mixing (65\%), indicating that a minimum amount of mixing is needed once a certain reaction extent is reached. 
Samaniuk et al. (2011) also reported higher conversion was achieved in the presence of some gentle mixing compared to no mixing.

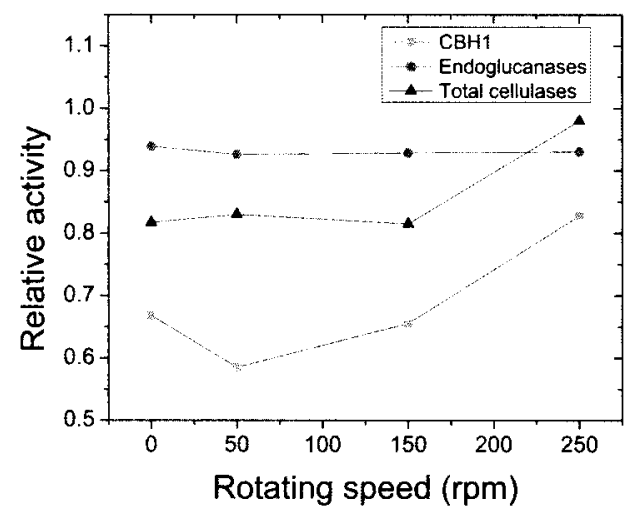

Figure 7.2. Effect of mixing speed on cellulase deactivation after 24-h incubation.

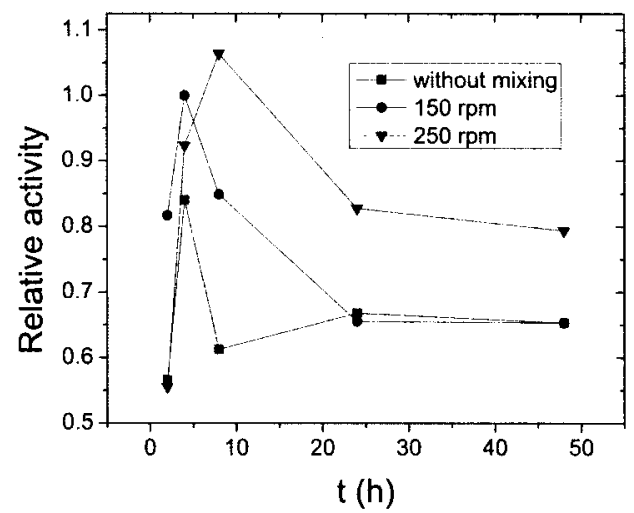

Figure 7.3. Time dependent deactivation of $\mathrm{CBH} 1$ for different mixing conditions.

Shear stress, as determined by CFD simulations, is quantified in terms of (1) maximum shear, which occurs at the wall of the flask where there is a large velocity gradient due to the swirling motion imparted by the shaker, and (2) mass-averaged shear throughout the flask (Table 7.1). The maximum shear imparted by the fluid for 50, 100 , and $150 \mathrm{rpm}$ were $0.226,7.38$, and $18.7 \mathrm{~Pa}$. Although, relatively little of the enzyme 
experienced the maximum shear since there was only a very small region of shear at this magnitude on the wall of the flask (red area in Figure 7.4). The bulk of the enzymes were exposed to the mass-average shear stress, with values of $0.00427,0.234$, and $0.221 \mathrm{~Pa}$ for the three speeds tested.

\section{Table 7.1}

Effect of rotating speed on the generated shear stress in a flask

\begin{tabular}{ccc}
\hline Rotating speed (rpm) & Maximum shear stress $(\mathrm{Pa})$ & Mass-average shear stress (Pa) \\
\hline 50 & 0.226 & 0.00427 \\
150 & 7.38 & 0.234 \\
250 & 18.7 & 0.221 \\
\hline
\end{tabular}

The data in Figures 7.2 and 7.3, which show less deactivation of CBH1 in higher rpm Erlenmeyer flask, is contrary to other findings where increased mixing resulted in more deactivation of cellulase activity (Ghadge et al., 2005a). That data, though, was generated in a system using a stirred reactor with moving parts for mixing, and the average stress in a stirred tank is typically greater than $50 \mathrm{~Pa}$ (Ghadge et al., 2005a), which is more than two orders higher than the $0.2 \mathrm{~Pa}$ in the Erlenmeyer flask. Brethauer et al. (1998) reported that high shear in a stirred tank caused shear sensitive deactivation of cellulase and, therefore, lower yields for hydrolysis of Avicel and corn stover in the stirred tank reactor compared to those with flask. 

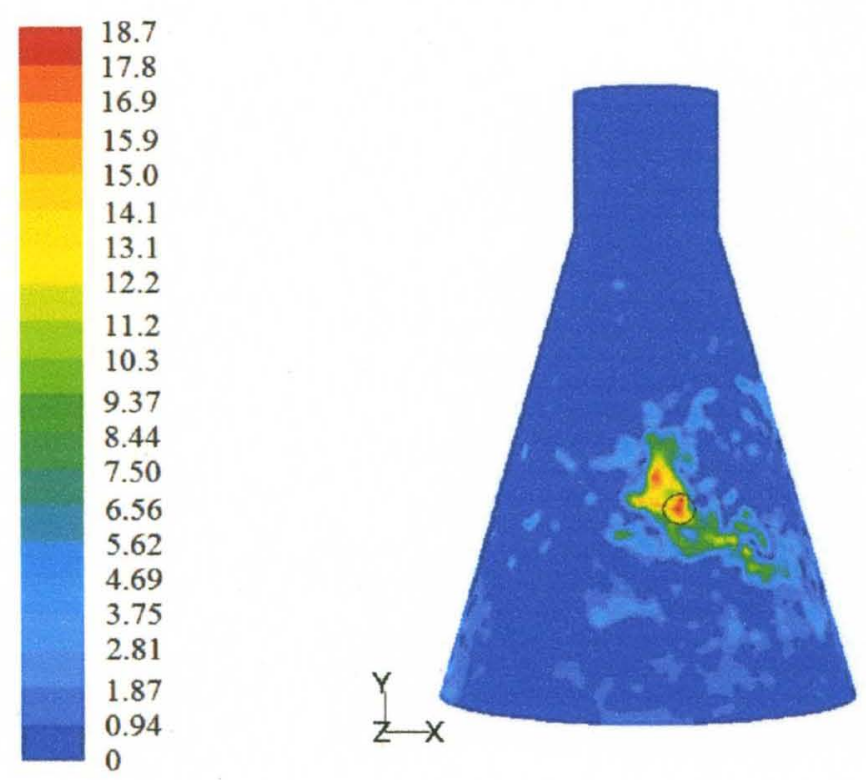

Figure 7.4. Wall shear stress $(\mathrm{Pa})$ in an orbital shaking flask at $250 \mathrm{rpm}$.

\subsection{Effect of Enzyme Concentration on Cellulase Deactivation}

Effect of enzyme concentration on deactivation was studied at two conditions, without mixing and with mixing at $250 \mathrm{rpm}$ (Figure 7.5). Enzyme deactivation without mixing appears to be concentration independent. About $20-25 \%$ of the initial total cellulases activity was lost following 24 hours of incubation for all enzyme doses. On the other hand, deactivation decreased from about $24 \%$ at $0.15 \mathrm{FPU} / \mathrm{ml}$ to about $2 \%$ at 0.75 FPU/ml at $250 \mathrm{rpm}$ mixing, suggesting that cellulase concentration affects activity in the presence of mixing. Ganesh et al. (2000) also found that as the concentration of the enzyme increased, the amount of deactivation decreased when cellulase loading was greater than $1 \mathrm{FPU} / \mathrm{ml}$ in the presence of mixing in a stirred tank reactor. This phenomenon may be due to the difference in the amount of exposure of enzyme at the air-liquid interface for different enzyme concentrations as suggested by Kim et al. (1982). They found that deactivation of cellulases was more significant with a combination of 
shear and enzyme exposure at an air-liquid interface than with shear only, and attributed this to a smaller ratio of enzyme present in the surface region to that in the bulk region for higher enzyme concentrations.

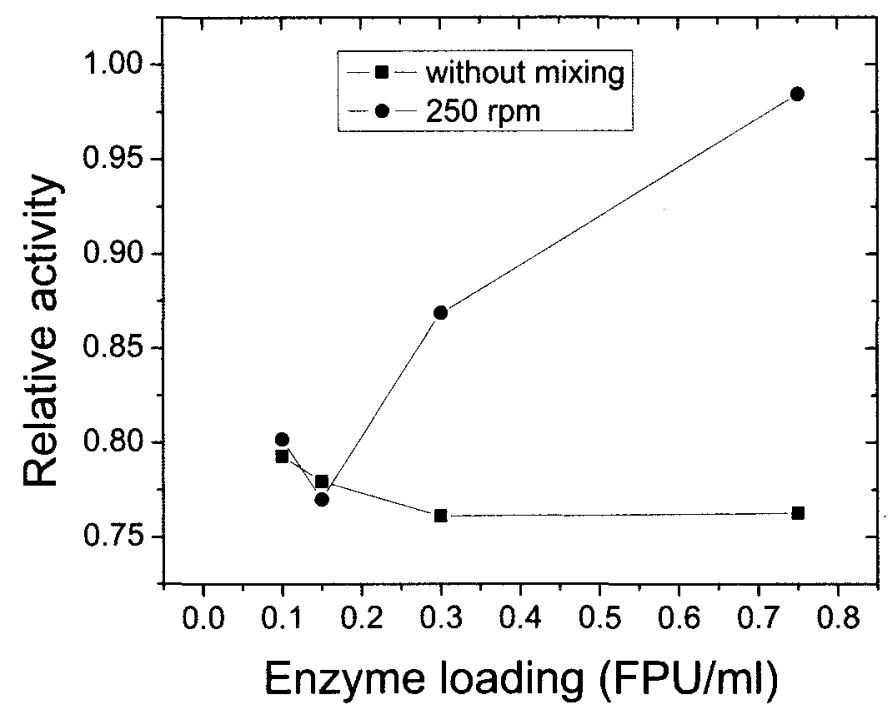

Figure 7.5. Effect of enzyme concentration on deactivation. The incubation time was 24 hours.

\subsection{Summary}

Deactivation of $\mathrm{CBH} 1$, endoglucanases, and total cellulases was studied here independently of each other. Based on activities peaking simultaneously and closer levels of deactivation, it is inferred that decrease in total cellulase activity was more closely associated with decrease of $\mathrm{CBH} 1$ activity than decrease of endoglucanase activity. Shear stress in an Erlenmeyer flask was more than two orders smaller than in a stirred tank as quantified by CFD. $\mathrm{CBH} 1$ and total cellulase activities were higher at $250 \mathrm{rpm}$ than at lower mixing speeds. Deactivation was enzyme concentration-independent without 
mixing, while higher concentrations resulted in less deactivation with mixing between $0.15-0.75 \mathrm{FPU} / \mathrm{ml}$. 


\section{CHAPTER VIII}

\section{DESORPTION OF CBH1 AT REDUCED ACTIVITY}

\subsection{Effect of Mechanical Deactivation}

Little deactivation of CBH1 occurred at $150 \mathrm{rpm}$, while at $300 \mathrm{rpm}$ about $70 \%$ of CBH1 activity was lost after 24 hours (Figure 8.1(a)). The fraction of free CBH1 at 150 rpm increased from about $25 \%$ at 0.5 hours to $95 \%$ at 24 hours (Figure 8.1 (b)). However, under higher intensity mixing at $300 \mathrm{rpm}$, the fraction of free $\mathrm{CBH} 1$ decreased at eight hours compared to that at four hours, and continued to decrease throughout the duration of the test. After 24 hours, the fraction of free CBH1 was less than $20 \%$ of the fraction of free $\mathrm{CBH} 1$ at $150 \mathrm{rpm}$. Desorption of $\mathrm{CBH} 1$ appears to have slowed under the more intense mechanical shaking and reduced activity. Reesei et al. (1980) also found that shaking reduced the activity of $T$. reesei cellulases and Avicelase (cellobiohydrolase) as well as their desorption from substrate.

\subsection{Effect of Inhibitors on CBH1 desorption}

CBH1 is strongly inhibited by cellobiose, which has an inhibition constant $K_{i}$ of $20 \mu \mathrm{M}$ (Henriksson et al., 1996). When $20 \mathrm{mM}$ cellobiose was added, $65 \%$ of the total enzyme desorbed at 24-h, and desorption was apparently slower compared to the control experiment where no inhibitor was present (Figure 8.2). Similarly, when another (but weaker) competitive inhibitor, $0.25 \mathrm{M} \mathrm{GdnHCl}\left(K_{i}=12 \mathrm{mM}\right)$ (Woodward et al., 1990a), 
was added to the reaction, $84.4 \% \pm 2.3 \%$ of pNPC activity was inhibited (Data not shown). Free CBH1 was about $25 \%$ less than the control experiment prior to 24 hours (Figure 8.2), although most CBH1 desorbed by 24 hours in the presence of $\mathrm{GdnHCl}$. These results further confirm the correlation between enzyme activity and desorption, implying that when $\mathrm{CBH} 1$ activity was reduced, desorption of $\mathrm{CBH} 1$ from substrate was inhibited or, at least, slowed.
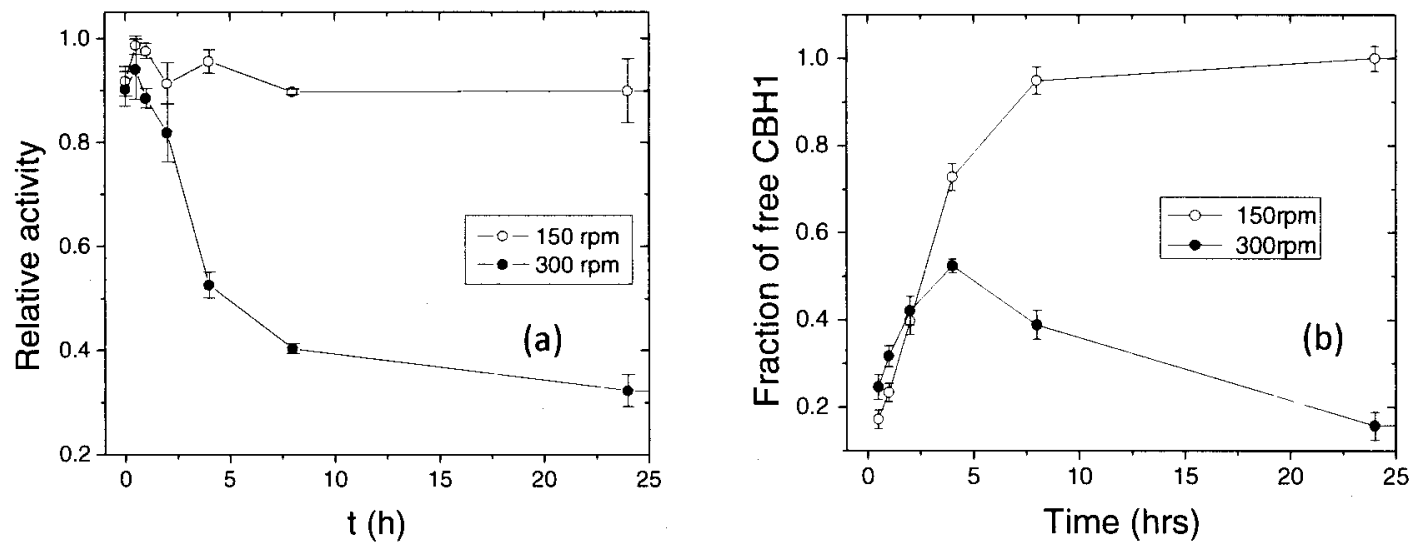

Figure 8.1. Effect of mechanical deactivation on CBH1 activity and desorption. (a) Activity of CBH1 at 150 and $300 \mathrm{rpm}$. Data were normalized according to the activity of $\mathrm{CBH} 1$ at 2 hours and $150 \mathrm{rpm}$. (b) Fraction of free $\mathrm{CBH} 1$ during desorption, which was normalized according to total enzyme added in the reaction. 


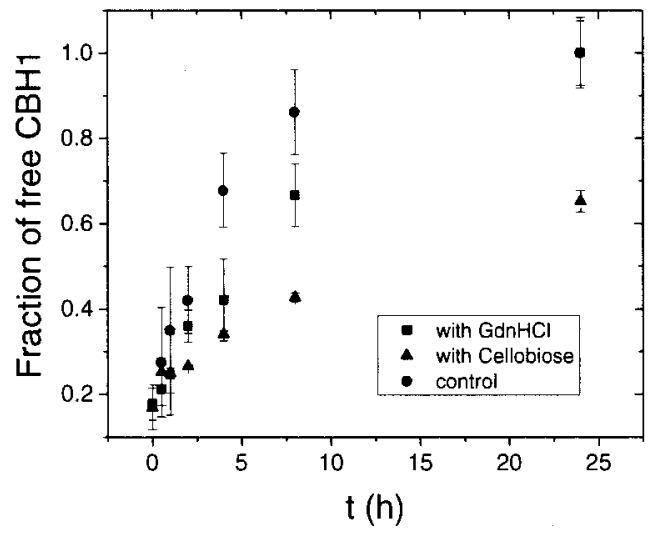

Figure 8.2. Effect of competitive inhibitors on $\mathrm{CBH} 1$ desorption. Fractions of free $\mathrm{CBH} 1$ were normalized according to total enzyme added in the reaction.

\subsection{Effect of Temperature on Desorption}

Figure 8.3 shows desorption of $\mathrm{CBH} 1$ at $0{ }^{\circ} \mathrm{C} .25 \%$ of the total enzyme desorbed after two hours, and there was no further desorption. Since the reaction rate increases with temperature, $\mathrm{CBH} 1$ has much less activity at $0{ }^{\circ} \mathrm{C}$ compared to at $50{ }^{\circ} \mathrm{C}$. Less desorption at $0{ }^{\circ} \mathrm{C}$ compared to at $50{ }^{\circ} \mathrm{C}$ (Figure 8.3) again implies a correlation between the amount of activity and the amount of desorption.

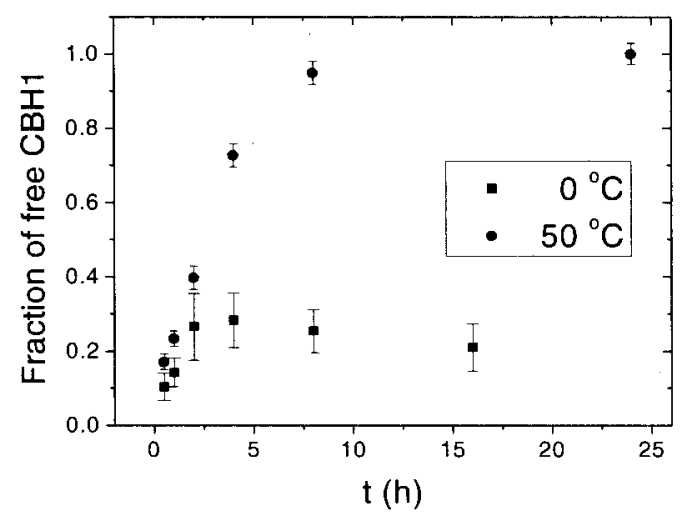

Figure 8.3. Desorption of $\mathrm{CBH} 1$ at 0 and $50{ }^{\circ} \mathrm{C}$. Fractions of free $\mathrm{CBH} 1$ were normalized according to the total enzyme added in the reaction. 


\subsection{Effect of $\mathrm{K}_{2} \mathrm{PdCl}_{6}$ (Denaturant) on CBH1 Desorption}

Lassig et al. (1995) reported that $\mathrm{K}_{2} \mathrm{PdCl}_{6}$ can irreversibly deactivate $\mathrm{CBH}$. When 50 and $162.5 \mu \mathrm{M}$ were added to the reaction, activity dropped about $70 \%$ and $63 \%$, which was consistent with Lassig et al's results showing that a $50: 1$ ratio of $\mathrm{K}_{2} \mathrm{PdCl}_{6}$ to CBH1 resulted in higher deactivation. Less than $10 \%$ of $\mathrm{CBH} 1$ desorbed during a time period of up to eight hours (Figure 8.4), further indicating that desorption of $\mathrm{CBH}$ correlated with enzyme activity.

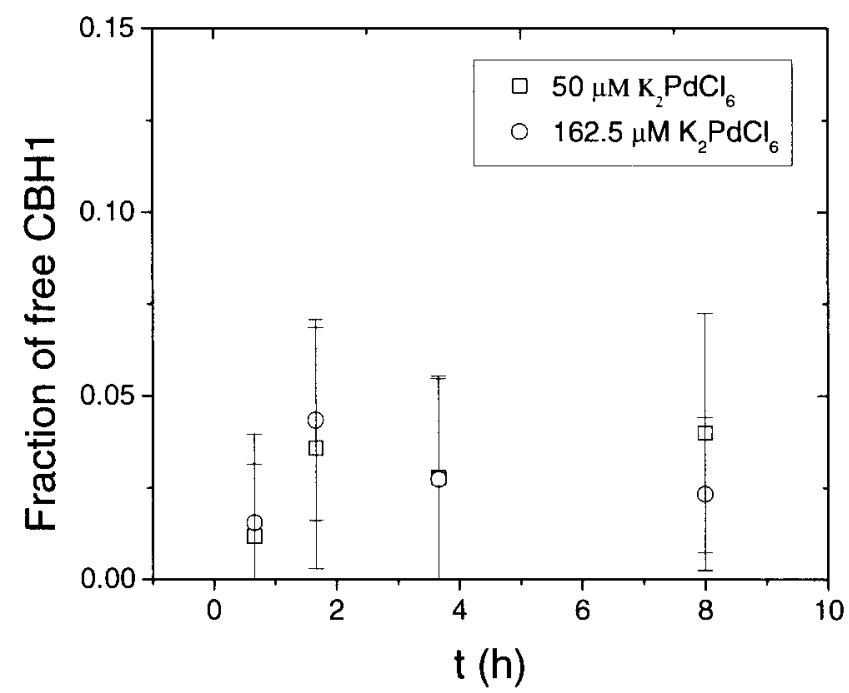

Figure 8.4. Effect of $\mathrm{K}_{2} \mathrm{PdCl}_{6}$ on CBH1desorption.

\subsection{Summary}

Desorption of $\mathrm{CBH} 1$ was compared under conditions of reduced and normal activity levels. CBH1 activity was reduced by each of the following methods: (1) mechanical deactivation, (2) addition of inhibitor, (3) low reaction temperature, and (4) deactivation with a denaturant. Decreasing desorption of $\mathrm{CBH} 1$ occurred when activity was reduced. Compared to almost complete desorption of $\mathrm{CBH} 1$ under little mechanical deactivation at $150 \mathrm{rpm}$, less than $\sim 20 \% \mathrm{CBHl}$ desorbed following 24 hours of 
incubation at $300 \mathrm{rpm}$ when $70 \%$ of the activity was lost due to more intense mechanical deactivation. After addition of $20 \mathrm{mM}$ cellobiose inhibitor, only about $65 \%$ of $\mathrm{CBH} 1$ desorbed after 24 hours. Desorption was about $25 \%$ less after being inhibited with $0.25 \mathrm{M}$ $\mathrm{GdnHCl}$ compared to that in the absence of the inhibitor. At $0{ }^{\circ} \mathrm{C}$, only $25 \%$ of the total enzyme desorbed within 24 hours at $150 \mathrm{rpm}$, compared to nearly $100 \%$ at $50{ }^{\circ} \mathrm{C}$. Less than $10 \%$ desorption occurred for $\mathrm{CBH} 1$ treated with $\mathrm{K}_{2} \mathrm{PdCl}_{6}$.

These results suggest that when $\mathrm{CBH} 1$ activity was reduced, regardless of the deactivation mechanism, much less enzyme desorbed and returned to solution as compared to active enzyme. This implies that more $\mathrm{CBH} 1$ remains bound to substrate, cannot dissociate and find new binding sites immediately to start another cycle, and therefore becomes inactive. The results here help support the relationship between the slow kinetics and inactivated enzyme predicted by the kinetics model developed in Chapter V. 


\section{CHAPTER IX}

\section{FACTORS TO CONSIDER WHEN DEVELOPING A CELLULOSE HYDROLYSIS PROCESS}

\subsection{Kinetic Modeling to Determine Activation Energy}

In order to examine the effects of reaction conditions such as temperature on cellulose hydrolysis, the activation energy of each reaction step needs to be determined first.

The mechanism in Figure 9.1 is used to represent cellulose hydrolysis here, which is similar to that proposed in Chapter V. In this mechanism, enzyme binds to substrate with association and dissociation rate constants $k_{l}$ and $k_{-l}$. Some of the active enzymesubstrate complexes produce product with an apparent hydrolysis rate $k_{2}$, while other complexes become inactive with an inactivation rate constant $k_{f}$ and active again with a reactivation rate constant $k_{r}$.

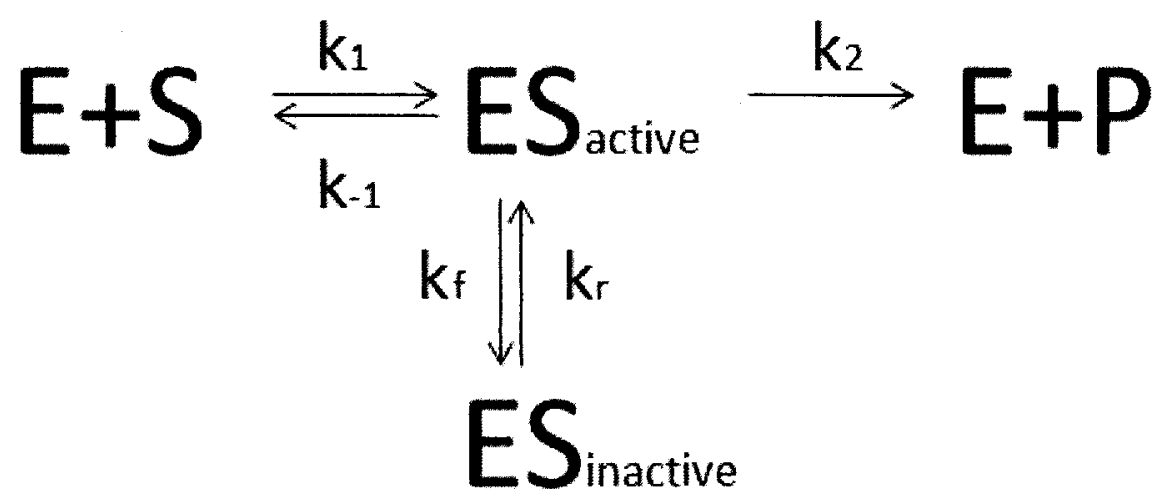

Figure 9.1. Proposed minimal theoretical model to account for cellulose hydrolysis. 
Using the modeling procedure as reported in Chapter $\mathrm{V}$, the rate equation of cellulose hydrolysis can be written as:

$$
\frac{d P}{d t}=V_{r}=k_{2} \times(E)_{0} \times \frac{(S)}{K_{m}+(S)} \times\left\{\frac{k_{r}}{k_{f}+k_{r}}+\frac{k_{f}}{k_{f}+k_{r}} \times \exp \left[-\left(k_{f}+k_{r}\right) \times t\right]\right\}
$$

where, $V_{r}$ is the real hydrolysis rate, $k_{2}$ is the rate for breakdown of the enzyme-substrate complex, $(E)_{0}$ is initial enzyme concentration, $(S)$ is substrate concentration, $k_{f}$ is the inactivation rate constant for adsorbed enzyme, $k_{r}$ is the reactivation rate constant, $t$ is reaction time, and $K_{\mathrm{m}}$ is derived from the Langmuir adsorption model as defined in Chapter V. Parameters in the model were determined as reported in Chapter V for three different temperatures: 50,35 , and $20^{\circ} \mathrm{C}$. Activation energies for the rate limiting step $\left(k_{2}\right)$ and the inactivation step $\left(k_{f}\right)$ were determined using an Arrhenius plot.

\subsection{Activation Energies for Hydrolysis and Inactivation Steps}

$0.1 \mathrm{~g}, 0.2 \mathrm{~g}, 0.4 \mathrm{~g}, 1.2 \mathrm{~g}, 2 \mathrm{~g}$ and $5 \mathrm{~g}$ of cellulose substrate and $0.6 \mathrm{ml}$ of Spezyme CP cellulases (50 FPU (filter paper unit)/mL cellulases activity) were incubated for up to three days at three temperatures: 50,35 and $20^{\circ} \mathrm{C}$ (Figure 9.2). Model parameters and rate constants in Table 9.1 were regressed using the procedure as reported in Chapter V. Theoretical predicted $P$ - $t$ curves in Figure 9.2 were generated from the rate Equation (9.1) using the parameters in Table 9.1, and compared to the experimental results. The theoretically predicted results were generally within one standard deviation of experimental results, implying that the theoretical modeling with the determined parameters can accurately account for hydrolysis at the three temperatures.

Activation energies for the hydrolysis step $\left(k_{2}\right)$ and the inactivation step $\left(k_{f}\right)$ were determined using Arrhenius plots (Figure 9.3). Activation energy is equal to (-slope $x R$ ), 
where $R\left(1.985 \mathrm{cal} \mathrm{K}^{-1} \mathrm{~mol}^{-1}\right)$ is the gas constant. The activation energies for the $k_{2}$ and $k_{f}$ steps are $16.3 \mathrm{kcal} \mathrm{mol}^{-1}$ and $18.0 \mathrm{kcal} \mathrm{mol}^{-1}$, respectively. The activation energy for the $k_{2}$ step is within the typical range of $4-20 \mathrm{kcal} \mathrm{mol}^{-1}$ for enzymatic reactions (Shuler and Kargi, 1992). The activation energy for the inactivation $\left(k_{f}\right)$ step is close to that of the hydrolysis $\left(k_{2}\right)$ step, implying that increasing the reaction temperature may cause a significant increase in the inactivation rate in addition to the catalytic reaction rate. Optimizing strategies are proposed and discussed below based on this kinetic model.

\section{Table 9.1}

Parameters for the cellulose hydrolysis model (Equation 9.1).

\begin{tabular}{llll}
\hline Temperature & 50 & 35 & 20 \\
$\left({ }^{\circ} \mathrm{C}\right)$ & & & \\
\hline$V_{\max }(\mathrm{g} /(\mathrm{L} \cdot \mathrm{h}))$ & 2.83 & 1.016 & 0.212 \\
$K_{m}(\mathrm{~g} / \mathrm{L})$ & 6.23 & 9.51 & 5.81 \\
$k_{2}\left(\mathrm{~h}^{-1}\right)$ & 2000 & 721 & 150 \\
$k_{f}\left(\mathrm{~h}^{-1}\right)$ & 0.38 & 0.169 & 0.0231 \\
$k_{r}\left(\mathrm{~h}^{-1}\right)$ & 0.02 & 0.0280 & 0.0009 \\
\hline
\end{tabular}



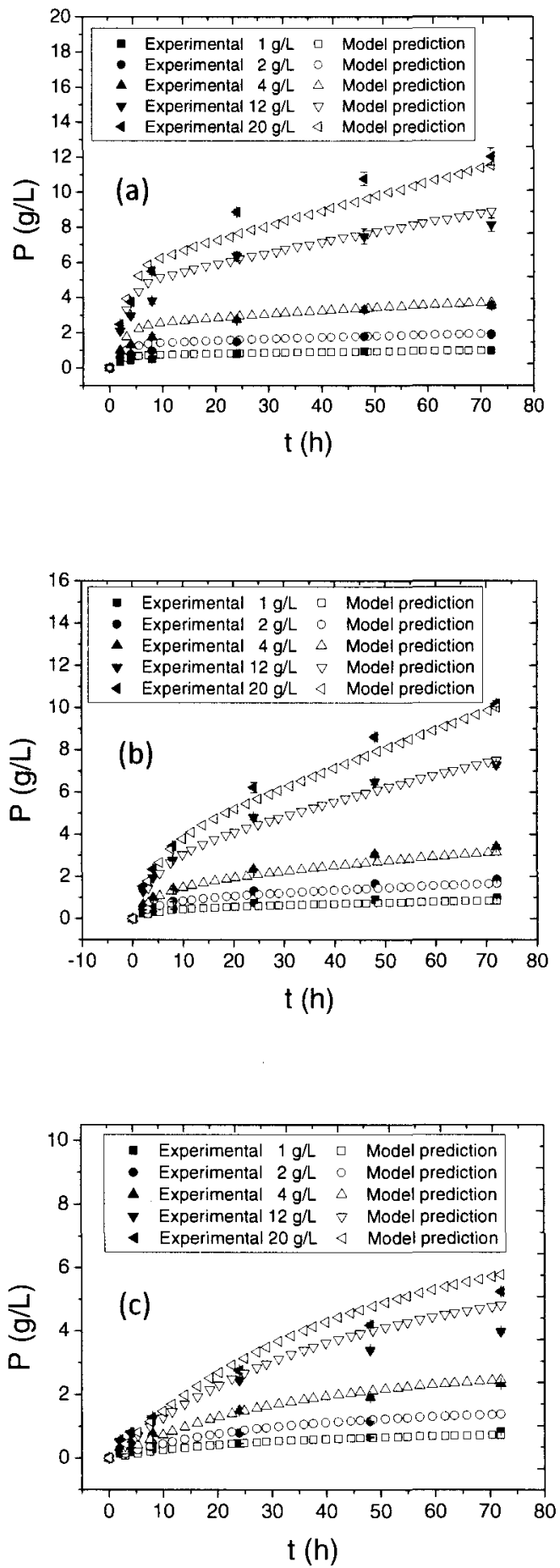

Figure 9.2. Comparison of experimental and predicted glucose released for Sigmacell at (a) $50{ }^{\circ} \mathrm{C}$; (b) $35^{\circ} \mathrm{C}$; (c) $20^{\circ} \mathrm{C}$. 

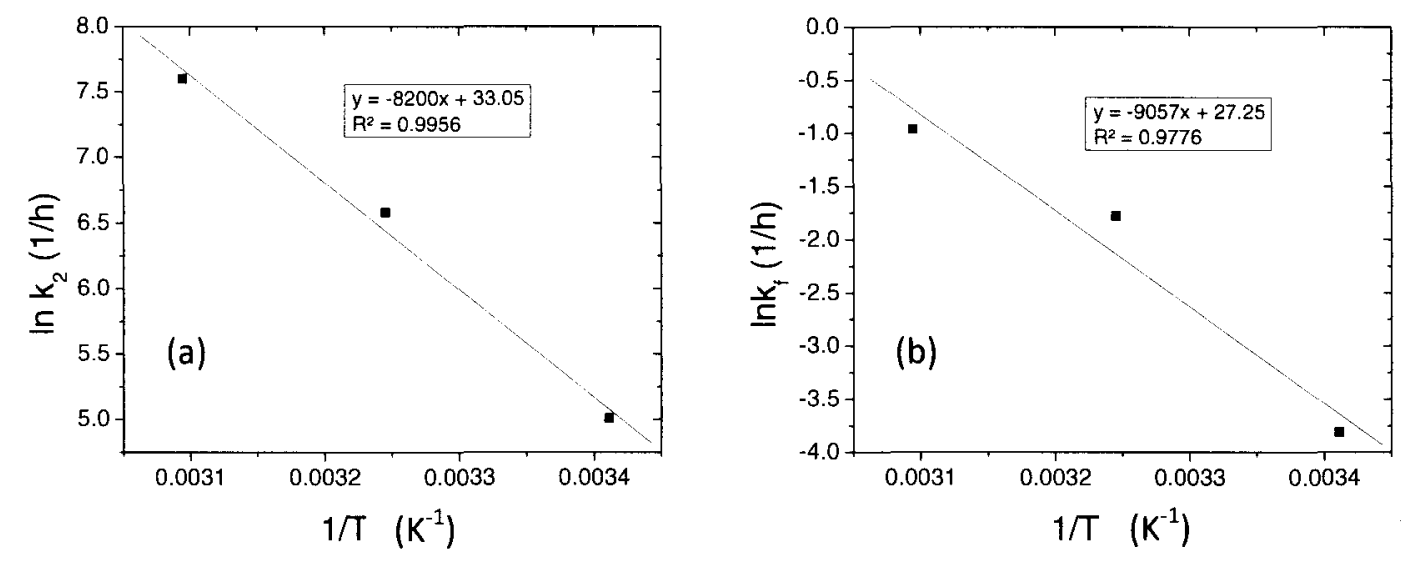

Figure 9.3. Arrhenius Plots for determining activation energies for (a) hydrolysis step and (b) inactivation step.

\subsection{Effect of Reaction Temperature on Cellulose Hydrolysis}

$V_{\text {max app }}$ was about seven times higher at two hours and a temperature of $50{ }^{\circ} \mathrm{C}$ than that at the same time at $20^{\circ} \mathrm{C}$, and two times higher than at $35^{\circ} \mathrm{C}$ (Figure 9.4a). However, $V_{\text {max app }}$ decreased significantly as the reaction proceeded, and the decrease was more significant at higher temperatures. This is consistent with the model predictions in previous section. $V_{\max , a p p}$ approached about the same value for all three temperatures by 24 hours.

The decrease in $V_{\text {max app }}$ implies that there would be little improvement in the hydrolysis rate after 24 hours, which is apparent in Figure 9.4b. After 24 hours of incubation, the hydrolysis rate (slope of the $P$ - $t$ curves) at $50{ }^{\circ} \mathrm{C}$ was similar to that at 35 or $20^{\circ} \mathrm{C}$, while the rate at $50^{\circ} \mathrm{C}$ is greater prior to 24 hours. The same trend was observed for hydrolysis of $0.1 \%(w / v)$ Sigmacell (Figure 9.4c). Increasing the reaction temperature appeared to only be effective in improving the hydrolysis rate during the first few hours. Therefore, it may be possible to lower the temperature after a few hours to reduce (1) inactivation, and (2) the amount of energy required for the cellulose hydrolysis process. 

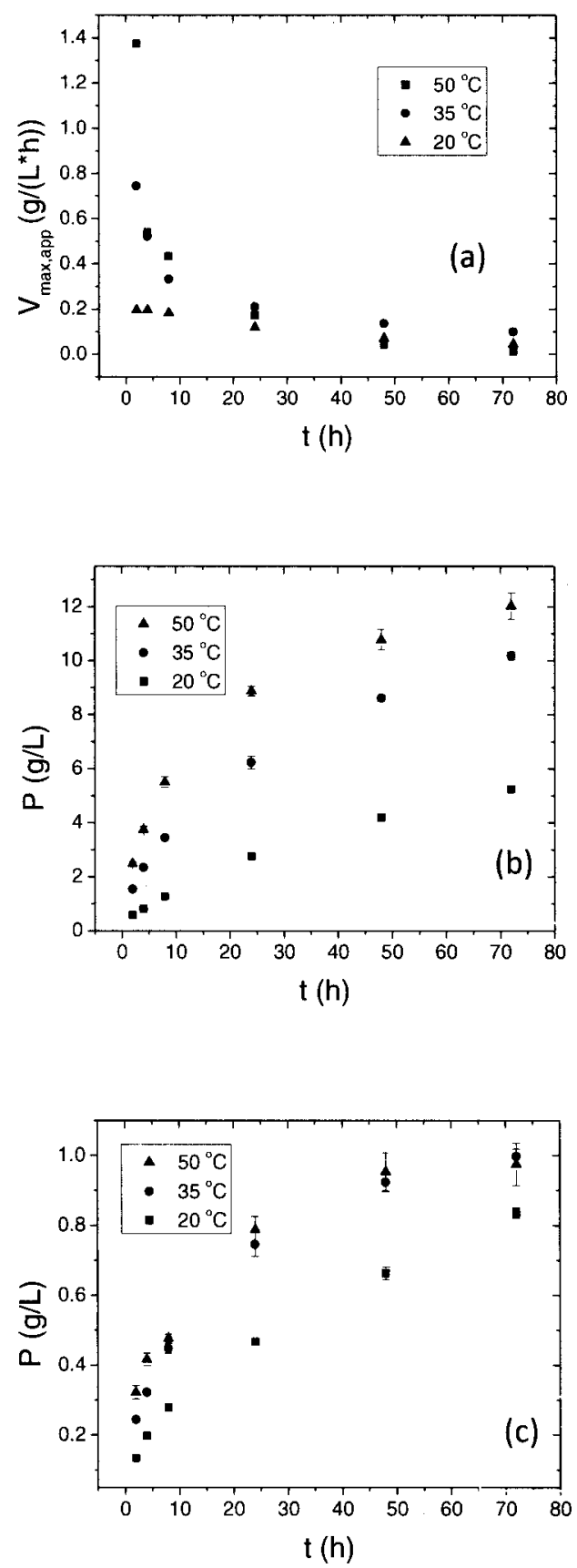

Figure 9.4. (a) $V_{\text {max, app }}$ as a function of incubating time at three different temperatures for Sigmacell; (b) effect of temperature on product formation for Sigmacell substrate with a solid concentration of $2.0 \%(\mathrm{w} / \mathrm{v})$; (c) effect of temperature on product formation for Sigmacell substrate with a solid concentration of $0.1 \%(\mathrm{w} / \mathrm{v})$. 


\subsection{Effect of Incubation Time on Cellulose Hydrolysis}

Hydrolysis was fast initially, but slowed down after about 24 hours (Figure 9.2).

This can be quantified in terms of $V_{\max \text {.upp }}$, which is defined as:

$$
V_{\text {max. app }}=k_{2} \times(E)_{0} \times\left\{\frac{k_{r}}{k_{f}+k_{r}}+\frac{k_{f}}{k_{f}+k_{r}} \times \exp \left[-\left(k_{f}+k_{r}\right) \times t\right]\right\}
$$

which was similar to the definition reported in Chapter V. $V_{\text {max,app }}$ decreased significantly throughout the reaction (Figure 9.4a); the value at 72 hours was only about $20 \%$ or less as compared to at 2 hours for all three temperatures. Since the reaction rate slows while inactivation continues, it is recommended to reduce the hydrolysis reaction time while performing the reaction at higher enzyme loading. Since the half-life of enzymatic activity is about 2.5 hours following interaction with substrate, this strategy should allow fast conversion of substrate before a large amount of enzyme becomes inactive. Igarashi et al. (2011) reported that BMCC can be completely hydrolyzed by $\mathrm{CBH} 1 / \mathrm{CBH} 2$ at high enzyme loading (about 100 times higher than typical enzyme loading) in less than one hour. However, the high enzyme cost (30 to more than 100 US cents per gallon ethanol produced) (Zhu et al., 2009) has limited the application of this strategy in cellulose hydrolysis so far. It may be practical to adopt this strategy when the cost of cellulases is significantly reduced; for comparison, the cost of starch-hydrolyzing enzymes is about 2-5 cents per gallon of starch-derived ethanol produced.

\subsection{Effect of Substrate Surface Area on Cellulose Hydrolysis}

The effect of substrate surface area on cellulose hydrolysis may depend on substrate concentration. When the substrate concentration $(S)$ is much higher than $K_{m}$, the hydrolysis rate equation may be simplified as reported in Chapter V:

$$
V=\frac{k_{2} \times(E)_{0} \times(S)}{K_{m}+(S)} \approx k_{2} \times(E)_{0}
$$


In this case, the hydrolysis rate is the product of the apparent hydrolysis rate constant and the initial enzyme concentration. No term reflecting substrate properties remains in the simplified rate equation, suggesting that the hydrolysis reaction is not affected by accessible surface area.

When the substrate concentration $(S)$ is not much greater than $K_{m}$, hydrolysis is governed by Equation (9.1). The substrate surface area is important since it affects the maximum adsorption capability $\left(A_{\max }\right)$ of the enzyme, which is inversely proportional to $K_{m}$ as defined in Chapter V. Since $K_{m}$ appears in the denominator of Equation (9.1), the substrate surface area is expected to affect the hydrolysis rate.

At a substrate loading of $5 \%(\mathrm{w} / \mathrm{v})$, the substrate concentration is equal to $50 \mathrm{~g} / \mathrm{L}$. At this condition, $(S)$ is much greater than $K_{m}$ for Sigmacell $(6.23 \mathrm{~g} / \mathrm{L})$ and Solka Floc $(16.03 \mathrm{~g} / \mathrm{L})$ as determined in Chapter V. The conversions of Solka Floc and Sigmacell were close in value to each other at each time point (Figure 9.5a), as was the conversion of microcrystalline cellulose, which implies that microcrystalline cellulose may have a relatively small value of $K_{m}$ as well. However, cotton fiber likely has a large value of $K_{m}$ since hydrolysis of cotton fiber shows much lower conversion and it has been reported to have low accessible surface area to enzyme (Grethlein et al., 1984). When hydrolyzed at a solid concentration of $0.1 \%(\mathrm{w} / \mathrm{v})$ (substrate concentration equal to $1 \mathrm{~g} / \mathrm{L}$ which is much less than $\mathrm{K}_{\mathrm{m}}$ ), cotton fiber also showed much lower conversion compared to the other substrates (Figure 9.5b), consistent with the expectation that the surface area will affect the hydrolysis rate.

The surface areas accessible to a molecule the size of an enzyme (51 A) (Grethlein et al., 1984) for different cellulose substrates are listed in Table 9.2. Substrate 
conversions did not increase exactly according to the order of increasing accessible surface area for the low $(S)$ cases. For example, microcrystalline cellulose has smaller accessible surface area (Table 9.2) but its hydrolysis rate was faster compared to Solka Floc. This may be because the binding domain of the major cellulase species CBH1 binds to hydrophobic surfaces of crystalline cellulose, which accounts for only a small portion of the total surface area of natural Cellulose I $\alpha$ (Lehtiö et al., 2003) or I $\beta$ (Mazeau and Rivet, 2008). Therefore, accessible surface area alone may not exactly reflect the capability of substrate to adsorb cellulases. Exposure of hydrophobic surfaces appears to be a more important factor for the affinity of enzyme to bind to substrate (Igarashi et al., 2011a; Liu et al., 2011).

\section{Table 9.2}

$\underline{\text { Accessible surface area for different substrates }}$

\begin{tabular}{lcclc}
\hline Substrate & Sigmacell & Solka Floc & Cellulose, & Cotton fiber \\
& Type-20 & & microcrystalline & \\
& & & & \\
\hline Accessible surface & $0.91-1.1$ & $0.73-0.94$ & $0.46-0.52$ & $0.22-0.29$ \\
area $\left(\mathrm{m}^{2} / \mathrm{g}\right)$ & & & & \\
\hline
\end{tabular}



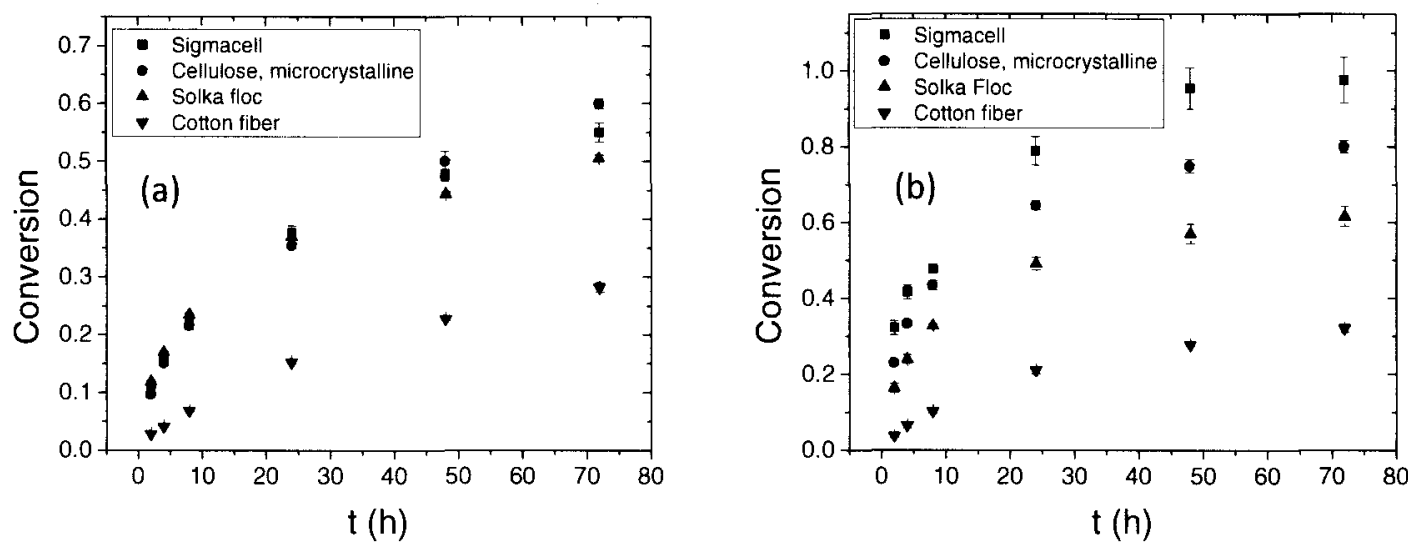

Figure 9.5. Comparison of hydrolysis of different substrates at (a) 5\% solid (w/v); (b) $0.1 \%$ solid (w/v).

Further, as discovered here, the accessible surface area of substrate did not affect hydrolysis when $(S) \gg>K_{m}$. High substrate concentration is desirable during enzymatic hydrolysis in order to maximize the product concentration in the sugar stream, minimize water and energy use, and minimize reactor volume, which all work to enhance the economic viability of the cellulosic fuel process. Therefore, it is then desirable to increase hydrophobic surface area rather than just total surface area. Transforming natural cellulose $\mathrm{I} \alpha$ to Cellulose $\mathrm{III}_{\mathrm{I}}$ using supercritical ammonia pretreatment was found to be a way to increase hydrophobic surface area and therefore increase the hydrolysis rate (Igarashi et al., 2011).

\subsection{Effect of Enzyme Binding Characteristics on Cellulose Hydrolysis}

As reported in Chapter VIII, dissociation of inactive enzyme from substrate may be a limiting step in cellulose hydrolysis. It is important to examine how cellulose hydrolysis may be theoretically improved if desorption of the inactivated cellulase can be improved, thereby freeing up binding sites. 
To simulate hydrolysis results in the absence of inactivated adsorbed cellulase, the inactivation term in Equation (9.1) was omitted:

$$
\frac{d P}{d t}=V_{r}=k_{2} \times(E)_{0} \times \frac{(S)}{K_{m}+(S)}
$$

Predicted $P$ - $t$ curves (Figure 9.6) were generated using Equation (9.4) and parameters from Table 1 for $50{ }^{\circ} \mathrm{C}$. The predicted times required for $99 \%$ conversion of each substrate were 11.8, 11.8, 11.8, 15.9 and 18.2 hours for substrate concentrations of 1 , $2,4,12$, and $20 \mathrm{~g} / \mathrm{L}$, respectively. With inactivation of adsorbed cellulase, however, the actual conversions were only $88 \%, 84 \%, 80 \%, 73 \%$ and $54 \%$ after 72 hours, respectively. The predicted improvement in the hydrolysis rate in the absence of inactivation is significant and more so at higher solids concentrations. Therefore, it would be very beneficial to somehow desorb the unproductive cellulase. Developing such a process would (1) provide more evidence for the proposed mechanisms and (2) improve the overall cellulose hydrolysis process. Woodward et al. (1990b) reported that inactive CBH1 could be desorbed from substrate using $4 \mathrm{M} \mathrm{GdnHCl}$, then recovered after dialyzing out the denaturant, at which point the enzyme became active again. Such a process may be modified and integrated into the cellulose hydrolysis process to improve desorption and hydrolysis. 


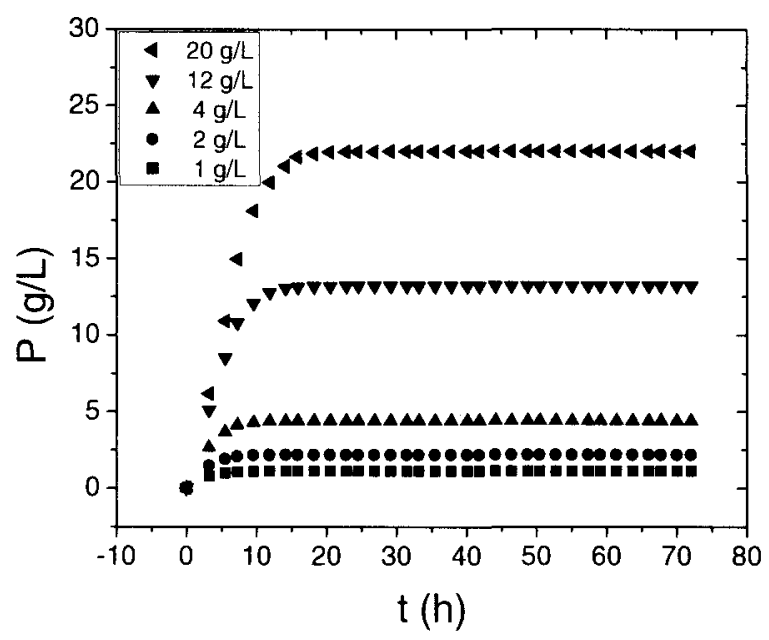

Figure 9.6. Predicted conversion of Sigmacell at $50{ }^{\circ} \mathrm{C}$ in the absence of inactivation of adsorbed enzyme.

\subsection{Summary}

Factors to consider to improve enzymatic hydrolysis of cellulose were discussed here based on a model considering first order inactivation of adsorbed cellulases. Using the model, the activation energy determined for the hydrolytic step $\left(k_{2}\right)$ is $16.3 \mathrm{kcal} \mathrm{mol}^{-1}$, which is in the typical range of 4-20 $\mathrm{kcal} \mathrm{mol}^{-1}$ for an enzymatic reaction. The activation energy for the inactivation step $\left(k_{f}\right)$ is $18.0 \mathrm{kcal} \mathrm{mol}^{-1}$, implying that increasing reaction temperature may also cause a significant increase in the inactivation rate in addition to the catalytic reaction rate. Due to more significant inactivation at higher temperature, increasing reaction temperature appeared to only be effective in improving hydrolysis rate during the first few hours. Therefore, it may be possible to lower the temperature after a few hours to reduce inactivation while also reducing the energy input needed for the cellulose hydrolysis process. 
$V_{\text {max,app }}$ was only $20 \%$ or less at 72 hours compared to at two hours as a result of inactivation of adsorbed cellulases, suggesting prolonged hydrolysis is not an efficient way to improve cellulose hydrolysis. A potential way to avoid long hydrolysis time is to perform the reaction at high enzyme loading.

At high solids loading, the hydrophobic surface area of the substrate may have a bigger affect on the hydrolysis rate than the total accessible surface area of substrate. However, if cellulose hydrolysis is carried out at low substrate loading, it may be beneficial to increase the surface binding area of substrate (by some pretreatment method) in order to improve the hydrolysis rate.

If inactivation of adsorbed cellulase can be prevented, near complete conversion (99\%) of cellulose is predicted to occur within 10 20 hours for initial substrate concentrations of $1 \sim 20 \mathrm{~g} / \mathrm{L}$, which is much higher than typical conversions achieved after 72 hours of incubation when adsorbed cellulases become inactivated. One proposed optimization strategy is to improve desorption of inactive cellulases from the substrate, for example by adding $\mathrm{GdnHCl}$, in order to increase the conversion rate. 


\section{CHAPTER X}

\section{CONCLUSIONS}

The rate of the enzymatic hydrolysis of cellulose reaction decreases significantly as the reaction proceeds, and inactivation of adsorbed enzyme was found to play a key role in affecting the hydrolysis rate.

First, in Chapter IV, some factors traditionally thought to substantially affect cellulose hydrolysis, such as enzyme deactivation due to the reaction environment and variation of substrate properties, were first examined, but it was found that these factors were not sufficient to account for the rate reduction during cellulose hydrolysis.

In Chapter $\mathrm{V}$, a mathematical model incorporating a first order inactivation of adsorbed cellulases was developed that accurately describes cellulose hydrolysis kinetics. The enzyme's apparent maximum rate surprisingly decreased with a first order exponential decay function of time due to inactivation of adsorbed enzyme. The model predicted enzymatic hydrolysis results within $10 \%$ of experimental results for both Solka Floc and Sigmacell substrates. The rate constants were within 5\% for the two substrates, further strengthening the value of the model and implying a common but yet undefined rate-limiting step associated with loss of enzyme activity likely exists in the pathway of cellulose hydrolysis. Activity loss due to some form of enzyme-substrate interaction was further validated since decrease in activity was seen to be a function of increasing initial substrate concentration. The relative extents of activity loss due to enzyme-substrate 
interactions and deactivation from thermal and mechanical mechanisms were compared, and enzyme-substrate interactions were found to contribute more towards the overall deactivation than did thermal and mechanical mechanisms. This was evident from the comparisons of three independent metrics: the relative extents of activity loss, half-lifes of enzyme, and inactivation rate constants.

To obtain a large amount of the purified cellulase component CBH1 needed for mechanistic studies, a technique for scaling-up separation of $\mathrm{CBH} 1$ from the commercial Spezyme CP cellulase cocktail was successfully developed by incorporating a vacuum manifold system and step elution to an ionic chromatography method. The CBH1 separated by this technique exhibited comparable purity and yield to $\mathrm{CBH} 1$ separated on a smaller scale by a conventional FPLC system. Meanwhile, separated CBH1 was identified as a single band on the SDS-PAGE gel, and showed good stability during a 24 hour incubation period at $50{ }^{\circ} \mathrm{C}$. This separation protocol can facilitate research in the investigation of $\mathrm{CBH} 1$ interactions with cellulose by providing large-scale quantities of purified CBH1 for less than 10\% of the cost of a FPLC system. Hydrolysis and inactivation mechanisms were examined on BMCC substrate using AFM imaging. The degradation of BMCC by $\mathrm{CBH} 1$ was fast, confirming good activity of separated $\mathrm{CBH} 1$. Only the height of the BMCC fiber changed during the reaction, indicating that $\mathrm{CBHI}$ tends to bind and hydrolyze cellulose only from certain surfaces. At the meantime, crowding of adsorbed $\mathrm{CBH} 1$ on substrate surface was observed on phase images, which provided supporting evidence for inactivation of adsorbed enzyme proposed in Chapter V.

In Chapter VII, deactivation of individual cellulase components (CBH1 and endoglucanases) due to environmental mechanisms was studied relative to deactivation of 
a total cellulase cocktail. The decrease of total cellulase activity was more closely associated with the decrease of $\mathrm{CBH} 1$ activity than the decrease of endoglucanase activity. Shear stress in an Erlenmeyer flask was determined by computational fluid dynamics and found to be more than two orders smaller than in a stirred tank. The deactivation of individual and total cellulases from thermal and mechanical mechanisms in the Erlenmeyer flask was insufficient to account for the hydrolysis rate reduction. This confirms the slow kinetics may not be a result of just enzyme deactivation due to environmental mechanisms.

If adsorbed enzyme becomes inactive, it would necessarily return to the bulk solution more slowly (if at all) and be unable to find a new binding site to start another hydrolysis cycle immediately. This underlying phenomenon was examined in Chapter VIII. Decreasing desorption of $\mathrm{CBH} 1$ was found when activity was reduced in any of the following four ways: (1) mechanical deactivation, (2) addition of competitive inhibitors, (3) low reaction temperature, or (4) deactivation with a denaturant. These results suggest that when $\mathrm{CBH} 1$ activity was reduced, regardless of the deactivation mechanism, much less enzyme desorbed and returned to solution as compared to active enzyme. This implies that more $\mathrm{CBH} 1$ remains bound to substrate, cannot dissociate and find new binding sites immediately to start another cycle, and therefore becomes inactive. The results here help support the relationship between the slow kinetics and inactivated enzyme predicted by the kinetics model developed in Chapter V.

Factors to consider when developing a cellulose hydrolysis process were discussed in Chapter IX. Increasing reaction temperature was found to cause a significant increase in the inactivation rate in addition to the catalytic reaction rate. Due to the 
inactivation dependence on temperature, increasing the reaction temperature appeared to only be effective in improving the hydrolysis rate during the first few hours. Therefore, it may be possible to lower the temperature after a few hours to reduce inactivation while also reducing the energy input needed for the cellulose hydrolysis process. Prolonged hydrolysis time is not an efficient way to improve cellulose conversion due to inactivation of adsorbed enzyme. A potential way to avoid long hydrolysis time is to perform the reaction at high enzyme loading, provided the cost of enzymes is eventually reduced.

At high solids loading, the hydrophobic surface area of the substrate may have a bigger affect on the hydrolysis rate than the total accessible surface area of substrate. However, if cellulose hydrolysis is carried out at low substrate loading, it may be beneficial to increase the surface binding area of substrate (by some pretreatment method) in order to improve the hydrolysis rate.

If inactivation of adsorbed cellulase can be prevented, near complete conversion (99\%) of cellulose is predicted to occur within 10 20 hours for initial substrate concentrations of $1 \sim 20 \mathrm{~g} / \mathrm{L}$, which is much higher than typical conversions achieved after 72 hours of incubation when adsorbed cellulases become inactivated. One proposed optimization strategy is to improve desorption of inactive cellulases from the substrate, for example by adding $\mathrm{GdnHCl}$, in order to increase the conversion rate. 


\section{CHAPTER XI}

\section{RECOMMENDATIONS FOR FUTURE STUDY}

\section{Experiment 1: Determine Optimal Operating Temperature Curve for Enzymatic}

\section{Hydrolysis}

In Chapter IX, it was proposed that it may be possible to lower the temperature after a few hours to reduce (1) inactivation, and (2) the amount of energy required for the cellulose hydrolysis process. The experimental plan to determine an optimal operating temperature curve is given here.

1. Hydrolysis of cellulose can be carried out for substrate in concentrations of 1$20 \mathrm{~g} / \mathrm{L}$ as in Chapter $\mathrm{V}$, at reaction temperatures of $50,45,40,35,30,25,20$, and $15^{\circ} \mathrm{C}$.

2. The $V_{\text {max,app }}$ at different time points can be determined using the modeling procedure described in Chapter $\mathrm{V}$ for the reaction temperatures listed in Step 1. Product sampling should be more frequent initially during hydrolysis since $V_{\text {max }, \text { app }}$ decreased with an exponential decay function as reported in Chapter V. For example, sampling for glucose release measurements can be every 20 minutes in the first two hours, and then the frequency can be reduced to every half or one hour from two to eight hours, and then further reduced to every two to eight hours after the first eight hours of incubation. 
3. Determine the time point at which $V_{\max , a p p}$ at a higher temperature is just equal to or less than the $V_{\max , a p p}$ at a lower temperature. Repeat this for several time points throughout the reaction. From this a curve can be generated showing optimal temperature versus time.

4. Run two reactions simultaneously. In (1), adjust the temperature periodically according to the curve generated in Step 3. In (2), run at a constant $50^{\circ} \mathrm{C}$ (typical hydrolysis temperature) as a control to compare results for this temperature optimization strategy.

\section{Experiment 2: Determine Efficiency of Cellulose Processing at High Enzyme}

\section{Loading}

As determined in Chapter $\mathrm{V}, V_{\text {max app }}$ decreased exponentially with a half life of only 2.5 hours. It is desirable to achieve high conversion of substrate before a large amount of enzyme becomes inactive. A strategy proposed here is to perform enzymatic hydrolysis at an enzyme loading based on an efficiency incorporating conversion and reaction time. Following is an experimental plan to investigate how much improvement in hydrolysis can be achieved at high enzyme loading.

1. Hydrolysis of cellulose should be carried out for substrate in concentrations of $1-20 \mathrm{~g} / \mathrm{L}$ at a reaction temperature of $50{ }^{\circ} \mathrm{C}$ (as in Chapter $\mathrm{V}$ ) using enzyme loadings of $15,30,75,150,300$ and $1500 \mathrm{FPU} / \mathrm{g}$ cellulose substrate (15 FPU/g is typical).

2. Determine the conversion after an incubation time of 24 hours for an enzyme loading of 15 FPU/g as a baseline. This is the approximately amount of time 
it took for $\mathrm{V}_{m a x, a p p}$ to drop from its maximum to its minimum value (see Figure 5.4).

3. Determine the times required to achieve the same conversion as in Step 2 for the other enzyme loadings. Calculate the "hydrolysis efficiency" for each enzyme loading, which is the conversion divided by the reaction time to achieve that conversion for each enzyme loading.

4. Plot hydrolysis efficiency against enzyme loading. If the slope is larger than 1 , this suggests that the increase in hydrolysis rate is high relative to the increase in enzyme loading, which supports the hypothesis that increasing the enzyme loading can avoid loss of activity associated with long hydrolysis time.

\section{Experiment 3. Investigating the Effect of Improved Enzyme Desorption on Cellulose}

\section{Hydrolysis}

As proposed in Chapter IX, improved enzyme desorption may increase the overall enzymatic hydrolysis efficiency. To test this hypothesis, the following experiment is proposed.

1. Hydrolysis of cellulose should be carried out for substrate concentrations of 1$20 \mathrm{~g} / \mathrm{L}$ at $50^{\circ} \mathrm{C}$ as in Chapter $\mathrm{V}$.

2. Every 2.5 hours, when half of the active enzyme becomes inactive (half life is 2.5 hour), add $4 \mathrm{M} \mathrm{GdnHCl}$ to the reaction to desorb enzyme. After desorption for 10 minutes, centrifuge samples to remove supernatant.

3. The supernatant will then be dialyzed in $20 \mathrm{mM}$ citrate buffer $(\mathrm{pH} 4.8)$ to recover and reactivate the enzyme. 
4. After dialyzing, apply the active enzyme back to the sample to resume the reaction.

5. Compare glucose released to a control experiment run without desorption of enzyme to examine the effect of increasing desorption on cellulose hydrolysis. 


\section{REFERENCES}

Baker, A.A., Helbert, W., Sugiyama, J., Miles, M.J., 1998. Surface structure of native cellulose microcrystals by AFM. Appl Phys a-Mater 66, 559-563.

Bansal, P., Hall, M., Realff, M.J., Lee, J.H., Bommarius, A.S., 2009. Modeling cellulase kinetics on lignocellulosic substrates. Biotechnol Adv 27, 833-48.

Berson, R.E., Purcell, M.R., Sharp, M.K., 2008. Computationally Determined Shear on Cells Grown in Orbiting Culture Dishes, in: Kang, K.A., Harrison, D.K., Bruley, D.F. (Eds.), Oxygen Transport to Tissue XXIX. Springer US, pp. 189-198.

Bertoldo, C., Antranikian, G., 2002. Starch-hydrolyzing enzymes from thermophilic archaea and bacteria. Curr. Opin. Chem. Biol. 6, 151-60.

Betrabet, S.M., Paralikar, K.M., 1977. Effect of cellulase on the morphology and fine structure of cellulosic substrates. Part 1. Wheat straw pulp Cellul. Chem. Technol. $11,615-625$.

Bothwell, M.K., Wilson, D.B., Irwin, D.C., Walker, L.P., 1997. Binding reversibility and surface exchange of Thermomonospora fusca E-3 and E-5 and Trichoderma reesei CBHI. Enzyme Microb. Technol. 20, 411-417.

Brethauer, S., Studer, M.H., Yang, B., Wyman, C.E., 2011. The effect of bovine serum albumin on batch and continuous enzymatic cellulose hydrolysis mixed by stirring or shaking. Bioresour. Technol. 102, 6295-6298.

Carrard, G., Linder, M., 1999. Widely different off rates of two closely related cellulosebinding domains from Trichoderma reesei. European journal of biochemistry / FEBS 262, 637-43.

Choi, I.G., Lee, J.W., Gwak, K.S., Park, J.Y., Park, M.J., Choi, D.H., Kwon, M., 2007. Biological pretreatment of softwood Pinus densiflora by three white rot fungi. $\mathrm{J}$ Microbiol 45, 485-491.

Converse, A.O., Matsuno, R., Tanaka, M., Taniguchi, M., 1988. A Model of Enzyme Adsorption and Hydrolysis of Microcrystalline Cellulose with Slow Deactivation of the Adsorbed Enzyme. Biotechnol. Bioeng. 32, 38-45. 
Crampton, N., Bonass, W.A., Kirkham, J., Thomson, N.H., 2005. Formation of aminosilane-functionalized mica for atomic force microscopy imaging of DNA. Langmuir 21, 7884-7891.

Dasari, R.K., Berson, R.E., 2007. The effect of particle size on hydrolysis reaction rates and rheological properties in cellulosic slurries. Appl. Biochem. Biotechnol. 137, 289-299.

Dasari, R.K., Dunaway, K., Berson, R.E., 2009. A Scraped Surface Bioreactor for Enzymatic Saccharification of Pretreated Corn Stover Slurries. Energy Fuels 23, 492-497.

Den Haan, R., Mcbride, J.E., La Grange, D.C., Lynd, L.R., Van Zyl, W.H., 2007. Functional expression of cellobiohydrolases in Saccharomyces cerevisiae towards one-step conversion of cellulose to ethanol. Enzyme Microb. Technol. 40, 12911299.

Desai, S.G., Converse, A.O., 1997. Substrate reactivity as a function of the extent of reaction in the enzymatic hydrolysis of lignocellulose. Biotechnol. Bioeng. 56, 650-655.

Divne, C., Stahlberg, J., Reinikainen, T., Ruohonen, L., Pettersson, G., Knowles, J.K., Teeri, T.T., Jones, T.A., 1994. The three-dimensional crystal structure of the catalytic core of cellobiohydrolase I from Trichoderma reesei. Science 265, 5248.

Du, F.Y., Wolger, E., Wallace, L., Liu, A., Kaper, T., Kelemen, B., 2010. Determination of Product Inhibition of $\mathrm{CBH} 1, \mathrm{CBH} 2$, and EG1 Using a Novel Cellulase Activity Assay. Appl. Biochem. Biotechnol. 161, 313-317.

Dunaway, K.W., Dasari, R.K., Bennett, N.G., Berson, R.E., 2010. Characterization of changes in viscosity and insoluble solids content during enzymatic saccharification of pretreated corn stover slurries. Bioresour. Technol. 101, 35753582 .

Eriksson, T., Borjesson, J., Tjerneld, F., 2002. Mechanism of surfactant effect in enzymatic hydrolysis of lignocellulose. Enzyme Microb. Technol. 31, 353-364.

Fan, L.T., Lee, Y.H., 1983. Kinetic studies of enzymatic hydrolysis of insoluble cellulose: Derivation of a mechanistic kinetic model. Biotechnol. Bioeng. 25, 2707-33.

Ferreira, S., Duarte, A.P., Ribeiro, M.H.L., Queiroz, J.A., Domingues, F.C., 2009. Response surface optimization of enzymatic hydrolysis of Cistus ladanifer and Cytisus striatus for bioethanol production. Biochem. Eng. J. 45, 192-200.

Fersht, A., 1999. Structure and mechanism in protein science: a guide to enzyme catalysis and protein folding. W.H. Freeman, New York. 
Gan, Q., Allen, S.J., Taylor, G., 2003. Kinetic dynamics in heterogeneous enzymatic hydrolysis of cellulose: an overview, an experimental study and mathematical modelling. Process Biochem. (Amsterdam, Neth.) 38, 1003-1018.

Ganesh, K., Joshi, J.B., Sawant, S.B., 2000. Cellulase deactivation in a stirred reactor. Biochem. Eng. J. 4, 137-141.

Ghadge, R.S., Ekambara, K., Joshi, J.B., 2005a. Role of hydrodynamic flow parameters in lipase deactivation in bubble column reactor. Chem. Eng. Sci. 60, 6320-6335.

Ghadge, R.S., Patwardhan, A.W., Sawant, S.B., Joshi, J.B., 2005b. Effect of flow pattern on cellulase deactivation in stirred tank bioreactors. Chem. Eng. Sci. 60, 10671083.

Godbole, S., Decker, S.R., Nieves, R.A., Adney, W.S., Vinzant, T.B., Baker, J.O., Thomas, S.R., Himmel, M.E., 1999. Cloning and expression of Trichoderma reesei cellobiohydrolase I in Pichia pastoris. Biotechnol. Prog. 15, 828-833.

Grethlein, H.E., Allen, D.C., Converse, A.O., 1984. A comparative study of the enzymatic hydrolysis of acid-pretreated white pine and mixed hardwood. Biotechnol. Bioeng. 26, 1498-505.

Gunjikar, T.P., Sawant, S.B., Joshi, J.B., 2001a. Shear deactivation of cellulase, exoglucanase, endoglucanase, and beta-glucosidase in a mechanically agitated reactor. Biotechnol. Prog. 17, 1166-1168.

Gusakov, A.V., Sinitsyn, A.P., 1992. A theoretical analysis of cellulase product inhibition: effect of cellulase binding constant, enzyme/substrate ratio, and betaglucosidase activity on the inhibition pattern. Biotechnol. Bioeng. 40, 663-71.

Hatfield, K., 2010. Enzyme-substrate interaction significantly affects activity loss during enzymatic hydrolysis of cellulose. M.Eng. dissertation, University of Louisville, United States.

Henriksson, H., Stahlberg, J., Isaksson, R., Pettersson, G., 1996. The active sites of cellulases are involved in chiral recognition: A comparison of cellobiohydrolase 1 and endoglucanase 1. FEBS Lett. 390, 339-344.

Hong, J., Ye, X., Zhang, Y.H., 2007. Quantitative determination of cellulose accessibility to cellulase based on adsorption of a nonhydrolytic fusion protein containing CBM and GFP with its applications. Langmuir : the ACS journal of surfaces and colloids 23, 12535-40.

Howell, J.A., Mangat, M., 1978. Enzyme Deactivation during Cellulose Hydrolysis. Biotechnol. Bioeng. 20, 847-863.

Howell, J.A., Stuck, J.D., 1975. Kinetics of Solka Floc Cellulose Hydrolysis by Trichoderma-Viride Cellulase. Biotechnol. Bioeng. 17, 873-893. 
Igarashi, K., Koivula, A., Wada, M., Kimura, S., Penttila, M., Samejima, M., 2009. High speed atomic force microscopy visualizes processive movement of Trichoderma reesei cellobiohydrolase I on crystalline cellulose. The Journal of biological chemistry 284, 36186-90.

Igarashi, K., Uchihashi, T., Koivula, A., Wada, M., Kimura, S., Okamoto, T., Penttilä, M., Ando, T., Samejima, M., 2011b. Traffic Jams Reduce Hydrolytic Efficiency of Cellulase on Cellulose Surface. Science 333, 1279-1282.

Imai, T., Boisset, C., Samejima, M., Igarashi, K., Sugiyama, J., 1998. Unidirectional processive action of cellobiohydrolase Cel7A on Valonia cellulose microcrystals. FEBS Lett. 432, 113-116.

Irwin, D.C., Spezio, M., Walker, L.P., Wilson, D.B., 1993. Activity Studies of 8 Purified Cellulases - Specificity, Synergism, and Binding Domain Effects. Biotechnol. Bioeng. 42, 1002-1013.

Jalak, J., Valjamae, P., 2010. Mechanism of Initial Rapid Rate Retardation in Cellobiohydrolase Catalyzed Cellulose Hydrolysis. Biotechnol. Bioeng. 106, 871883.

Jervis, E.J., Guarna, M.M., Doheny, J.G., Haynes, C.A., Kilburn, D.G., 2005. Dynamic localization and persistent stimulation of factor-dependent cells by a stem cell factor/cellulose binding domain fusion protein. Biotechnol. Bioeng. 91, 314-324.

Jung, H., Wilson, D.B., Walker, L.P., 2003. Binding and reversibility of Thermobifida fusca Cel5A, Cel6B, and Cel48A and their respective catalytic domains to bacterial microcrystalline cellulose. Biotechnol. Bioeng. 84, 151-9.

Kabel, M.A., van der Maarel, M.J., Klip, G., Voragen, A.G., Schols, H.A., 2006. Standard assays do not predict the efficiency of commercial cellulase preparations towards plant materials. Biotechnol. Bioeng. 93, 56-63.

Kim, M.H., Lee, S.B., Ryu, D.D.Y., Reese, E.T., 1982. Surface deactivation of cellulase and its prevention. Enzyme Microb. Technol. 4, 99-103.

Kim, Y., Ximenes, E., Mosier, N.S., Ladisch, M.R., 2011. Soluble inhibitors/deactivators of cellulase enzymes from lignocellulosic biomass. Enzyme Microb. Technol. 48, $408-415$

Kipper, K., Valjamae, P., Johansson, G., 2005. Processive action of cellobiohydrolase Cel7A from Trichoderma reesei is revealed as 'burst' kinetics on fluorescent polymeric model substrates. Biochem. J. 385, 527-535.

Klyosov, A.A., 1988. Cellulases of the third generation, in: Aubert, J.P., Beguin, P., Millet, J. (Eds.), Biochemistry and genetics of cellulose degradation. Academic Press, London, pp. 87-99. 
Koivula, A., Kinnari, T., Harjunpaa, V., Ruohonen, L., Teleman, A., Drakenberg, T., Rouvinen, J., Jones, T.A., Teeri, T.T., 1998. Tryptophan 272: an essential determinant of crystalline cellulose degradation by Trichoderma reesei cellobiohydrolase Cel6A. FEBS Lett. 429, 341-6.

Kotchoni, S.O., Gachomo, E.W., Omafuvbe, B.O., Shonukan, O.O., 2006. Purification and biochemical characterization of carboxymethyl cellulase (CMCase) from a catabolite repression insensitive mutant of Bacillus pumilus. Int J Agr Biol 8, 286292.

Kremer, S.M., Wood, P.M., 1992. Continuous Monitoring of Cellulase Action on Microcrystalline Cellulose. Appl. Microbiol. Biotechnol. 37, 750-755.

Kumar, R., Wyman, C.E., 2008. An improved method to directly estimate cellulase adsorption on biomass solids. Enzyme Microb. Technol. 42, 426-433.

Kyriacou, A., Neufeld, R.J., Mackenzie, C.R., 1988. Effect of Physical Parameters on the Adsorption Characteristics of Fractionated Trichoderma-Reesei Cellulase Components. Enzyme Microb. Technol. 10, 675-681.

Kyriacou, A., Neufeld, R.J., Mackenzie, C.R., 1989. Reversibility and Competition in the Adsorption of Trichoderma-Reesei Cellulase Components. Biotechnol. Bioeng. $33,631-637$.

Lee, I., Evans, B.R., Woodward, J., 2000. The mechanism of cellulase action on cotton fibers: evidence from atomic force microscopy. Ultramicroscopy 82, 213-221.

Lee, Y.H., Fan, L.T., 1982. Kinetic studies of enzymatic hydrolysis of insoluble cellulose: analysis of the initial rates. Biotechnol. Bioeng. 24, 2383-406.

Lehtiö, J., Sugiyama, J., Gustavsson, M., Fransson, L., Linder, M., Teeri, T.T., 2003. The binding specificity and affinity determinants of family 1 and family 3 cellulose binding modules. Proc. Natl. Acad. Sci. U. S. A. 100, 484-489.

Lemos, M.A., Teixeira, J.A., Domingues, M.R.M., Mota, M., Gama, F.M., 2003. The enhancement of the cellulolytic activity of cellobiohydrolase I and endoglucanase by the addition of cellulose binding domains derived from Trichoderma reesei. Enzyme Microb. Technol. 32, 35-40.

Lenz, J., Esterbauer, H., Sattler, W., Schurz, J., Wrentschur, E., 1990. Changes of Structure and Morphology of Regenerated Cellulose Caused by Acid and Enzymatic-Hydrolysis. J. Appl. Polym. Sci. 41, 1315-1326.

Levine, S.E., Fox, J.M., Blanch, H.W., Clark, D.S., 2010. A mechanistic model of the enzymatic hydrolysis of cellulose. Biotechnol. Bioeng. 107, 37-51. 
Linder, M., Salovuori, I., Ruohonen, L., Teeri, T.T., 1996. Characterization of a double cellulose-binding domain. Synergistic high affinity binding to crystalline cellulose. The Journal of biological chemistry $271,21268-72$.

Linder, M., Teeri, T.T., 1996. The cellulose-binding domain of the major cellobiohydrolase of Trichoderma reesei exhibits true reversibility and a high exchange rate on crystalline cellulose. Proc. Natl. Acad. Sci. U. S. A. 93, 122515.

Liu, Y.S., Baker, J.O., Zeng, Y.N., Himmel, M.E., Haas, T., Ding, S.Y., 2011. Cellobiohydrolase Hydrolyzes Crystalline Cellulose on Hydrophobic Faces. J. Biol. Chem. 286, 11195-11201.

Lynd, L.R., Weimer, P.J., van Zyl, W.H., Pretorius, I.S., 2002. Microbial cellulose utilization: Fundamentals and biotechnology (vol 66, pg 506, 2002). Microbiol Mol Biol R 66, 739-739.

Ma, A.Z., Hu, Q., Qu, Y.B., Bai, Z.H., Liu, W.F., Zhuang, G.Q., 2008. The enzymatic hydrolysis rate of cellulose decreases with irreversible adsorption of cellobiohydrolase I. Enzyme Microb Tech 42, 543-547.

Mansfield, S.D., Mooney, C., Saddler, J.N., 1999. Substrate and enzyme characteristics that limit cellulose hydrolysis. Biotechnol. Prog. 15, 804-816.

Master, E.R., Rudsander, U.J., Zhou, W., Henriksson, H., Divne, C., Denman, S., Wilson, D.B., Teeri, T.T., 2004. Recombinant Expression and Enzymatic Characterization of PttCel9A, a KOR Homologue from Populus tremula $\mathrm{x}$ tremuloides. Biochemistry 43, 10080-10089.

Mazeau, K., Rivet, A., 2008. Wetting the (110) and (100) Surfaces of I $\beta$ Cellulose Studied by Molecular Dynamics. Biomacromolecules 9, 1352-1354.

Medve, J., Stahlberg, J., Tjerneld, F., 1997. Isotherms for adsorption of cellobiohydrolase I and II from Trichoderma reesei on microcrystalline cellulose. Appl. Biochem. Biotechnol. 66, 39-56.

Medve, J., Karlsson, J., Lee, D., Tjerneld, F., 1998a. Hydrolysis of microcrystalline cellulose by cellobiohydrolase I and endoglucanase II from Trichoderma reesei: Adsorption, sugar production pattern, and synergism of the enzymes. Biotechnol. Bioeng. 59, 621-634.

Medve, J., Lee, D., Tjerneld, F., 1998b. Ion-exchange chromatographic purification and quantitative analysis of Trichoderma reesei cellulases cellobiohydrolase I, II and endoglucanase II by fast protein liquid chromatography. J Chromatogr A 808, 153-165. 
Mizunoya, W., Wakamatsu, J.I., Tatsumi, R., Ikeuchi, Y., 2008. Protocol for highresolution separation of rodent myosin heavy chain isoforms in a mini-gel electrophoresis system. Anal. Biochem. 377, 111-113.

Mosier, N.S., Hall, P., Ladisch, C.M., Ladisch, M.R., 1999. Reaction kinetics, molecular action, and mechanisms of cellulolytic proteins. Adv Biochem Eng Biotechnol 65, $23-40$.

Nidetzky, B., Steiner, W., 1993. A New Approach for Modeling Cellulase Cellulose Adsorption and the Kinetics of the Enzymatic-Hydrolysis of Microcrystalline Cellulose. Biotechnol. Bioeng. 42, 469-479.

Nidetzky, B., Steiner, W., Claeyssens, M., 1994. Cellulose Hydrolysis by the Cellulases from Trichoderma-Reesei - Adsorptions of 2 Cellobiohydrolases, 2 Endocellulases and Their Core Proteins on Filter-Paper and Their Relation to Hydrolysis. Biochem J 303, 817-823.

Ohmine, K., Ooshima, H., Harano, Y., 1983. Kinetic-Study on Enzymatic-Hydrolysis of Cellulose by Cellulase from Trichoderma-Viride. Biotechnol. Bioeng. 25, 20412053.

Ooshima, H., Kurakake, M., Kato, J., Harano, Y., 1991. Enzymatic-Activity of Cellulase Adsorbed on Cellulose and Its Change during Hydrolysis. Appl. Biochem. Biotechnol. 31, 253-266.

Ooshima, H., Sakata, M., Harano, Y., 1983. Adsorption of Cellulase from TrichodermaViride on Cellulose. Biotechnol. Bioeng. 25, 3103-3114.

Philippidis, G., Spindler, D., Wyman, C., 1992. Mathematical modeling of cellulose conversion to ethanol by the simultaneous saccharification and fermentation process. Appl. Biochem. Biotechnol. 34-35, 543-556.

Puls, J., Wood, T.M., 1991. The Degradation Pattern of Cellulose by Extracellular Cellulases of Aerobic and Anaerobic Microorganisms. Bioresour. Technol. 36, 15-19.

Qi, B., Chen, X., Shen, F., Su, Y., Wan, Y., 2009. Optimization of Enzymatic Hydrolysis of Wheat Straw Pretreated by Alkaline Peroxide Using Response Surface Methodology. Ind. Eng. Chem. Res. 48, 7346-7353.

Reese, E.T., Mandels, M., 1980. Stability of the cellulase of Trichoderma reesei under use conditions. Biotechnol. Bioeng. 22, 323-35.

Reinikainen, T., Ruohonen, L., Nevanen, T., Laaksonen, L., Kraulis, P., Jones, T.A., Knowles, J.K.C., Teeri, T.T., 1992. Investigation of the Function of Mutated Cellulose-Binding Domains of Trichoderma-Reesei Cellobiohydrolase-I. Proteins Struct, Funct, Genet 14, 475-482. 
Rezania, S., Ye, Z., Berson, R., 2009. Enzymatic Saccharification and Viscosity of Sawdust Slurries Following Ultrasonic Particle Size Reduction. Appl. Biochem. Biotechnol. 153, 103-115.

Schurz, J., Honel, A., 1989. Enzymatic-Hydrolysis of Regenerated Pulp with Cellulase from Trichoderma-Reesei. Cellul. Chem. Technol. 23, 465-476.

Shen, J., Agblevor, F.A., 2008. Kinetics of Enzymatic Hydrolysis of Steam-exploded Cotton Gin Waste. Chem. Eng. Commun. 195, 1107-1121.

Shigapov, A.N., Graham, G.W., McCabe, R.W., Plummer Jr, H.K., 2001. The preparation of high-surface area, thermally-stable, metal-oxide catalysts and supports by a cellulose templating approach. Applied Catalysis A: General 210, 287-300.

Shuler, M.L., Kargi, F., 1992. Bioprocess Engineering: Basic Concepts. Prentice-Hall, Englewood Cliffs, NJ, USA.

Srisodsuk, M., Reinikainen, T., Penttila, M., Teeri, T.T., 1993. Role of the Interdomain Linker Peptide of Trichoderma-Reesei Cellobiohydrolase-I in Its Interaction with Crystalline Cellulose. J. Biol. Chem. 268, 20756-20761.

Stahlberg, J., Johansson, G., Pettersson, G., 1993. Trichoderma-Reesei Has No True ExoCellulase - All Intact and Truncated Cellulases Produce New Reducing End Groups on Cellulose. Biochim. Biophys. Acta 1157, 107-113.

Stone J, E., Scallan A, M., Donefer, E., Ahlgren, E., 1969. Digestibility as a Simple Function of a Molecule of Similar Size to a Cellulase Enzyme, in, Cellulases and Their Applications. AMERICAN CHEMICAL SOCIETY, pp. 219-241.

Takashima, S., Iikura, H., Nakamura, A., Hidaka, M., Masaki, H., Uozumi, T., 1998. Overproduction of recombinant Trichoderma reesei cellulases by Aspergillus oryzae and their enzymatic properties. J. Biotechnol. 65, 163-171.

Takashima, S., Nakamura, A., Hidaka, M., Masaki, H., Uozumi, T., 1996. Cloning, sequencing, and expression of the cellulase genes of Humicola grisea var thermoidea. J. Biotechnol. 50, 137-147.

Thomas, J.M.D., Chakraborty, A., Sharp, M.K., Berson, R.E., 2011. Spatial and temporal resolution of shear in an orbiting petri dish. Biotechnol. Prog. 27, 460-465.

Tolan, J., Foody, B., 1999. Cellulase from Submerged Fermentation, in: Tsao, G., Brainard, A., Bungay, H., Cao, N., Cen, P., Chen, Z., Du, J., Foody, B., Gong, C., Hall, P., Ho, N., Irwin, D., Iyer, P., Jeffries, T., Ladisch, C., Ladisch, M., Lee, Y., Mosier, N., Mühlemann, H., Sedlak, M., Shi, N., Tolan, J., Torget, R., Wilson, D., Xia, L. (Eds.), Recent Progress in Bioconversion of Lignocellulosics. SpringerHeidelberg, Berlin, pp. 41-67. 
Tormo, J., Lamed, R., Chirino, A.J., Morag, E., Bayer, E.A., Shoham, Y., Steitz, T.A., 1996. Crystal structure of a bacterial family-III cellulose-binding domain: A general mechanism for attachment to cellulose. EMBO J. 15, 5739-5751.

Tu, M.B., Chandra, R.P., Saddler, J.N., 2007. Evaluating the distribution of cellulases and the recycling of free cellulases during the hydrolysis of lignocellulosic substrates. Biotechnol. Prog. 23, 398-406.

Valjamae, P., Sild, V., Pettersson, G., Johansson, G., 1998. The initial kinetics of hydrolysis by cellobiohydrolases I and II is consistent with a cellulose surface erosion model. Eur. J. Biochem. 253, 469-475.

von Ossowski, I., Ståhlberg, J., Koivula, A., Piens, K., Becker, D., Boer, H., Harle, R., Harris, M., Divne, C., Mahdi, S., Zhao, Y., Driguez, H., Claeyssens, M., Sinnott, M.L., Teeri, T.T., 2003. Engineering the Exo-loop of Trichoderma reesei Cellobiohydrolase, Cel7A. A comparison with Phanerochaete chrysosporium Cel7D. J. Mol. Biol. 333, 817-829.

Wada, M., Heux, L., Sugiyama, J., 2004. Polymorphism of cellulose I family: reinvestigation of cellulose IVI. Biomacromolecules 5, 1385-91.

Walker, L.P., Wilson, D.B., Irwin, D.C., Mcquire, C., Price, M., 1992. Fragmentation of Cellulose by the Major Thermomonospora-Fusca Cellulases, Trichoderma-Reesei Cbhi, and Their Mixtures. Biotechnol. Bioeng. 40, 1019-1026.

Weimer, P.J., Weston, W.M., 1985. Relationship between the Fine-Structure of Native Cellulose and Cellulose Degradability by the Cellulase Complexes of Trichoderma-Reesei and Clostridium-Thermocellum. Biotechnol. Bioeng. 27, 1540-1547.

Woodward, J., Carmichael, J.S., Capps, K.M., Herrmann, P.C., Lee, N.E., 1990a. The competitive inhibition of Trichoderma reesei C30 cellobiohydrolase I by guanidine hydrochloride. FEBS Lett. 270, 143-146.

Woodward, J., Lee, N.E., Carmichael, J.S., McNair, S.L., Wichert, J.M., 1990b. Comparison of the hydrolytic activity and fluorescence of native, guanidine hydrochloride-treated and renatured cellobiohydrolase I from Trichoderma reesei. Biochim. Biophys. Acta 1037, 81-5.

Xu, F., Ding, H.S., 2007. A new kinetic model for heterogeneous (or spatially confined) enzymatic catalysis: Contributions from the fractal and jamming (overcrowding) effects. Appl Catal a-Gen 317, 70-81.

Yang, B., Willies, D.M., Wyman, C.E., 2006. Changes in the enzymatic hydrolysis rate of avicel cellulose with conversion. Biotechnol. Bioeng. 94, 1122-1128. 
Ye, Z., Lane, A.N., Willing, G.A., Berson, R.E., 2011. Scaled-up separation of cellobiohydrolase 1 from a cellulase mixture by ion-exchange chromatography. Biotechnol. Prog. 27, 1644-1652.

Zhang, S., Wolfgang, D.E., Wilson, D.B., 1999. Substrate heterogeneity causes the nonlinear kinetics of insoluble cellulose hydrolysis. Biotechnol. Bioeng. 66, 3541 .

Zhang, Y., Xu, J.L., Xu, H.J., Yuan, Z.H., Guo, Y., 2010. Cellulase deactivation based kinetic modeling of enzymatic hydrolysis of steam-exploded wheat straw. Bioresour. Technol. 101, 8261-8266.

Zhang, Y.H.P., Lynd, L.R., 2004. Toward an aggregated understanding of enzymatic hydrolysis of cellulose: Noncomplexed cellulase systems. Biotechnol. Bioeng. 88 , 797-824.

Zhu, Z., Sathitsuksanoh, N., Percival Zhang, Y.H., 2009. Direct quantitative determination of adsorbed cellulase on lignocellulosic biomass with its application to study cellulase desorption for potential recycling. Analyst 134 . 


\section{CURRICULUM VITAE}

NAME:

ZHUOLIANG YE

ADDRESS:

Department of Chemical Engineering

University of Louisville

Louisville, KY 40292

EDUCATION:

B.E., Chemical Engineering

Fuzhou University, Fuzhou, China

2002-2006

Ph.D., Chemical Engineering

University of Louisville, Louisville, KY

2006-2012

AWARDS

- Doctoral Dissertation Completion Fellowship, University of Louisville, KY, Spring 2012

- University of Louisville Graduate Student Council Travel Award for 33rd Symposium on Biotechnology for Fuels and Chemicals, Seattle, WA, May 2011

- Honorable Mention at 2011 Kentucky Statewide Workshop: Renewable Energy \& Energy Efficiency, Louisville, KY

- Conn Center for Renewable Energy Research Fellowship Award, University of Louisville, Louisville, KY, August 2010-August 2011 


\section{AFFILIATIONS}

- American Institute of Chemical Engineers (AIChE)

- Sigma Xi Society

- Society for Industrial Microbiology and Biotechnology

- Golden Key International Honor Society

- Phi Kappa Phi National Honor Society

\section{PRINCIPLE PUBLICATIONS}

- Ye Z, Hatfield KM, Berson RE. Deactivation of Individual Cellulase Components. Bioresource Technology, 2012:106, 133-137.

- Ye Z, Lane AN, Willing GA, Berson RE. Scaled-up Separation of CBH1 from a Cellulase Mixture by Ion Exchange Chromatography. Biotechnology Progress, 2011:27, 1644-1652.

- Ye Z, Berson RE. Kinetic Modeling of Cellulose Hydrolysis with First Order Inactivation of Adsorbed Cellulase. Bioresource Technology, 2011:102, $11194-$ 11199.

- Rezania S, Ye Z, Berson RE. Enzymatic Saccharification and Viscosity of Sawdust Slurries Following Ultrasonic Particle Size Reduction. Applied Biochemistry and Biotechnology, 2009:153(1-3), 103-115. 